\title{
A Small-scale Response of Urban Bat Activity to Tree
} Cover

\author{
by \\ Lauren Moretto
}

A thesis submitted to the Faculty of Graduate and Postdoctoral Affairs in partial fulfillment of the requirements for the degree of

Master of Science

in

Biology

Carleton University

Ottawa, Ontario

(C) 2018, Lauren Moretto 


\begin{abstract}
Bats in urban areas depend on trees, and bat activity increases with tree cover. To effectively manage bat habitat in cities, it is important to know the distance to which tree cover most strongly influences bats (i.e., the 'scale of effect'). The aim of this study was to estimate the scale of effect of tree cover on bats in Toronto, Canada. I measured bat activity at 52 sampling sites across the city. I then examined the relationships between bat activity and percent tree cover measured within each of 19 landscape scales, $0.025-$ $3.5 \mathrm{~km}$ in radius, surrounding each sampling site. My results suggest that adding or removing urban trees influences bats up to $200 \mathrm{~m}$ away. Urban tree management decisions should consider the impacts to bats beyond the site of management and within the surrounding landscape of a $200 \mathrm{~m}$-radius scale.
\end{abstract}




\section{Acknowledgements}

I would like to thank my co-supervisors, Lenore Fahrig, Charles M. Francis, and Adam C. Smith, for their endless support in guiding me through my Master of Science Degree. Even through the toughest challenges of my thesis, they remained patient and encouraging. I am very fortunate to have had the opportunity to work under their expertise.

I would also like to thank my committee member from the University of Ottawa, Jeremy Kerr, for his valuable intellectual contributions during committee meetings.

I am truly thankful for my keen field assistant, Erik Pervin, and undergraduate insect processing team, Karim Mufarrij, Mahmoud El-Saadi, Steffani Guenette, Kelly Maki, Sidney Potter, and Jamie Evans for their valuable hard work and contribution to this research. Their assistance, determination, and genuine interest in my research not only helped to reduce my workload, but undoubtedly enhanced the overall quality of my project.

Thank you to my friends/ the supportive team at GLEL for providing a positive and inspirational environment in which to complete this project. Thank you also to Dan Bert, a lab manager that can make anything possible and a very supportive friend.

I am grateful to Mike Anissimoff from the Canadian Wildlife Federation and Ryan Zimmerling from Environment and Climate Change Canada for their assistance with bat call processing and identification, and to Christian Shmidt from Agriculture Canada, Krista Patriquin and Cylita Guy from the University of Toronto, and Brock Fenton for their advice about bat and insect sampling. I am also grateful to John Pasher from Environment and Climate Change Canada and Don Boyes from the University of 
Toronto for their assistance with analyses in ArcGIS. Thank you to fellow and previous Masters students, Julia Put, Liv Monck-Whipp, and Kevin Ethier, and to Matthew Long from the University of Virginia for their support and general advice about project logistics and sampling equipment. Thank you to Cara Webster and Joel Harrison-Off from the City of Toronto for providing the mapped data about Ash Trees and Emerald Ash Borer, and to Lauren Hooton and Amanda Adams, previous students in the Fenton Laboratory at the University of Western Ontario, for providing the reference library of bat echolocation calls for analysis. Thank you also to Pablo Mendez, for helping me to explore the non-biological side of urban trees.

I would also like to thank all of the interested homeowners in Toronto who participated in my project and very kindly allowed me to set up bat and insect sampling equipment on their property. This project would not have been possible without their support.

Last but certainly not least, thank you to my mom, dad, sister, family, and friends for being unconditionally supportive, loving, and a beacon of light during the highs and lows of my Masters degree.

I am incredibly fortunate to have received all of this amazing support.

This research was supported by a Natural Sciences and Engineering Research Council of Canada (NSERC) scholarship and an Ontario Graduate Scholarship (OGS), and by grants to Lenore Fahrig from NSERC and the Canada Foundation for Innovation. 


\section{Table of Contents}

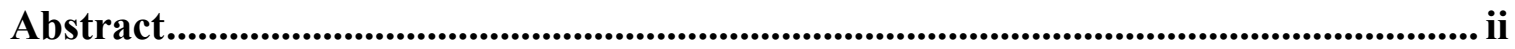

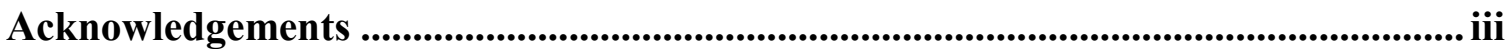

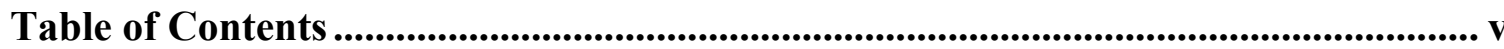

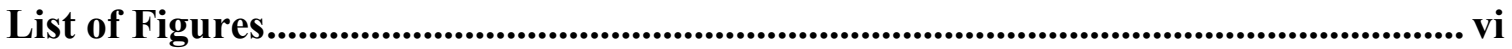

List of Appendices ...................................................................................................................... ix

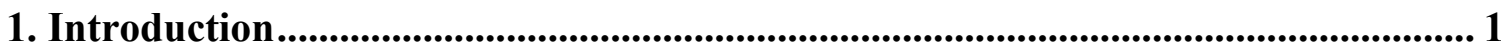

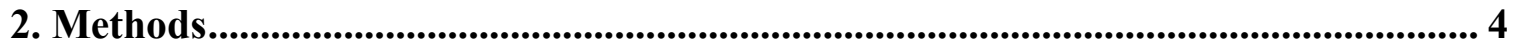

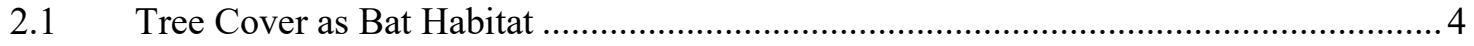

2.2 Sampling Site Selection and Measurement of Percent Tree Cover ...............................5

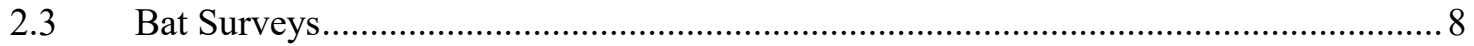

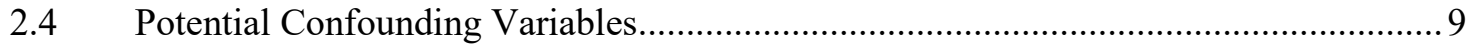

2.5 Quantifying Bat Activity and Identifying Bat Species ......................................... 10

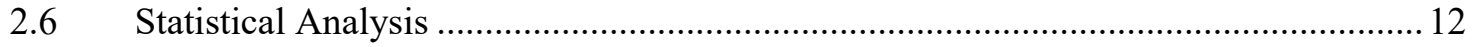

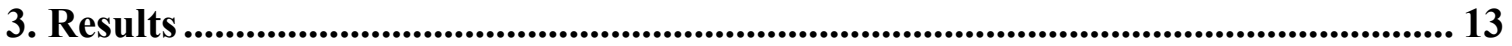

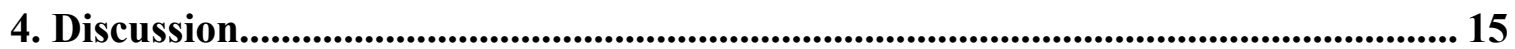

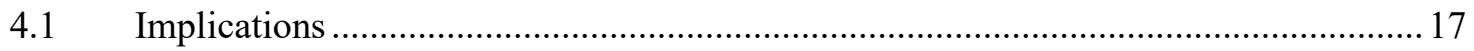

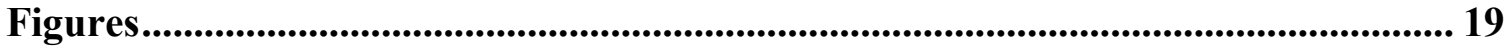

Appendices............................................................................................................................... 28

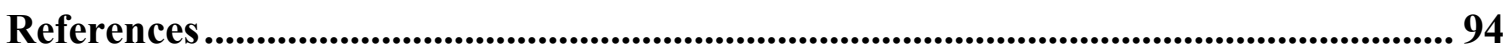




\section{List of Figures}

Figure 1. Locations of 52 bat sampling sites in Toronto, Canada. Sampling sites are indicated as black points. Circles around each site are not to scale, but represent percent tree cover in the surrounding, circular landscape with a $3.5 \mathrm{~km}$ radius. Note that percent tree cover was analyzed as a continuous variable in models

Figure 2. (a) An example sampling site surrounded by the 19 circular landscapes in which percent tree cover was measured. Landscapes ranged between $0.025 \mathrm{~km}$ and $3.5 \mathrm{~km}$ in radius. (b) A closeup of the smallest landscape scales in (a) measuring between $0.025 \mathrm{~km}$ and $0.25 \mathrm{~km}$ in radius. Examples of landscapes with (c) low, (d) medium, and (e) high percent tree cover within $1 \mathrm{~km}$ of the sampling site.

Figure 3. Box and whisker plots showing the range across sampling sites in percent cover of (a) buildings and (b) trees measured within each of 19 circular landscape scales around the bat sampling sites. Black horizontal bars are the medians, red dots are the means, and grey regions show the interquartile ranges (i.e., IQR; $25^{\text {th }}-75^{\text {th }}$ percentile). Whiskers represent percent cover values that lie outside of the IQR, but within $1.5 \times$ IQR.

Outliers are indicated with black dots 
Figure 4. (a) Pairwise Pearson correlations of percent tree cover between all pairs of landscape scales. Row and column labels indicate the radius of each scale. (b) Pairwise Pearson correlations between percent building cover at the $1 \mathrm{~km}$ scale (row label) and percent tree cover at each landscape scale (column labels). Square size and intensity of colour indicate the strength of the correlation, while colour indicates the direction of the correlation, as shown in the colour ramp (red is a negative correlation and blue is a

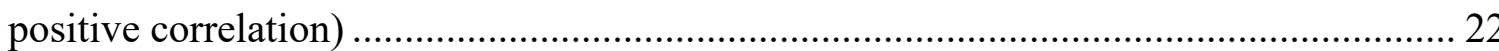

Figure 5. A bat pass is series of echolocation pulses that are grouped into different types of calls (Griffin et al. 1960). A pass begins with a "Search Phase Call" used by the bat for navigation and general perception of the environment. An "Approach Phase Call” may follow if the bat approaches prey or tries to land. For this call, pulse rate and frequency are higher and the overall call duration is lower than in the Search Phase. Often following the Approach Phase is a "Feeding Buzz," which the bat uses to gain precise information about prey location. Pulse rate increases and overall call duration decreases further, and pulse frequency immediately drops at the end. Since the characteristics of pulses in Search Phase Calls are fairly consistent within species, they are used for species identification (Fenton and Bell 1981) 
Figure 6. Regression coefficients (black dots, solid line) $\pm \mathrm{SE}$ (vertical lines) and $\triangle \mathrm{AIC}$ values (open circles, dashed line) from generalized linear mixed models of the relationship between the percent tree cover in landscapes and (a) total bat activity and (b - e) species-specific activity. Bat activity was measured at 52 sampling sites distributed across Toronto, Canada. Percent tree cover was measured within each of 19 circular landscape scales with radii between $0.025 \mathrm{~km}$ and $3.5 \mathrm{~km}$ surrounding the sampling sites. The scale of effect (vertical dotted red line) was selected based on the model AIC value and regression coefficient of percent tree cover

Figure 7. Total number of bat passes recorded at each site in relation to percent tree cover measured around each of the 52 sampling sites at the scale of effect for total bat activity, $0.2 \mathrm{~km}$. Colours of dots indicate the round of bat sampling. While the points are the raw data, the grey line shows the predicted number of bat passes for each percent tree cover. This predicted data was taken from the generalized linear mixed model for the relationship between total bat activity and percent tree cover at $0.2 \mathrm{~km}$, after controlling for potential confounding variables 


\section{List of Appendices}

Appendix 1A. Pairwise Pearson correlations and p-values between percent tree cover and the number of dead Ash trees (Fraxinus sp.) per percent tree cover measured within $0.25 \mathrm{~km}, 1 \mathrm{~km}, 2 \mathrm{~km}$, and $3.5 \mathrm{~km}$-radius circular landscape scales around each sampling site. Since the arrival of Emerald Ash Borer (Agrilus planipennis) to Toronto in 2008, most Ash trees in the city have been killed. However, the Forest and Land Cover raster dataset (City of Toronto 2009), which I used to measure percent tree cover, predates most of the Ash tree mortality. I used the results of these correlations to ensure that this discrepancy did not affect the accuracy of percent tree cover measurements 28

Appendix 1B. The number of dead Ash trees (Fraxinus sp.) and number of dead Ash trees per percent tree cover measured within $0.25 \mathrm{~km}, 1 \mathrm{~km}, 2 \mathrm{~km}$, and $3.5 \mathrm{~km}$-radius circular landscape scales around each sampling site. The number of dead Ash trees per percent tree cover was calculated and correlated to percent tree cover at each scale....... 29 Appendix 2. Results of generalized linear mixed models examining the relationship between percent tree cover measured within each of 19 circular landscape scales and (a) total bat activity and $(\mathbf{b}-\mathbf{e})$ species-specific activity. Regression coefficients $[\beta \pm$ standard error (SE)] and p-values are shown for percent tree cover at each scale and for the control for percent building cover at the $1 \mathrm{~km}$-scale (if included in the model).......... 31 
Appendix 3. Additional results of generalized linear mixed models examining the relationship between percent tree cover measured within each of 19 circular landscape scales and (a) total bat activity and (b-e) species-specific activity. Regression coefficients $[\beta \pm$ standard error $(\mathrm{SE})]$ and $p$-values are shown for standardized temperature $\left({ }^{\circ} \mathrm{C}\right)$ and standardized Julian Date at each scale 36

Appendix 4. AIC, $\triangle \mathrm{AIC}$, relative likelihood, and AIC weights from generalized linear mixed models (GLMM) examining the relationship between percent tree cover measured within each of 19 circular landscape scales and (a) total bat activity and (b-e) speciesspecific activity. AIC values are shown for GLMM without a statistical control for percent building cover, and with a statistical control for percent building cover included in models separately at the $0.5 \mathrm{~km}, 1 \mathrm{~km}$, or $1.5 \mathrm{~km}$-radius landscape scales. $\Delta \mathrm{AIC}$, relative likelihood, and AIC weights correspond to the best-fitting model, which is shaded (i.e., either with or without percent building cover at $1 \mathrm{~km}$ included as a statistical control) ... 41 Appendix 5. Residual plots showing the spread of residuals relative to predicted values of total number of passes for (a) total bat activity and $(\mathbf{b}-\mathbf{e})$ species-specific activity at the $0.025 \mathrm{~km}, 1 \mathrm{~km}$, and $3.5 \mathrm{~km}$-radius landscape scales. I used these plots to assess the fit of the generalized linear mixed models and negative binomial link functions in estimating the relationship between percent tree cover and bat activity 46 
Appendix 6. Results of Moran's I tests [observed and expected values, standard deviation (sd), and p-values] for all 19 landscape scales measuring spatial autocorrelation in residuals of generalized linear mixed models that related percent tree cover to (a) total bat activity and $(\mathbf{b}-\mathbf{e})$ activity for each species. Moran's $I$ tests were performed separately for each round of sampling (i.e., round 1 or round 2) ……............................54

Appendix 7. Mapped residuals of generalized linear mixed models relating (a) total bat activity and $(\mathbf{b}-\mathbf{e})$ species-specific activity to percent tree cover. These results are displayed for the scale of effect for each bat activity response (i.e., $0.2 \mathrm{~km}$ for Total Bat Activity and Big Brown Bat; $0.15 \mathrm{~km}$ for Silver-haired Bat/ Hoary Bat; and $0.025 \mathrm{~km}$ for Little Brown Myotis/ Northern Myotis/ Tri-colored Bat and Eastern Red Bat), and at the $1 \mathrm{~km}$ and $3.5 \mathrm{~km}$-radius landscape scales. Results are shown separately for each round of sampling (i.e., round 1 or round 2). Red dots represent negative residuals, and blue dots represent positive residuals. Dot size reflects the absolute value of the residual. Overall, the residuals show an even spatial distribution for each response variable

Appendix 8. Percent tree cover within 19 circular landscape scales $(0.025-3.5 \mathrm{~km})$ around each of 52 bat sampling sites, and percent cover of trees in parks within the $0.2 \mathrm{~km}$-radius landscape scale around each site 
Appendix 9. Percent building cover within 19 circular landscape scales $(0.025-3.5 \mathrm{~km})$

around each of 52 bat sampling sites........ 80

Appendix 10. Date, Start and End Recording Time, and Mean Nightly Temperature $\left({ }^{\circ} \mathrm{C}\right)$ from sampling round $1(\mathrm{R} 1)$ and round $2(\mathrm{R} 2)$ of bat recording at each sampling site .... 86 Appendix 11. Total number of bat passes, passes with more than one bat, feeding buzzes, and duration of bat passes from sampling round $1(\mathrm{R} 1)$ and round 2 (R2) of bat recording at each sampling site 88

Appendix 12. Total number of passes identified to each species or species group and unidentified passes (unknown) from sampling round 1 (R1) and round 2 (R2) of bat recording at each sampling site

Appendix 13. Total number of feeding buzzes identified to each species or species group and unidentified feeding buzzes (unknown) from sampling round 1 (R1) and round 2 (R2) of bat recording at each sampling site 


\section{Introduction}

Areas of primarily natural or semi-natural land cover provide habitat for wildlife in urban areas, containing resources for feeding, nesting, and refuge from human disturbance. Although large parks, including ravine systems or woodlots, contain the greatest biodiversity in urban environments (Blair and Launer 1997, Cornelis and Hermy 2004, Avila-Flores and Fenton 2005, Beninde et al. 2015), this natural habitat need not be a large, contiguous area to be important; a collection of many small areas of natural habitat can be just as valuable to wildlife as a single large area of the same total size (Fahrig 2017). For example, Smith et al. (2014) found that bird diversity responded as strongly to small residential green spaces (e.g., backyards) as to larger non-residential green spaces, on a per-area basis. In other words, the summed effect of a large number of small green spaces was equivalent to the effect of a large green space of the same total area.

Since areas of natural habitat in urban environments are often small, many species access habitat over a large area to obtain sufficient resources. For example, Fox Squirrels (Scurius niger) in urban Texas must access multiple treed and grassy areas in urban environments for roosting and caching space, respectively (McCleery et al. 2007). Coyotes (Canis latrans) in Tucson, Arizona commute between multiple naturalized forests in golf courses for food and water, and between areas with sandy loam soils for constructing dens (Grubbs and Krausman 2009). The need to access multiple small areas of habitat is further reinforced by the seasonal changes in resource needs of species and the availability of resources within these areas. For instance, the network of nesting sites and foraging grounds between which birds and mammals commute in urban areas often 
changes seasonally, thereby increasing the total area of habitat upon which they rely throughout the year (Law and Dickman 1998).

The use of multiple areas of natural habitat by urban species means that adding or removing habitat in an urban landscape can influence species within some distance away. For instance, Clark et al. (2007) found that the total amount of green space and number of flowering plants within the surrounding $1 \mathrm{~km}$ in urban environments positively affected butterfly species richness. Furthermore, Melles et al. (2003) also found that urban green space influenced ground- and shrub-nesting bird species occurrence up to $1 \mathrm{~km}$ away.

Tree cover comprises a large proportion of the natural habitat in urban environments and is important to urban species (Dixon 2012, Pardee and Philpott 2014, Ferenec et al. 2014, Smith et al. 2014), and knowing the distance to which tree cover influences urban species is informative for management. For example, Pardee and Philpott (2014) found that the total amount of tree cover in the surrounding 500m and $2 \mathrm{~km}$ of backyard gardens positively influenced the abundance of cavity- and groundnesting bee species, respectively. Similarly, Ferenec et al. (2014) found that the species richness of birds at sampling sites was positively related to the proportion of tree cover within 500m of sampling sites.

Urban bats rely on trees to satisfy their requirements for prey and roosts (van Zyll de Jong 1985). These trees are found throughout cities, in parks, along streets, and on private property such as in front and back yards. Bats move between trees in cities because they often forage some distance away from their roosts (Duchamp et al. 2004, Duchamp and Swihart 2008, Dixon 2012). The resource requirements of bats also change seasonally, so they may rely on different trees throughout the year (Law and Dickman 
1998); while a street tree may provide an adequate summer roost, a tree in a woodlot with less ambient disturbance may be preferred for hibernation. Even bats that roost in buildings commute to trees to forage around their canopies, and may also rely on them to provide a second roosting space (Evelyn et al. 2004).

To maintain bat populations in urban areas, it is important to know the spatial extent over which tree cover in the surrounding landscape influences bat activity at a site, that is, the 'scale of effect' (Jackson and Fahrig 2012). The scale of effect of tree cover on temperate urban bats is not well known. Landscape-scale studies on urban bats often select only a single landscape scale for study, leading to uncertainty that the selected scale is in fact the scale of effect (e.g., Duchamp and Swihart 2008, Threlfall et al. 2012). Multi-scale studies typically use a small number of scales (i.e., three or fewer; e.g., Dixon 2012, Bazelman 2016, Gallo et al. in press). These studies suggest scales of effect between 0.1 and $3 \mathrm{~km}$ for urban bats. Although one European study (Lintott 2015) measured habitat features within seven landscape scales, the scale of effect was not estimated. To date, Fabianek et al. (2011) and Ethier and Fahrig (2011) provide the most precise estimates of the scale of effect for bats in North America, by measuring the relationship between bat activity and land cover within five or more scales. In Montréal, Fabianek et al. (2011) found a $0.1 \mathrm{~km}$ scale of effect of forest and non-woody plant cover for urban bats, which was also the smallest landscape scale that they examined. In agricultural eastern Ontario, Ethier and Fahrig (2011) found scales of effect of forest amount on bats of $1-5 \mathrm{~km}$, depending on the species. The goal of this study was to estimate the scale of effect of tree cover on bat activity in Toronto, Canada's largest city. 


\section{Methods}

I estimated the scale of effect of tree cover on total bat activity and on the activity of individual species using bat recorders at 52 sampling sites across Toronto. I measured the percent tree cover within 19 landscape scales with radii from $0.025-3.5 \mathrm{~km}$ that were centred on each sampling site. I then modelled the relationship between bat activity and percent tree cover at each spatial extent. I estimated the scale of effect as the radius with both a strong relationship between bat activity and percent tree cover and a good fit of the data to the model.

\subsection{Tree Cover as Bat Habitat}

I defined bat habitat as the area covered by tree canopies of $2 \mathrm{~m}^{2}$ or larger. Trees of this size are used as habitat by all seven bat species previously documented in Toronto. Some species roost among the foliage [Eastern Red Bat (Lasiurus borealis), Hoary Bat (Lasiurus cinereus), and Tri-colored Bat (Perimyotis subflavus)], while others roost in cavities or under loose bark [Big Brown Bat (Eptesicus fuscus), Little Brown Myotis (Myotis lucifigus), Northern Myotis (Myotis septentrionalis), and Silver-haired Bat (Lasionycteris noctivagans) (van Zyll de Jong 1985)]. All species also forage for insects either among trees or above the tree canopy (van Zyll de Jong 1985). Measuring tree cover of trees with a canopy of at least $2 \mathrm{~m}^{2}$ excluded isolated saplings that would be too small to provide roosting or foraging space for bats. Trees with a canopy of $2 \mathrm{~m}^{2}$ or 
greater were available as a mapped raster dataset in the Forest and Land Cover layer (City of Toronto 2009).

Buildings can be considered habitat for bat species that also roost in artificial structures [Big Brown Bat (Eptesicus fuscus), Little Brown Myotis (Myotis lucifigus), Northern Myotis (Myotis septentrionalis), and Silver-haired Bat (Lasionycteris noctivagans) (van Zyll de Jong 1985, Whitaker et al. 2006, Geluso and Mink 2009)]. However, my objective was to estimate the scale of effect of tree cover on bats. Therefore, I controlled for percent building cover in site selection (below). Depending on model fit, I also added an additional statistical control for percent building cover to the models of species that roost in buildings.

\subsection{Sampling Site Selection and Measurement of Percent Tree Cover}

The overall objective of site selection was to simultaneously maximize the total number of sampling sites and the range of percent tree cover in the surrounding landscapes across sampling sites, at each of the 19 scales. To achieve this, I first mapped percent tree cover in Toronto using the Forest and Land Cover raster dataset (City of Toronto 2009) at a $2 \mathrm{~m}$ resolution. I then examined the range in percent tree cover across the city by conducting a moving window analysis in ArcGIS 10.3.1 (ESRI 2015), which calculated percent tree cover around each pixel in the raster dataset for a given window size. For this step, I used a circular window with a radius of $3.5 \mathrm{~km}$, the largest landscape scale I considered. To maximize the range of percent tree cover across sites, I first identified pixels (potential sampling sites) having the highest and lowest percent tree cover in the surrounding $3.5 \mathrm{~km}$-radius landscapes. I considered only pixels in residential 
backyards with similar local characteristics (i.e., unpaved, with some trees, and without large, artificial structures, including swimming pools). I then verified that these potential sampling sites also maximized the range of percent tree cover at smaller scales. To achieve this, I performed moving window analyses at $1 \mathrm{~km}$ and $2 \mathrm{~km}$-radius landscape scales.

The next step in sampling site selection was to add potential sites with intermediate percent tree cover. These were selected such that the number of sites in total was maximized, within the constraint that all selected sites were at least $1.8 \mathrm{~km}$ apart to limit spatial autocorrelation in the bat responses. $1.8 \mathrm{~km}$ is the mean commuting distance of Big Brown Bat, a common, long-distance flying species in Toronto (Brigham 1991). Following this, I adjusted site locations at a fine scale to ensure that all sites were at least $200 \mathrm{~m}$ from major arterial roads and highways. This was to eliminate the negative influences of roads, moving vehicles, and traffic noise on bat activity immediately surrounding the sampling sites (Kitzes and Merenlender 2014, Bennett and Zurcher 2013).

Lastly, I eliminated some sampling sites and shifted some others to limit the range in percent building cover in the surrounding landscapes across sampling sites, thus controlling for building roost availability. Older buildings with larger footprints are commonly used for bat roosting (Soper and Fenton 2007, Neubaum et al. 2007). My goal was to limit the range in availability of these buildings, but there was no available dataset for building age across the City of Toronto. However, Li and Wilkins (2014) documented a positive relationship between overall building density and bat activity. Therefore, I used percent building cover as a proxy of building roost availability, mapped with the Toronto 
Building Outlines shapefile (City of Toronto 2014c). I measured percent building cover by converting the building outline polygons into $2 \mathrm{~m}$ resolution raster datasets and conducting a moving window analysis with a $3.5 \mathrm{~km}$-radius, circular window to examine the range in percent building cover across the city. I adjusted the sampling site locations such that the surrounding landscapes had a building cover ranging from $14-19 \%$ of the total landscape, at the $3.5 \mathrm{~km}$-radius scale. This range in percent building cover prevented site placement in the downtown urban core, where building density is very high and there are likely very few building roosts (Neubaum et al. 2007), and in non-urban areas, such as an agricultural area in the east end of the city.

The site selection process resulted in a final set of 52 sampling sites (Figure 1), dispersed across the City of Toronto with a wide range in percent tree cover $(15-49 \%)$ and a narrow range in percent building cover $(14-19 \%)$ in the surrounding $3.5 \mathrm{~km}$-radius landscapes. I visited each site to verify the similarity among sites in local characteristics and to obtain the approval of homeowners to set up sampling equipment.

After confirming the sampling site locations, I measured percent tree cover in 19 circular landscape scales, centered around each site (i.e., $0.025,0.05,0.1,0.2,0.25,0.5$, $0.75,1,1.25,1.5,1.75,2,2.25,2.5,2.75,3,3.25$, and $3.5 \mathrm{~km}$; Figure $2 \mathrm{a}, \mathrm{b}$ ) using the Forest and Land Cover raster dataset (City of Toronto 2009). I also verified that the range of percent tree cover across sites was similar among the 19 scales (Figure 3b).

The non-native Emerald Ash Borer (Agrilus planipennis) has killed most Ash trees (Fraxinus sp.) in Toronto since its arrival in 2008. The Forest and Land Cover raster dataset (City of Toronto 2009) that I used to measure percent tree cover predates most of the infestation and thus does not capture all of the Ash tree mortality. To ensure that this 
discrepancy did not affect the accuracy of my measurements of percent tree cover, I tested for a relationship between the number of dead Ash trees and percent tree cover within $0.25 \mathrm{~km}, 1 \mathrm{~km}, 2 \mathrm{~km}$, and $3.5 \mathrm{~km}$ of my sampling sites. I obtained the locations of all dead public Ash trees in the city (City of Toronto 2014a, b), summed them at each scale around each sampling site, and calculated the number of dead Ash trees per percent tree cover. This was then correlated to percent tree cover at each scale (Appendix 1). The pairwise Pearson correlations were non-significant and weak $(\mathrm{r}=-0.21-0.02, \mathrm{p}=0.13$ 0.98 ), except at the $3.5 \mathrm{~km}$ scale, where there was a significant but weak negative correlation between percent tree cover and the number of dead Ash trees per percent tree cover $(r=-0.29, p=0.03)$. This suggests that the inclusion of Ash trees, predating their city-wide mortality, did not bias my measurements of percent tree cover.

\subsection{Bat Surveys}

I surveyed bat activity at each of the 52 sampling sites by recording bat calls using Wildlife Acoustic SM2+ recorders with SMX-U1 microphones. Calls were recorded between May 30 and August 8, 2017, the period of summer residency for Ontario bat species (van Zyll de Jong 1985). At each site, I positioned one recorder two meters above the ground with its microphone angled $45^{\circ}$ downwards to protect the microphones from potential rain. I recorded bat calls continuously from sunset to sunrise over two, non-consecutive nights per site.

To ensure that date of sampling did not confound the effects of tree cover, I sampled bat activity at four sampling sites per night that varied in percent tree cover in the surrounding landscapes. The combination of four sites sampled each night contained 
one site with low percent tree cover, one site with high percent tree cover, and two sites with intermediate percent tree cover at both the $1 \mathrm{~km}$ and $3.5 \mathrm{~km}$-radius landscape scales (Figure 2, c-e). After all sites were sampled once, I began a second round of sampling on June 21, 2017. I ensured that each night's combination of sites visited in the second round was different from that of the first round.

\subsection{Potential Confounding Variables}

The main objective of the study was to identify the scale of effect of tree cover on bat activity in an urban environment. However, bat activity around a recorder is likely to be influenced by variables other than tree cover, which might obscure the relationship between bat activity and surrounding tree cover. I controlled for this by collecting data only during good weather (i.e., no rain, average wind speed below $20 \mathrm{~km} / \mathrm{h}$, average wind gusts below $25 \mathrm{~km} / \mathrm{h}$, and average nightly temperature above $9^{\circ} \mathrm{C}$ ), and by ensuring minimal human disturbance during data collection (i.e., avoiding sampling overnight on Fridays, Saturdays, and holidays). At each site, I also deployed one Onset HOBO Pendant Temperature and Light Data Logger and one Digi-Sense Data Logging Light Meter to measure temperature $\left({ }^{\circ} \mathrm{C}\right)$ and light intensity (lux) at 10 minute increments during the recording period.

Although I had tried to minimize variation in the surrounding building cover among sampling sites during site selection, there was a greater range in percent building cover at smaller landscape scales than at larger landscape scales (Figure 3a). Percent building cover was also negatively correlated with percent tree cover (Figure 4b), particularly when percent tree cover was measured at smaller scales $(0.5-1 \mathrm{~km})$. 
Therefore, I included percent building cover as a statistical control when appropriate (see below).

\subsection{Quantifying Bat Activity and Identifying Bat Species}

Bat activity was indexed as the number of bat passes per sampling site. A bat pass is a grouping of echolocation pulses separated by at least 1 second of silence $(2$ seconds for Hoary Bat) from the next pulse (Coleman and Barclay 2012, Griffin et al. 1960; Figure 5). A pass begins with a "Search Phase Call," which the bat uses for navigation and general perception of the environment. As the bat approaches a prey item or attempts to land, pulse rate and frequency increase and the overall duration of the call decreases. This is the "Approach Phase." Following the Approach Phase, there is often a "Feeding Buzz," which the bat uses to gain precise information about prey location before it attempts a capture. The Feeding Buzz is characterized by a further increase in pulse rate, a decrease in overall call duration, and an immediate drop in pulse frequency at the end. Feeding Buzzes do not denote the end of a pass, as a single bat pass can contain multiple Feeding Buzzes, often followed by Search Phase Calls.

Bats can be identified to species using the acoustic characteristics of the echolocation pulses. To identify each pass to species, I used two identification software programs to account for discrepancies in their identification algorithms (Lemen et al. 2015). These were the Bats of North America 3.1.0 classifier package in Kaleidoscope Pro 3.1.1. (Wildlife Acoustics 2015) and the quadratic discriminate function analysis model (QDFA) created by Ethier and Fahrig (2011), which used reference calls from the Fenton Laboratory (Hooton and Adams, unpublished data, University of Western 
Ontario) and was coded into R by J. Put (unpublished). I included only the seven species of bats that have been documented in Toronto as possible outcomes for each program [i.e., Big Brown Bat (Eptesicus fuscus), Eastern Red Bat (Lasiurus borealis), Hoary Bat (Lasiurus cinereus), Silver-haired Bat (Lasionycteris noctivagans), Little Brown Myotis (Myotis lucifugus), Northern Myotis (Myotis septentrionalis), and Tri-colored Bat (Perimyotis subflavus)].

I used the pulses of Search Phase Calls for species identification (Fenton and Bell 1981). Parameters of unidentified pulses were measured and compared to clusters of parameters from identified pulses. This process was automated in Kaleidoscope. For the QDFA, I input the Search Phase Calls of all passes into Scan'R 1.6.0 to obtain the parameters of pulses. This program measured pulse duration, interpulse interval, maximum frequency, minimum frequency, bandwidth, dominant frequency, characteristic frequency, slope, and curvature.

To identify each bat pass to species, I compared the results from the two identification programs, and reviewed each pass manually to confirm the identity. The identification of a pass was accepted if the results of Kaleidoscope's identification agreed with that of the QDFA. When the programs did not agree on the identity of a pass, it was classified as "unidentified." When possible, I classified these unidentified passes by visually comparing them to a temporally adjacent, identified pass.

I analysed bat activity for all bats combined, two individual species (Big Brown Bat and Eastern Red Bat), and two species groups, each of which contained two or three species with calls that are difficult to distinguish. The first group contained calls of 
Myotis species (Little Brown Myotis and Northern Myotis) and Tri-colored Bat, and the second group contained calls of Hoary Bat and Silver-haired Bat.

\section{$\underline{2.6 \text { Statistical Analysis }}$}

I used generalized linear mixed models (GLMM) to estimate the relationship between each of the five bat activity response variables (total bat activity and activity of each of the species and species groups) and percent tree cover measured within each of the 19 spatial scales. Therefore, for each bat response variable there were 19 models, one for each landscape scale. Since bat activity was surveyed twice at each sampling site, models contained a random effect of site, to account for variance within sites. Each model also contained the potential confounding effects of standardized mean nightly temperature $\left({ }^{\circ} \mathrm{C}\right)$ and Julian date. The light-intensity loggers did not register any variance in light intensity (lux) among sites and nights, so lux was not included in any models. The inclusion of percent building cover at the $1 \mathrm{~km}$-radius landscape scale in the GLMM as a statistical control was based on model fit. Firstly, I controlled for percent building cover at the $1 \mathrm{~km}$-radius scale because the AIC values of the 19 models with percent building cover included at this scale were lower overall than with percent building cover included at other scales (e.g., $0.5 \mathrm{~km}$ and $1.5 \mathrm{~km})$. Then, for each bat activity response variable, I compared AIC values of the 19 models with and without the control for percent building cover at the $1 \mathrm{~km}$ scale. AIC values were lower in models without percent building cover for Little Brown Myotis/ Northern Myotis/ Tri-colored Bat and Eastern Red Bat, so percent building cover was not included in further analyses for these species groups. I 
modeled bat activity with a negative binomial error and a log link function, based on the distributions of the response variables in histograms and residual plots.

Finally, I estimated the scale of effect of percent tree cover for each response variable by evaluating both the AIC values and regression coefficients of each model. AIC values were examined first and indicated the scale at which the data best fit the model. I then used the regression coefficients to verify that the model at the scale with the lowest AIC value showed a strong relationship between a bat activity response variable and percent tree cover. If there was less than a 0.1 difference in the AIC values between two or more scales, the scale with the largest regression coefficient was deemed the scale of effect.

I assessed spatial autocorrelation among the residuals of the models using Moran's $I$ and by mapping the residuals. Additionally, I calculated the cross-scale, pairwise Pearson correlations in percent tree cover between all pairs of scales. I also calculated the correlations between percent tree cover at each scale and percent building cover at the $1 \mathrm{~km}$ scale (i.e. the scale at which it was entered in models as a control). All analyses were conducted in R version 3.4.1. (R Core Team 2017), using the MASS, glmmADMB (Bolker et al. 2012), ape (Paradis et al. 2017), psych (Revelle 2017), ggplot2 (Wickham and Chang 2016), dplyr (Wickham et al. 2017), corrplot (Wei et al. 2017), maptools (Bivand et al. 2017), and GIStools (Brunsdon and Chen 2014) packages.

\section{Results}

I recorded 7,593 bat passes. Forty-nine percent of these were identified as Big Brown Bat (Eptesicus fuscus), 6\% as Eastern Red Bat (Lasiurus borealis), 21\% as Hoary 
Bat (Lasiurus cinereus)/ Silver-haired Bat (Lasionycteris noctivagans), and 1\% as Little Brown Myotis (Myotis lucifugus)/ Northern Myotis (Myotis septentrionalis)/ Tri-colored Bat (Perimyotis subflavus). Twenty-three percent of passes could not be identified to species or species group. The average number of bat passes per sampling site was 73 (range 7 -296), with an average of 8.1 passes per hour (range 0.8 - 31.6). On average, there were 3 species/ species groups per site (range $1-4)$.

The range of percent tree cover across sites was fairly consistent across the 19 scales (Figure 3b). The pairwise Pearson correlations between percent tree cover at different scales (range $0.48-1$ ), and between percent building cover at $1 \mathrm{~km}$ and percent tree cover at different scales (range $0.002--0.65$ ) are shown in Figure 4.

For total bat activity, the scale of effect of percent tree cover was the $0.2 \mathrm{~km}$ radius landscape scale (Figure 6a, Appendix 2 -4). Total bat activity increased by $44 \%$ for each $10 \%$ increase in tree cover, with the predicted total number of passes ranging from $22-287$ (Figure 7). The scale of effect of percent tree cover differed among species/ species groups. Big Brown Bat and Hoary Bat/ Silver-haired Bat showed scales of effect of $0.2 \mathrm{~km}$ and $0.15 \mathrm{~km}$, respectively (Figure 6b, c). Little Brown Myotis/ Northern Myotis/ Tri-colored Bat and Eastern Red Bat both had smaller scales of effect at $0.025 \mathrm{~km}$ (Figure $6 \mathrm{~d}, \mathrm{e})$, but the relationship between percent tree cover and bat activity was not significant for Little Brown Myotis/ Northern Myotis/ Tri-colored Bat. There was also a positive effect of percent building cover within a $1 \mathrm{~km}$-radius landscape on total bat activity, Big Brown Bat, and Hoary Bat/ Silver-haired Bat at the scale of effect of percent tree cover for these bat activity responses (Appendix 2). 
Residual plots suggested that most models fit the data well, with an even spread of residuals in most cases (Appendix 5). There was no significant spatial autocorrelation of the residuals for total bat activity, or for any species or species group (Appendix 6, 7).

\section{Discussion}

I found a relatively small scale of effect of percent tree cover on the activity of urban bats. Percent tree cover within $0.2 \mathrm{~km}$ from my sampling sites had the strongest influence on total bat activity. Previously documented scales of effect for temperate bats generally range from $0.1-5 \mathrm{~km}$ (Ethier and Fahrig 2011, Fabianek et al. 2011, Dixon 2012, Bazelman 2016, Gallo et al. in press), although $0.1 \mathrm{~km}$ was the smallest scale measured in two previous studies (Fabianek et al. 2011, Dixon 2012). In my study, two species groups showed even smaller scales of effect than $0.1 \mathrm{~km}$, namely Little Brown Myotis/ Northern Myotis/ Tri-colored Bat and Eastern Red Bat at $0.025 \mathrm{~km}$.

It is possible that this small scale of effect of tree cover on all bats reflects the general influence of urban environments on bat activity and life histories. Since urban infrastructure, such major roads, traffic, and artificial lighting, disrupts the movement of bats (Russell et al. 2009, Bennett and Zurcher 2013, Moretto and Francis 2017), this could confine bat activity, and thus the greatest influence of tree cover, to a small landscape scale in cities. It is also possible that the tendency of insects to aggregate in urban environments (e.g., around trees or lights) drives localized bat foraging activity. Insectivorous bats frequently forage around insect aggregations (Müller et al. 2012), and most bats in Toronto forage within 40m of tree canopies (van Zyll de Jong 1985, Janzen and Fenton 2013). Street trees and trees on private property in cities are often spaced for 
aesthetics, providing ample area for insects to aggregate and bats to forage. Especially in light of the small scales of effect of tree cover on Little Brown Myotis/ Northern Myotis/ Tri-colored Bat and Eastern Red Bat $(0.025 \mathrm{~km})$, tree cover further away may not be as important to bats if tree cover in the vicinity is sufficient to provide insects.

Although not the primary goal of this study, my results also suggest that the total urban tree cover, not just that in parks, influences bats within $0.2 \mathrm{~km}$. All sampling sites in this study were in residential backyards, surrounded mostly by trees outside of parks. Using the Zoning By-law layer (City of Toronto 2014d) to map park space in the city, I found that at the $0.2 \mathrm{~km}$ scale, greater than $70 \%$ of tree cover was not located in parks for 48 of 52 sampling sites, and none of the tree cover was in parks for 17 sites (Appendix 8). In addition, there is a weak correlation between total bat activity and the percent tree cover within parks at the $0.2 \mathrm{~km}$ scale $\left(\mathrm{r}^{2}=0.02\right)$, indicating that non-park trees (i.e., street trees and trees on private property) are the main drivers of the overall positive relationship between tree cover and bat activity.

Although there are no North American studies that directly compare the importance of trees within parks and outside of parks to bats, my results are supported by other studies that have noted the importance of all local tree and vegetation cover in residential neighbourhoods to invertebrates, amphibians, birds, and other wildlife (Fernandez-Juricic 2000, Sperling and Lortie 2010, Lerman and Warren 2011, Scheffers and Paszkowski 2013, Pardee and Philpott 2014, Belaire et al. 2014, Smith et al. 2014). Conversely, one study in Vitória, Brazil that compared the influence of parks to other treed space on urban bat diversity found a much stronger effect of parks than wooded streets (Opera et al. 2009). I speculate that this difference between my results and those 
of Opera et al. (2009) is due to differences among our studies in species and their resource requirements. Opera et al. (2009) reported that most of the captured bats (92\%) in their study are frugivores, nectivores, and omnivores, and only $8 \%$ are insectivores. All of the bat species in my study are insectivores. Resources for insectivorous bats are often more abundant throughout urban environments than are resources for other bats (Bredt and Uieda 1996, Silva et al. 1996). It is possible, then, that resources for noninsectivorous bats were concentrated in urban parks in Vitória, which could explain the greater importance of park trees than street trees to bats in their study.

I also found a positive influence of percent building cover within $1 \mathrm{~km}$ of my sampling sites for Big Brown Bat and Hoary Bat/ Silver-haired Bat. This was expected because both Big Brown Bat and Silver-haired Bat roost in artificial structures (van Zyll de Jong 1985, Whitaker et al. 2006, Geluso and Mink 2009). The positive response of the Hoary Bat/ Silver-haired Bat species group to building cover suggests that this species group could be dominated by Silver-haired Bat, because Hoary Bat is a tree-roosting obligate (van Zyll de Jong 1985) and thus should not show a positive response to building cover.

\subsection{Implications}

This study provides information useful for the management of bat habitat in cities. Firstly, the scale of effect of tree cover on bats suggests that land management decisions should consider the impacts of the addition or removal of tree cover not just at the site of addition or removal, but within approximately the surrounding two residential city blocks. Furthermore, while my study was not designed to evaluate the influence of 
building cover on bats, my finding of a positive effect of building cover for two species (i.e., Big Brown Bat and Silver-haired Bat) suggests that artificial roost availability should be further explored in managing urban habitat for these species (Soper and Fenton 2007, Neubaum et al. 2007). Lastly, my results suggest that all urban trees, including privately-owned trees and street trees, and not just trees in parks, are important for bats. Private and public trees are often managed separately, and management of urban trees often occurs on a tree-by-tree basis (Carreiro et al. 2008). As the landscapes in my study primarily included privately-owned trees in residential neighbourhoods, this emphasizes the potential for small groups of property owners (e.g., the houses on a single residential street) to increase local bat activity. Management for bats in cities should therefore include education of property owners about the value of their trees for bats, and could even include a requirement for permission to remove trees on their property, as is the case in some jurisdictions (e.g., City of Toronto by-law No. 248-2013, City of Ottawa by-law No. 2009-200). 


\section{Figures}

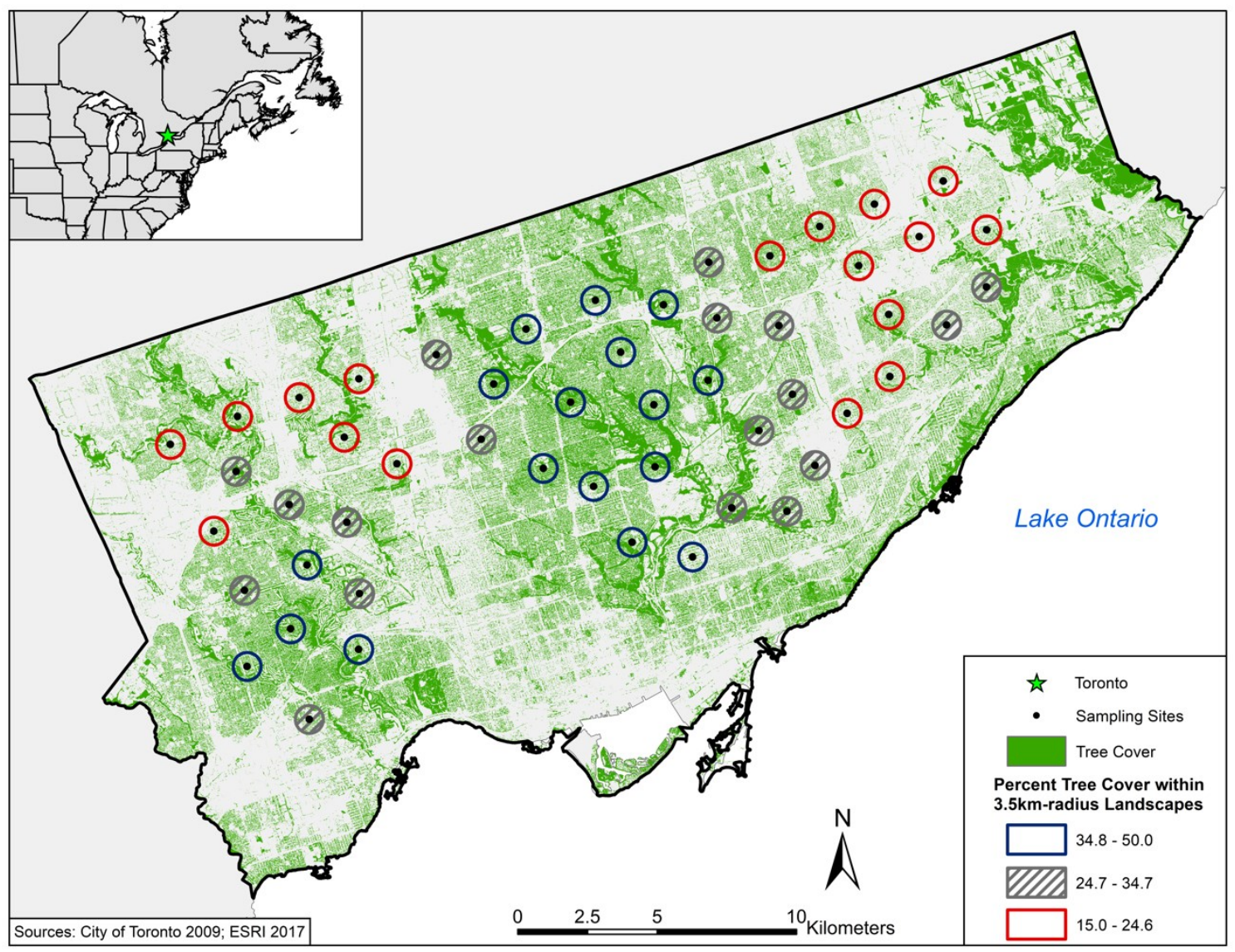

Figure 1. Locations of 52 bat sampling sites in Toronto, Canada. Sampling sites are indicated as black points. Circles around each site are not to scale, but represent percent tree cover in the surrounding, circular landscape with a $3.5 \mathrm{~km}$ radius. Note that percent tree cover was analyzed as a continuous variable in models. 


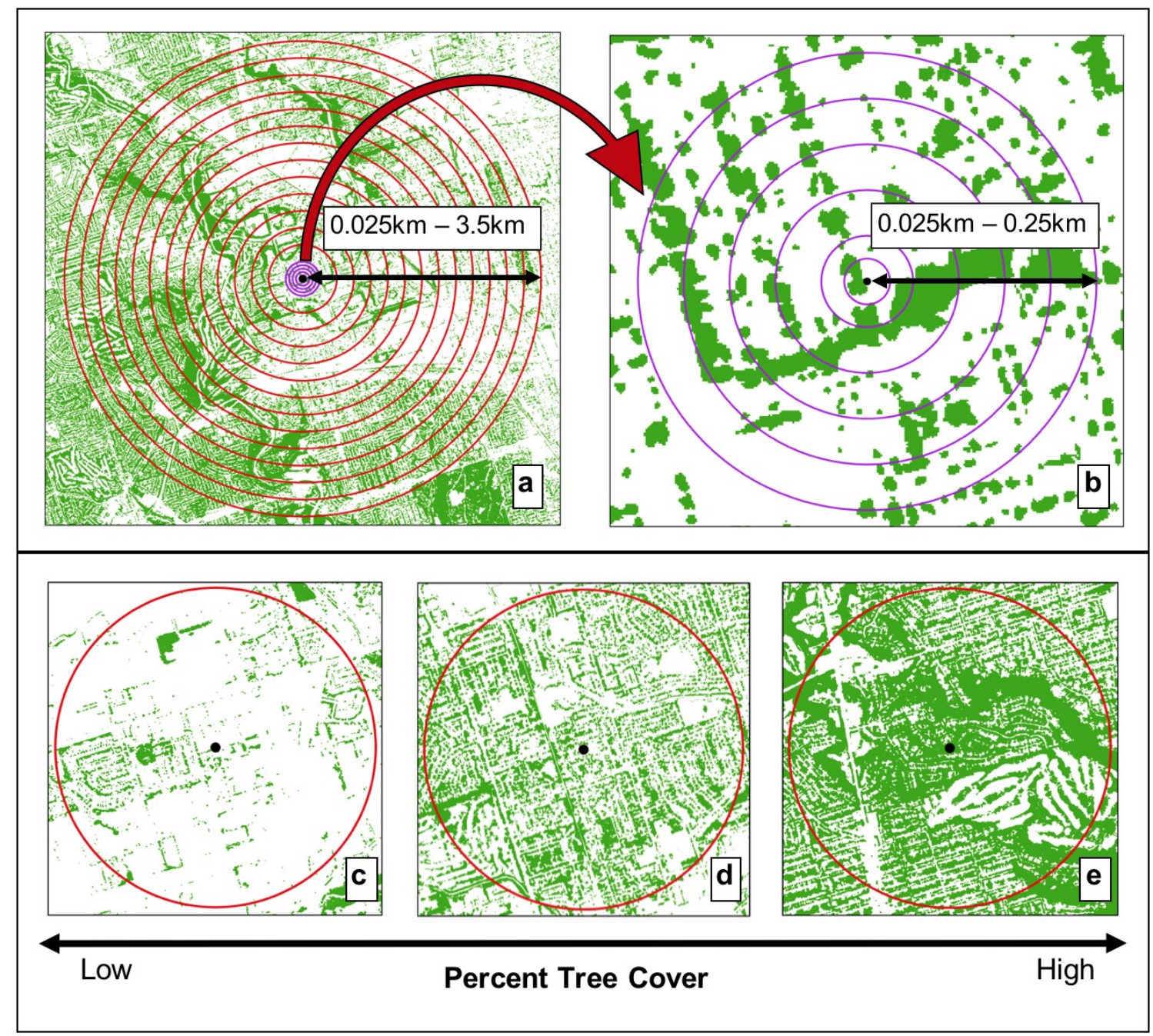

Figure 2. (a) An example sampling site surrounded by the 19 circular landscapes in which percent tree cover was measured. Landscapes ranged between $0.025 \mathrm{~km}$ and $3.5 \mathrm{~km}$ in radius. (b) A closeup of the smallest landscape scales in (a) measuring between $0.025 \mathrm{~km}$ and $0.25 \mathrm{~km}$ in radius. Examples of landscapes with (c) low, (d) medium, and (e) high percent tree cover within $1 \mathrm{~km}$ of the sampling site. 

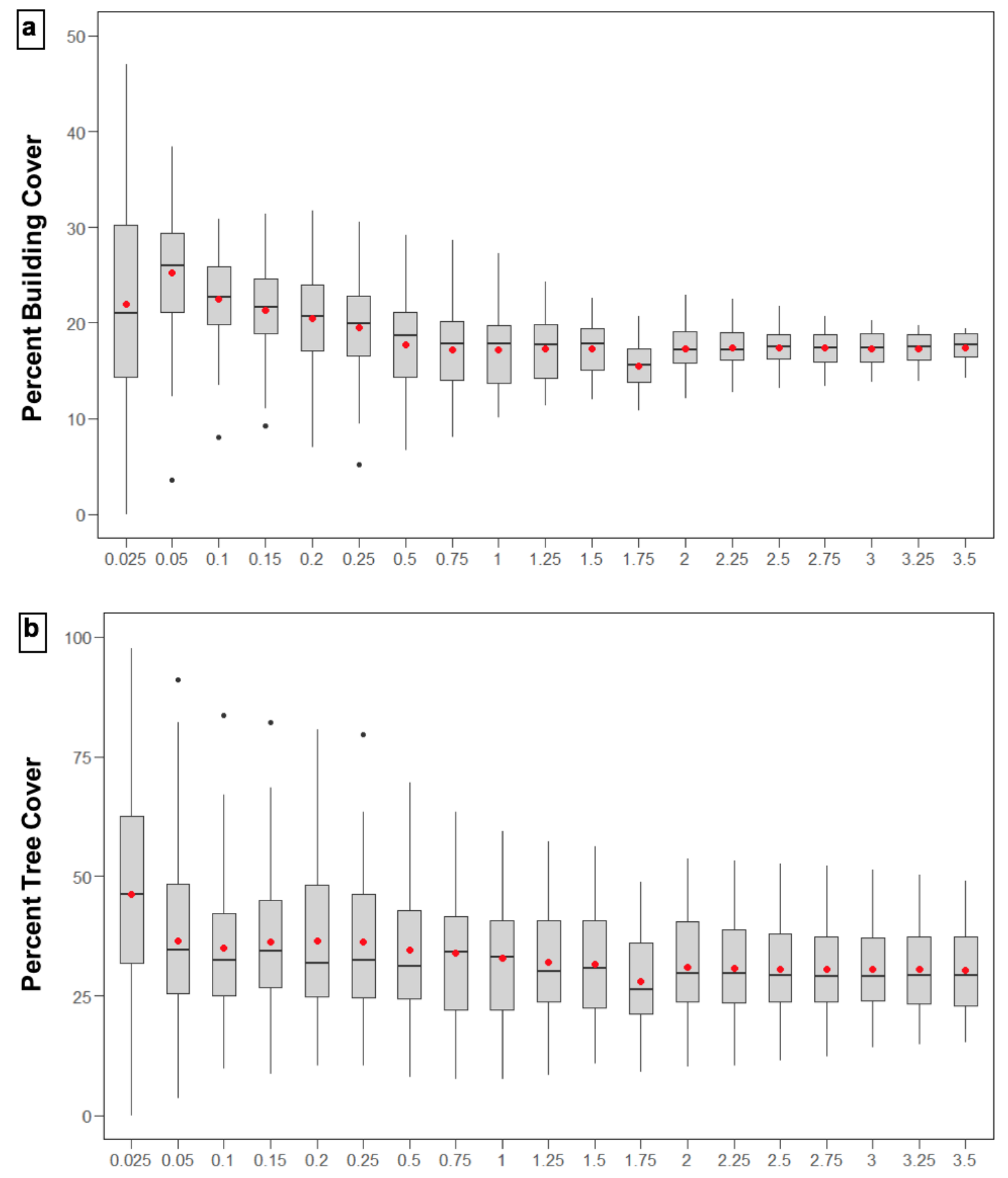

Radius (km) of Landscape Scale Surrounding Sampling Sites

Figure 3. Box and whisker plots showing the range across sampling sites in percent cover of (a) buildings and (b) trees measured within each of 19 circular landscape scales around the bat sampling sites. Black horizontal bars are the medians, red dots are the means, and grey regions show the interquartile ranges (i.e., IQR; $25^{\text {th }}-75^{\text {th }}$ percentile). Whiskers represent percent cover values that lie outside of the IQR, but within $1.5 \times \mathrm{IQR}$. Outliers are indicated with black dots. 


\section{Radius (km) of Landscape Scale Surrounding Sampling Sites} (Percent Tree Cover)

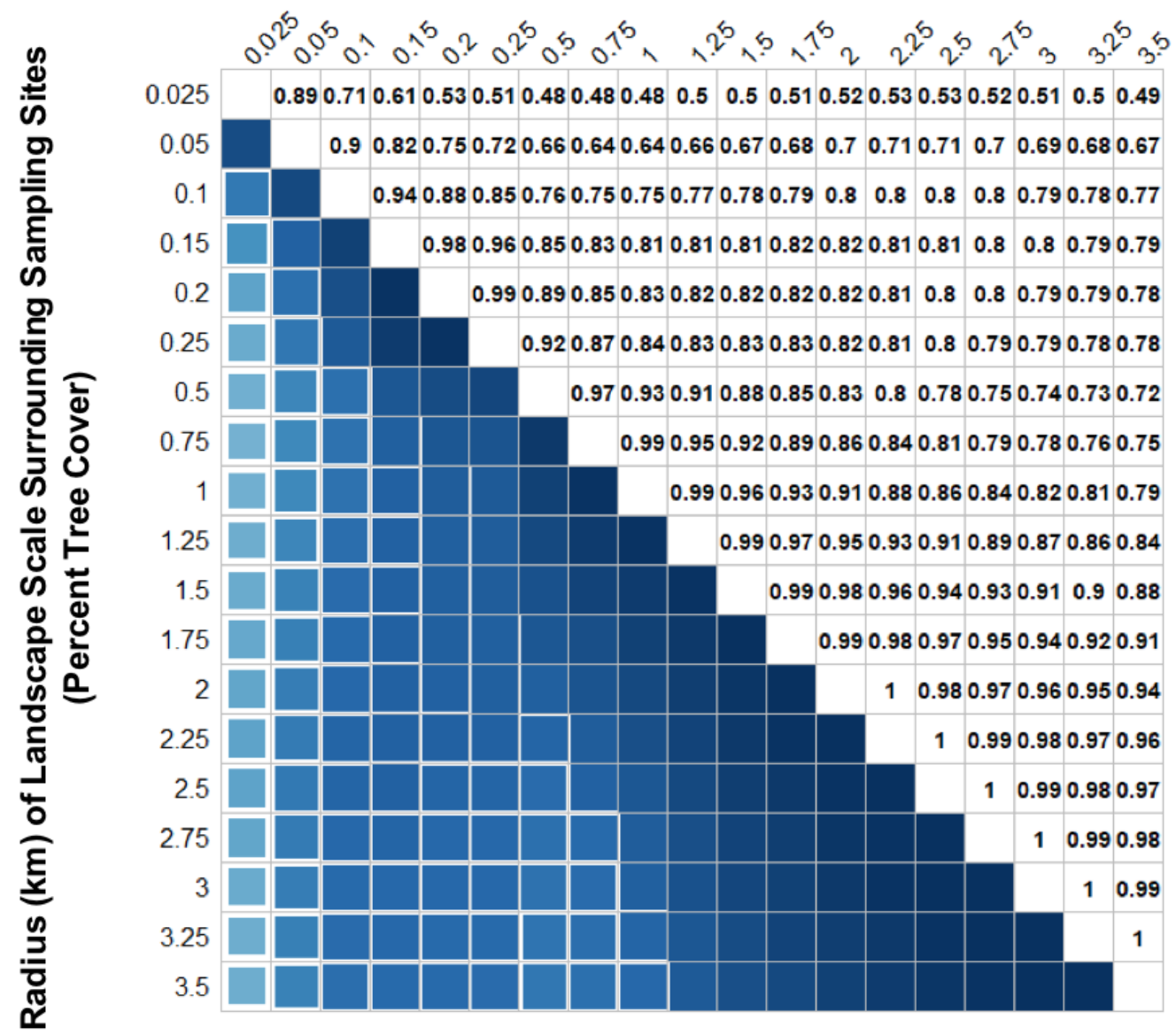

b

\section{Radius (km) of Landscape Scale Surrounding Sampling Sites (Percent Tree Cover)}

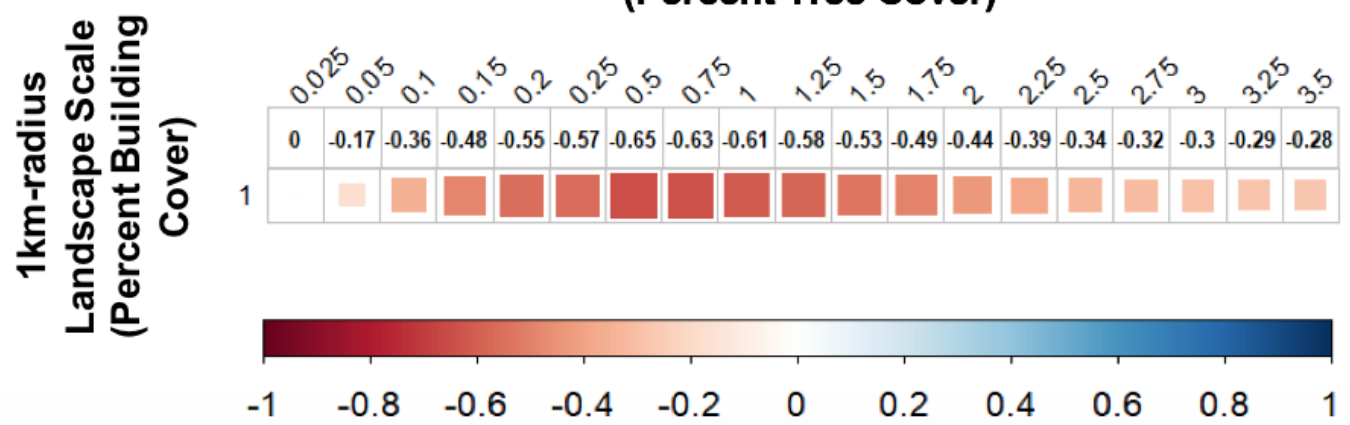

Figure 4. (a) Pairwise Pearson correlations of percent tree cover between all pairs of landscape scales. Row and column labels indicate the radius of each scale. (b) Pairwise Pearson correlations between percent building cover at the $1 \mathrm{~km}$ scale (row label) and percent tree cover at each landscape scale (column labels). Square size and intensity of colour indicate the strength of the correlation, while colour indicates the direction of the correlation, as shown in the colour ramp (red is a negative correlation and blue is a positive correlation). 


\section{Bat Pass}

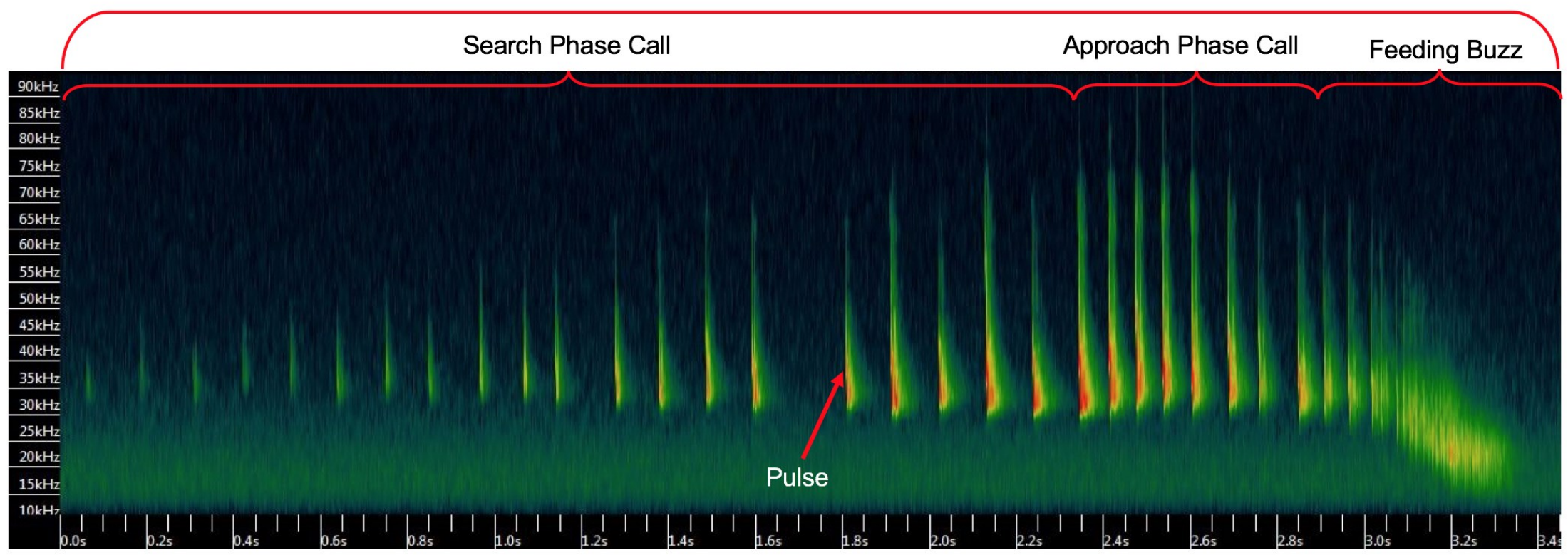

Figure 5. A bat pass is series of echolocation pulses that are grouped into different types of calls (Griffin et al. 1960). A pass begins with a "Search Phase Call" used by the bat for navigation and general perception of the environment. An "Approach Phase Call" may follow if the bat approaches prey or tries to land. For this call, pulse rate and frequency are higher and the overall call duration is lower than in the Search Phase. Often following the Approach Phase is a "Feeding Buzz," which the bat uses to gain precise information about prey location. Pulse rate increases and overall call duration decreases further, and pulse frequency immediately drops at the end. Since the characteristics of pulses in Search Phase Calls are fairly consistent within species, they are used for species identification (Fenton and Bell 1981). 


\section{(a) Total Bat Activity}

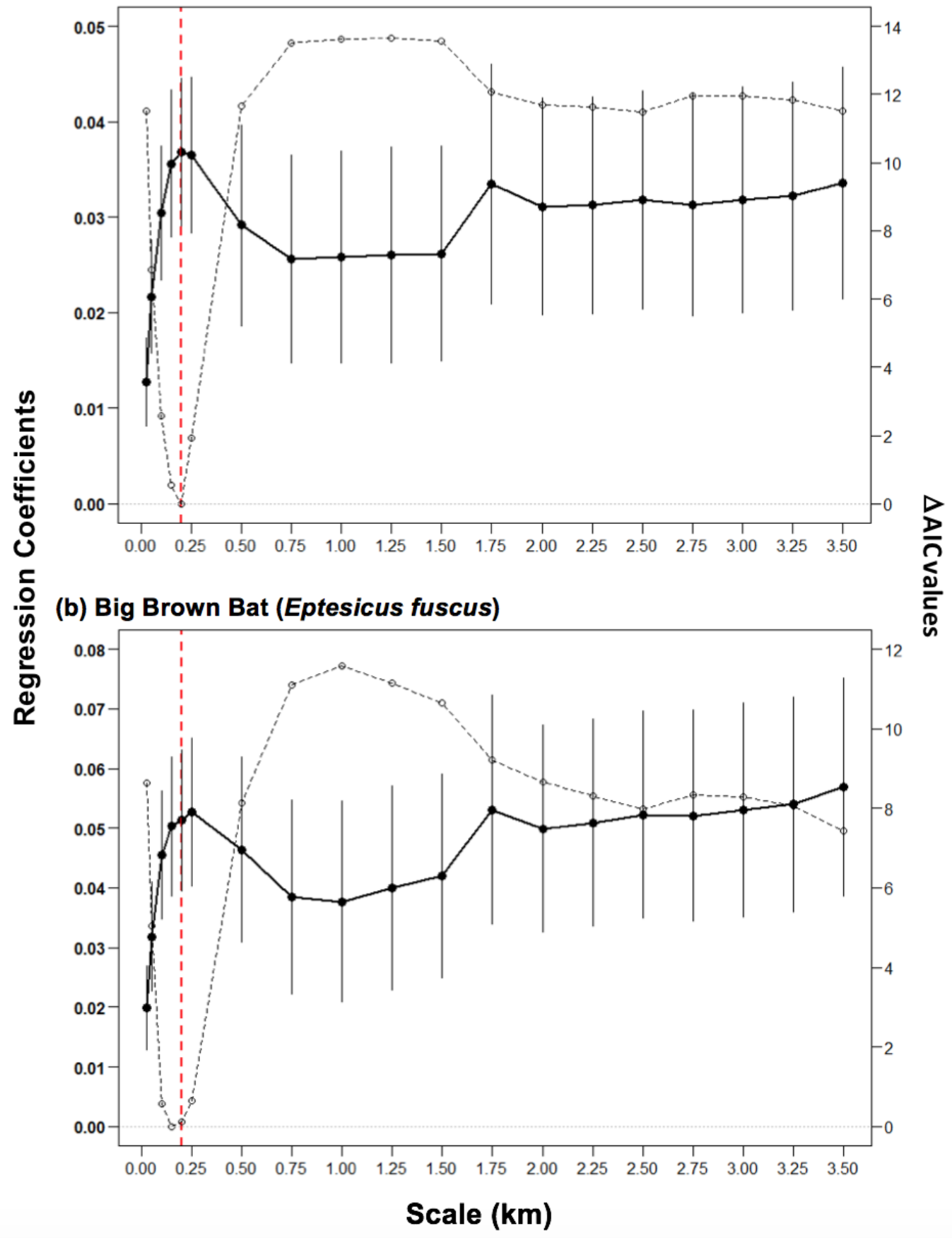

Figure 6. Regression coefficients (black dots, solid line) $\pm \mathrm{SE}$ (vertical lines) and $\triangle \mathrm{AIC}$ values (open circles, dashed line) from generalized linear mixed models of the relationship between the percent tree cover in landscapes and (a) total bat activity and (b - e) species-specific activity. Bat activity was measured at 52 sampling sites distributed across Toronto, Canada. Percent tree cover was measured within each of 19 circular landscape scales with radii between $0.025 \mathrm{~km}$ and $3.5 \mathrm{~km}$ surrounding the sampling sites. The scale of effect (vertical dotted red line) was selected based on the model AIC value and regression coefficient of percent tree cover. 
(c) Hoary Bat (Lasiurus cinereus)/

Silver-haired Bat (Lasionycteris noctivagans)

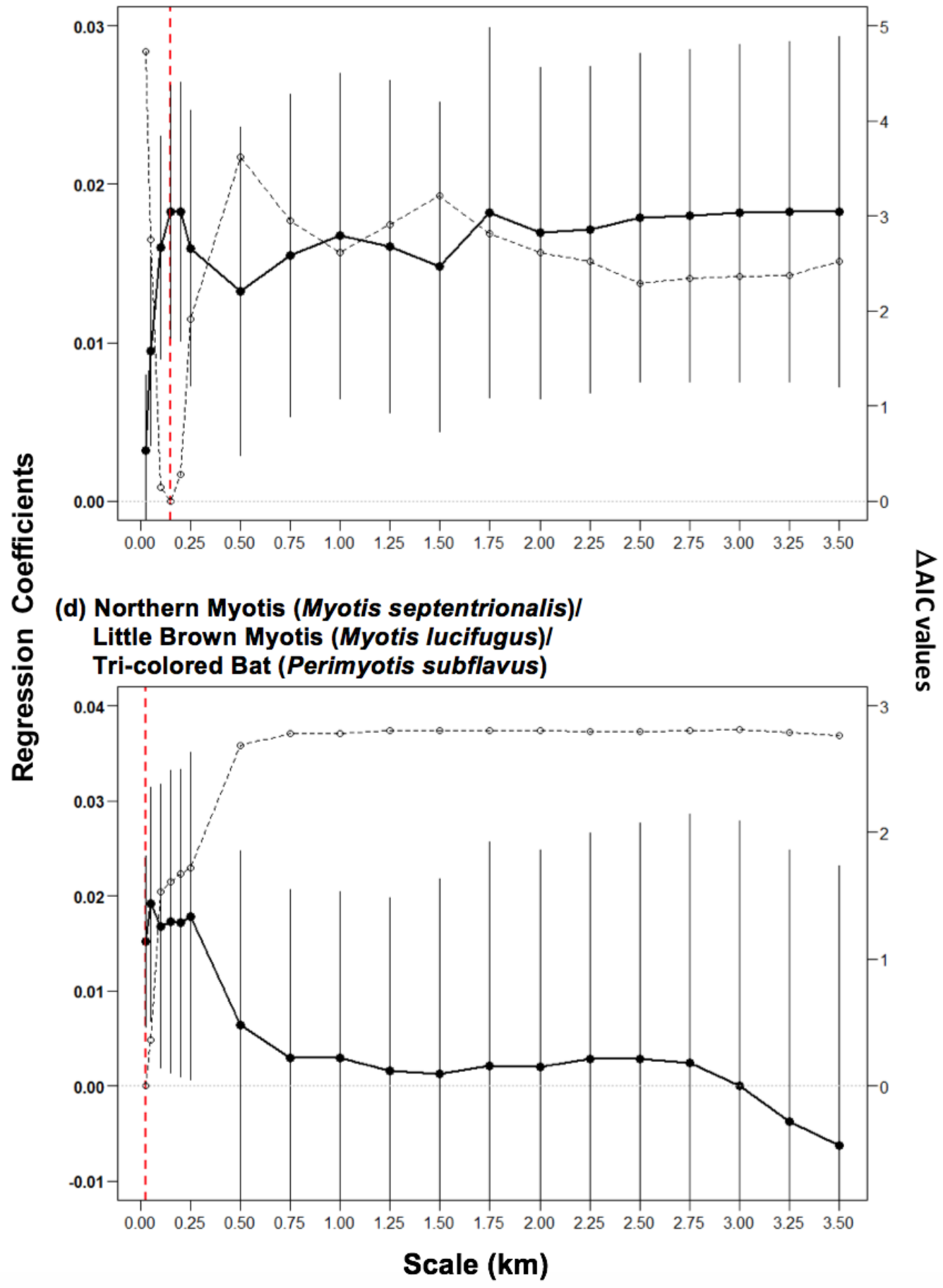

Figure 6. Continued. 
(e) Eastern Red Bat (Lasiurus borealis)

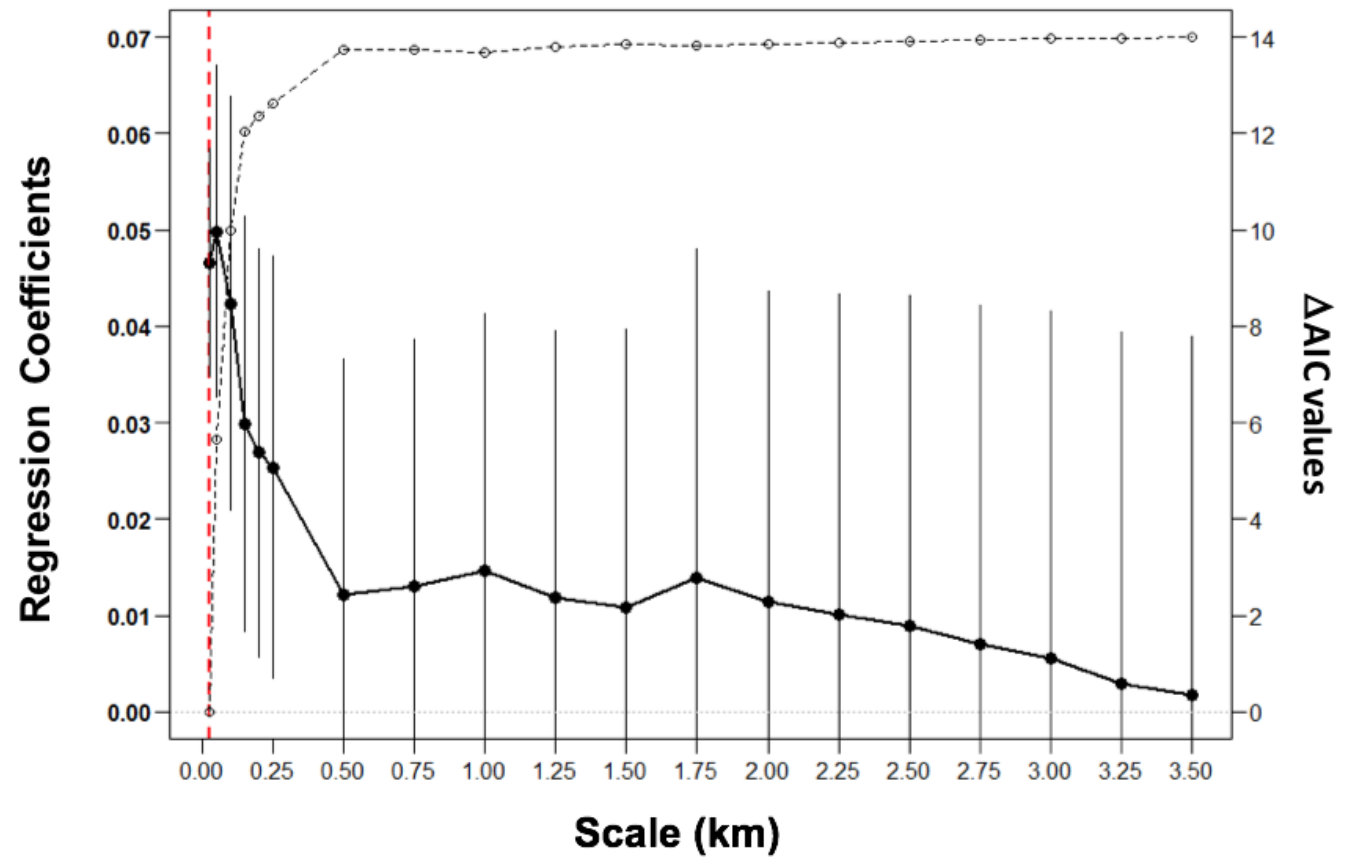

Figure 6. Continued. 


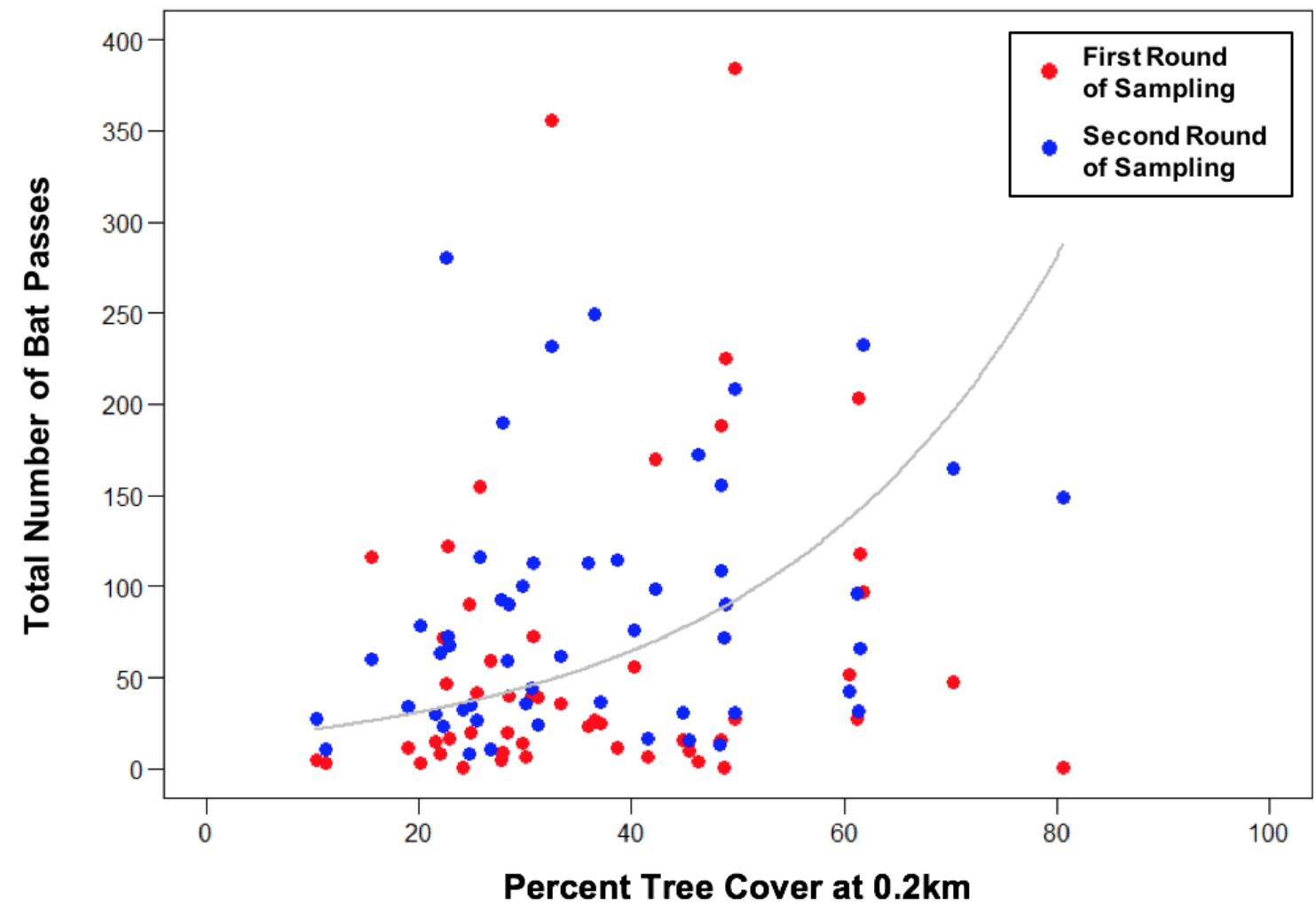

Figure 7. Total number of bat passes recorded at each site in relation to percent tree cover measured around each of the 52 sampling sites at the scale of effect for total bat activity, $0.2 \mathrm{~km}$. Colours of dots indicate the round of bat sampling. While the points are the raw data, the grey line shows the predicted number of bat passes for each percent tree cover. This predicted data was taken from the generalized linear mixed model for the relationship between total bat activity and percent tree cover at $0.2 \mathrm{~km}$, after controlling for potential confounding variables. 


\section{Appendices}

Appendix 1A. Pairwise Pearson correlations and p-values between percent tree cover and the number of dead Ash trees (Fraxinus sp.) per percent tree cover measured within $0.25 \mathrm{~km}, 1 \mathrm{~km}, 2 \mathrm{~km}$, and $3.5 \mathrm{~km}$-radius circular landscape scales around each sampling site. Since the arrival of Emerald Ash Borer (Agrilus planipennis) to Toronto in 2008, most Ash trees in the city have been killed. However, the Forest and Land Cover raster dataset (City of Toronto 2009), which I used to measure percent tree cover, predates most of the Ash tree mortality. I used the results of these correlations to ensure that this discrepancy did not affect the accuracy of percent tree cover measurements.

\begin{tabular}{|c|c|c|c|c|}
\hline & \multicolumn{4}{|c|}{ Percent Tree Cover vs. Number of Dead Ash per Percent Tree Cover } \\
\hline & $0.25 \mathrm{~km}$ & $1 \mathrm{~km}$ & $2 \mathrm{~km}$ & $3.5 \mathrm{~km}$ \\
\hline Pearson's $r$ & 0.0044 & 0.0151 & -0.2135 & -0.2935 \\
\hline p-value & 0.9751 & 0.9152 & 0.1286 & 0.0347 \\
\hline
\end{tabular}


Appendix 1B. The number of dead Ash trees (Fraxinus sp.) and number of dead Ash trees per percent tree cover measured within $0.25 \mathrm{~km}, 1 \mathrm{~km}, 2 \mathrm{~km}$, and $3.5 \mathrm{~km}$-radius circular landscape scales around each sampling site. The number of dead Ash trees per percent tree cover was calculated and correlated to percent tree cover at each scale.

\begin{tabular}{|c|c|c|c|c|c|c|c|c|}
\hline \multirow{3}{*}{ Site } & \multicolumn{8}{|c|}{ Radius of Circular Landscape } \\
\hline & \multicolumn{2}{|c|}{$0.25 \mathrm{~km}$} & \multicolumn{2}{|r|}{$1 \mathrm{~km}$} & \multicolumn{2}{|c|}{$2 \mathrm{~km}$} & \multicolumn{2}{|c|}{$3.5 \mathrm{~km}$} \\
\hline & $\begin{array}{c}\text { Number } \\
\text { of Dead } \\
\text { Ash }\end{array}$ & $\begin{array}{l}\text { Number of } \\
\text { Dead Ash } \\
\text { per Percent } \\
\text { Tree Cover }\end{array}$ & $\begin{array}{c}\text { Number } \\
\text { of Dead } \\
\text { Ash }\end{array}$ & $\begin{array}{l}\text { Number of } \\
\text { Dead Ash } \\
\text { per Percent } \\
\text { Tree Cover }\end{array}$ & $\begin{array}{c}\text { Number } \\
\text { of Dead } \\
\text { Ash }\end{array}$ & $\begin{array}{l}\text { Number of } \\
\text { Dead Ash } \\
\text { per Percent } \\
\text { Tree Cover }\end{array}$ & $\begin{array}{c}\text { Number } \\
\text { of Dead } \\
\text { Ash }\end{array}$ & $\begin{array}{l}\text { Number of } \\
\text { Dead Ash } \\
\text { per Percent } \\
\text { Tree Cover }\end{array}$ \\
\hline $\mathbf{0}$ & 1 & 0.066 & 105 & 7.916 & 326 & 32.222 & 714 & 42.026 \\
\hline 1 & 0 & 0 & 74 & 1.998 & 474 & 14.034 & 3019 & 109.282 \\
\hline 2 & 0 & 0 & 8 & 0.598 & 132 & 8.749 & 564 & 37.222 \\
\hline 3 & 5 & 0.483 & 30 & 3.938 & 170 & 14.542 & 543 & 32.253 \\
\hline 4 & 3 & 0.084 & 13 & 0.927 & 146 & 9.061 & 444 & 24.235 \\
\hline 5 & 0 & 0 & 126 & 3.311 & 410 & 12.765 & 772 & 25.281 \\
\hline 6 & 0 & 0 & 23 & 1.453 & 84 & 5.258 & 561 & 27.334 \\
\hline 7 & 3 & 0.078 & 69 & 1.702 & 324 & 7.200 & 1947 & 40.892 \\
\hline 8 & 0 & 0 & 88 & 1.545 & 218 & 4.639 & 809 & 20.234 \\
\hline 9 & 0 & 0 & 59 & 3.077 & 206 & 9.772 & 693 & 29.492 \\
\hline 10 & 1 & 0.042 & 33 & 1.701 & 792 & 33.001 & 2161 & 82.672 \\
\hline 11 & 7 & 0.591 & 376 & 13.619 & 1078 & 47.903 & 1407 & 75.581 \\
\hline 12 & 0 & 0 & 32 & 0.680 & 118 & 2.908 & 509 & 14.611 \\
\hline 13 & 0 & 0 & 31 & 1.284 & 85 & 2.955 & 528 & 18.063 \\
\hline 14 & 2 & 0.078 & 33 & 1.493 & 308 & 12.606 & 929 & 41.032 \\
\hline 15 & 1 & 0.035 & 33 & 1.191 & 168 & 7.274 & 451 & 18.118 \\
\hline 16 & 0 & 0 & 76 & 2.114 & 160 & 5.193 & 1489 & 60.537 \\
\hline 17 & 0 & 0 & 34 & 0.694 & 426 & 10.181 & 1524 & 38.855 \\
\hline 18 & 22 & 0.346 & 393 & 8.182 & 958 & 21.769 & 1870 & 40.436 \\
\hline 19 & 3 & 0.052 & 160 & 3.094 & 337 & 7.678 & 766 & 17.926 \\
\hline 20 & 0 & 0 & 24 & 0.403 & 232 & 4.320 & 1099 & 22.392 \\
\hline 21 & 0 & 0 & 45 & 1.049 & 106 & 2.872 & 621 & 16.102 \\
\hline 22 & 0 & 0 & 19 & 0.480 & 124 & 2.793 & 656 & 15.759 \\
\hline 23 & 1 & 0.034 & 38 & 1.437 & 128 & 4.862 & 652 & 21.241 \\
\hline 24 & 0 & 0 & 54 & 1.403 & 487 & 10.952 & 1495 & 35.853 \\
\hline 25 & 1 & 0.022 & 51 & 1.062 & 326 & 7.902 & 966 & 20.461 \\
\hline
\end{tabular}


Appendix 1B. Continued.

\begin{tabular}{|c|c|c|c|c|c|c|c|c|}
\hline \multirow{3}{*}{ Site } & \multicolumn{8}{|c|}{ Radius of Circular Landscape } \\
\hline & \multicolumn{2}{|c|}{$0.25 \mathrm{~km}$} & \multicolumn{2}{|r|}{$1 \mathrm{~km}$} & \multicolumn{2}{|c|}{$2 \mathrm{~km}$} & \multicolumn{2}{|c|}{$3.5 \mathrm{~km}$} \\
\hline & $\begin{array}{c}\text { Number } \\
\text { of Dead } \\
\text { Ash }\end{array}$ & $\begin{array}{c}\text { Number of } \\
\text { Dead Ash } \\
\text { per Percent } \\
\text { Tree Cover }\end{array}$ & $\begin{array}{c}\text { Number } \\
\text { of Dead } \\
\text { Ash }\end{array}$ & $\begin{array}{c}\text { Number of } \\
\text { Dead Ash } \\
\text { per Percent } \\
\text { Tree Cover }\end{array}$ & $\begin{array}{c}\text { Number } \\
\text { of Dead } \\
\text { Ash }\end{array}$ & $\begin{array}{c}\text { Number of } \\
\text { Dead Ash } \\
\text { per Percent } \\
\text { Tree Cover }\end{array}$ & $\begin{array}{c}\text { Number } \\
\text { of Dead } \\
\text { Ash }\end{array}$ & $\begin{array}{c}\text { Number of } \\
\text { Dead Ash } \\
\text { per Percent } \\
\text { Tree Cover }\end{array}$ \\
\hline 26 & 5 & 0.213 & 41 & 2.130 & 888 & 40.071 & 1687 & 74.264 \\
\hline 27 & 3 & 0.132 & 163 & 4.801 & 452 & 17.305 & 1332 & 62.016 \\
\hline 28 & 0 & 0 & 17 & 0.787 & 76 & 4.071 & 631 & 31.034 \\
\hline 29 & 0 & 0 & 30 & 0.795 & 290 & 8.034 & 723 & 20.981 \\
\hline 30 & 0 & 0 & 177 & 4.543 & 590 & 19.987 & 1321 & 56.500 \\
\hline 31 & 0 & 0 & 62 & 2.041 & 182 & 6.406 & 630 & 18.851 \\
\hline 32 & 0 & 0 & 32 & 1.227 & 234 & 7.890 & 597 & 21.846 \\
\hline 33 & 5 & 0.099 & 233 & 4.102 & 1029 & 19.893 & 1713 & 36.243 \\
\hline 34 & 28 & 0.541 & 306 & 5.894 & 1107 & 25.064 & 1962 & 49.809 \\
\hline 35 & 0 & 0 & 6 & 0.246 & 301 & 9.203 & 1713 & 46.342 \\
\hline 36 & 5 & 0.095 & 98 & 2.017 & 249 & 6.967 & 1254 & 36.836 \\
\hline 37 & 64 & 1.393 & 160 & 4.099 & 284 & 9.049 & 1199 & 36.378 \\
\hline 38 & 0 & 0 & 5 & 0.245 & 57 & 2.344 & 347 & 13.371 \\
\hline 39 & 0 & 0 & 15 & 0.600 & 105 & 3.193 & 446 & 13.342 \\
\hline 40 & 0 & 0 & 0 & 0 & 28 & 0.986 & 1021 & 31.999 \\
\hline 41 & 0 & 0 & 61 & 2.031 & 284 & 9.478 & 807 & 27.421 \\
\hline 42 & 4 & 0.169 & 211 & 6.391 & 499 & 18.113 & 1228 & 53.229 \\
\hline 43 & 16 & 0.315 & 75 & 2.427 & 415 & 15.144 & 1100 & 41.924 \\
\hline 44 & 0 & 0 & 72 & 1.973 & 284 & 7.002 & 627 & 16.323 \\
\hline 45 & 9 & 0.208 & 107 & 2.568 & 296 & 7.823 & 803 & 22.925 \\
\hline 46 & 1 & 0.041 & 66 & 3.078 & 217 & 10.372 & 444 & 21.500 \\
\hline 47 & 0 & 0 & 36 & 2.068 & 219 & 11.098 & 717 & 27.719 \\
\hline 48 & 0 & 0 & 55 & 3.074 & 229 & 9.308 & 3067 & 117.873 \\
\hline 49 & 19 & 0.695 & 106 & 3.197 & 173 & 10.039 & 487 & 27.631 \\
\hline 50 & 0 & 0 & 57 & 1.657 & 256 & 9.776 & 1677 & 81.752 \\
\hline 51 & 5 & 0.081 & 77 & 1.683 & 431 & 10.470 & 1312 & 36.780 \\
\hline
\end{tabular}


Appendix 2. Results of generalized linear mixed models examining the relationship between percent tree cover measured within each of 19 circular landscape scales and (a) total bat activity and $(\mathbf{b}-\mathbf{e})$ species-specific activity. Regression coefficients $[\beta \pm$ standard error (SE)] and p-values are shown for percent tree cover at each scale and for the control for percent building cover at the $1 \mathrm{~km}$-scale (if included in the model).

\begin{tabular}{|c|c|c|c|c|c|c|}
\hline \multicolumn{7}{|c|}{ (a) Total Bat Activity } \\
\hline \multirow{2}{*}{$\begin{array}{r}\text { Scale } \\
(\mathbf{k m}) \\
0.025\end{array}$} & \multicolumn{2}{|c|}{$\begin{array}{c}\text { Percent Tree Cover } \\
\text { B }( \pm \text { SE })\end{array}$} & \multirow{2}{*}{$\begin{array}{l}\text { p-value for } \\
\text { Percent Tree } \\
\text { Cover } \mathbf{B} \\
0.0052\end{array}$} & \multicolumn{2}{|c|}{$\begin{array}{c}\text { Percent Building } \\
\text { Cover within a 1km- } \\
\text { radius Landscape } \\
\quad \text { 乃 }( \pm \mathrm{SE})\end{array}$} & \multirow[t]{2}{*}{$\begin{array}{c}\text { p-value for } \\
\text { Percent Building } \\
\text { Cover within a } \\
\text { 1 km-radius } \\
\text { Landscape } \mathbf{B} \\
0.0227\end{array}$} \\
\hline & 0.0128 & $( \pm 0.0046)$ & & 0.0678 & $( \pm 0.0298)$ & \\
\hline 0.05 & 0.0217 & $( \pm 0.0059)$ & 0.0003 & 0.0881 & $( \pm 0.0289)$ & 0.0023 \\
\hline 0.1 & 0.0304 & $( \pm 0.0071)$ & $<0.0001$ & 0.1161 & $( \pm 0.0297)$ & 0.0001 \\
\hline 0.15 & 0.0356 & $( \pm 0.0077)$ & $<0.0001$ & 0.1434 & $( \pm 0.0319)$ & $<0.0001$ \\
\hline 0.2 & 0.0368 & $( \pm 0.0077)$ & $<0.0001$ & 0.1575 & $( \pm 0.0333)$ & $<0.0001$ \\
\hline 0.25 & 0.0365 & $( \pm 0.0081)$ & $<0.0001$ & 0.1531 & $( \pm 0.0338)$ & $<0.0001$ \\
\hline 0.5 & 0.0292 & $( \pm 0.0105)$ & 0.0056 & 0.1368 & $( \pm 0.0397)$ & 0.0006 \\
\hline 0.75 & 0.0256 & $( \pm 0.0109)$ & 0.0184 & 0.1248 & $( \pm 0.0399)$ & 0.0018 \\
\hline 1 & 0.0258 & $( \pm 0.0111)$ & 0.0198 & 0.1203 & $( \pm 0.0389)$ & 0.0020 \\
\hline 1.25 & 0.0261 & $( \pm 0.0113)$ & 0.0206 & 0.1157 & $( \pm 0.0379)$ & 0.0023 \\
\hline 1.5 & 0.0262 & $( \pm 0.0112)$ & 0.0195 & 0.1094 & $( \pm 0.0363)$ & 0.0026 \\
\hline 1.75 & 0.0335 & $( \pm 0.0126)$ & 0.0077 & 0.1096 & $( \pm 0.0348)$ & 0.0017 \\
\hline 2 & 0.0311 & $( \pm 0.0114)$ & 0.0061 & 0.1046 & $( \pm 0.0336)$ & 0.0019 \\
\hline 2.25 & 0.0312 & $( \pm 0.0114)$ & 0.0059 & 0.0994 & $( \pm 0.0327)$ & 0.0024 \\
\hline 2.5 & 0.0318 & $( \pm 0.0114)$ & 0.0054 & 0.0953 & $( \pm 0.0321)$ & 0.0030 \\
\hline 2.75 & 0.0313 & $( \pm 0.0117)$ & 0.0072 & 0.0921 & $( \pm 0.0319)$ & 0.0039 \\
\hline 3 & 0.0318 & $( \pm 0.0118)$ & 0.0072 & 0.0908 & $( \pm 0.0318)$ & 0.0043 \\
\hline 3.25 & 0.0323 & $( \pm 0.0119)$ & 0.0068 & 0.0899 & $( \pm 0.0316)$ & 0.0045 \\
\hline 3.5 & 0.0336 & $( \pm 0.0121)$ & 0.0055 & 0.0900 & $( \pm 0.0315)$ & 0.0043 \\
\hline
\end{tabular}


Appendix 2. Continued.

\begin{tabular}{|c|c|c|c|c|c|c|}
\hline \multicolumn{7}{|c|}{ (b) Big Brown Bat } \\
\hline \multirow{2}{*}{\begin{tabular}{r|} 
Scale \\
$(\mathbf{k m})$
\end{tabular}} & \multicolumn{2}{|c|}{$\begin{array}{c}\text { Percent Tree Cover } \\
\text { B }( \pm \text { SE })\end{array}$} & \multirow{2}{*}{$\begin{array}{l}\text { p-value for } \\
\text { Percent Tree } \\
\text { Cover } \mathbf{B} \\
0.0043\end{array}$} & \multicolumn{2}{|c|}{$\begin{array}{l}\text { Percent Building } \\
\text { Cover within a 1km- } \\
\text { radius Landscape } \\
\text { 及 }( \pm \mathrm{SE})\end{array}$} & \multirow[t]{2}{*}{\begin{tabular}{|} 
p-value for \\
Percent Building \\
Cover within a \\
1km-radius \\
Landscape $\mathbf{B}$ \\
0.0522
\end{tabular}} \\
\hline & 0.0199 & $( \pm 0.0070)$ & & 0.0891 & $( \pm 0.0459)$ & \\
\hline 0.05 & 0.0319 & $( \pm 0.0091)$ & 0.0004 & 0.1176 & $( \pm 0.0452)$ & 0.0092 \\
\hline 0.1 & 0.0455 & $( \pm 0.0108)$ & $<0.0001$ & 0.1612 & $( \pm 0.0461)$ & 0.0005 \\
\hline 0.15 & 0.0503 & $( \pm 0.0116)$ & $<0.0001$ & 0.1917 & $( \pm 0.0488)$ & 0.0001 \\
\hline 0.2 & 0.0513 & $( \pm 0.0118)$ & $<0.0001$ & 0.2102 & $( \pm 0.0511)$ & $<0.0001$ \\
\hline 0.25 & 0.0527 & $( \pm 0.0123)$ & $<0.0001$ & 0.2104 & $( \pm 0.0514)$ & $<0.0001$ \\
\hline 0.5 & 0.0464 & $( \pm 0.0155)$ & 0.0028 & 0.2010 & $( \pm 0.0595)$ & 0.0007 \\
\hline 0.75 & 0.0385 & $( \pm 0.0163)$ & 0.0181 & 0.1758 & $( \pm 0.0602)$ & 0.0035 \\
\hline 1 & 0.0377 & $( \pm 0.0168)$ & 0.0246 & 0.1669 & $( \pm 0.0592)$ & 0.0048 \\
\hline 1.25 & 0.0401 & $( \pm 0.0171)$ & 0.0189 & 0.1637 & $( \pm 0.0573)$ & 0.0043 \\
\hline 1.5 & 0.0420 & $( \pm 0.0171)$ & 0.0137 & 0.1565 & $( \pm 0.0547)$ & 0.0042 \\
\hline 1.75 & 0.0531 & $( \pm 0.0192)$ & 0.0056 & 0.1557 & $( \pm 0.0524)$ & 0.0030 \\
\hline 2 & 0.0499 & $( \pm 0.0173)$ & 0.0040 & 0.1481 & $( \pm 0.0506)$ & 0.0034 \\
\hline 2.25 & 0.0509 & $( \pm 0.0173)$ & 0.0032 & 0.1406 & $( \pm 0.0492)$ & 0.0042 \\
\hline 2.5 & 0.0523 & $( \pm 0.0173)$ & 0.0026 & 0.1342 & $( \pm 0.0481)$ & 0.0053 \\
\hline 2.75 & 0.0521 & $( \pm 0.0177)$ & 0.0032 & 0.1294 & $( \pm 0.0478)$ & 0.0068 \\
\hline 3 & 0.0531 & $( \pm 0.0179)$ & 0.0031 & 0.1273 & $( \pm 0.0475)$ & 0.0074 \\
\hline 3.25 & 0.0541 & $( \pm 0.0180)$ & 0.0027 & 0.1259 & $( \pm 0.0472)$ & 0.0077 \\
\hline 3.5 & 0.0569 & $( \pm 0.0182)$ & 0.0018 & 0.1264 & $( \pm 0.0469)$ & 0.0070 \\
\hline
\end{tabular}


Appendix 2. Continued.

(c) Hoary Bat/ Silver-haired Bat

\begin{tabular}{|c|c|c|c|c|c|c|}
\hline \multirow{2}{*}{$\begin{array}{r}\text { Scale } \\
(\mathbf{k m}) \\
0.025\end{array}$} & \multicolumn{2}{|c|}{$\begin{array}{c}\text { Percent Tree Cover } \\
\text { B }( \pm \text { SE })\end{array}$} & \multirow{2}{*}{ 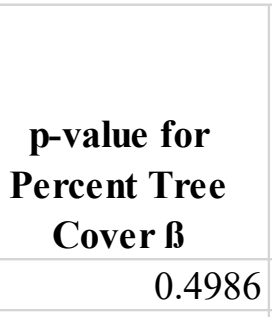 } & \multicolumn{2}{|c|}{$\begin{array}{l}\text { Percent Building } \\
\text { Cover within a 1km- } \\
\text { radius Landscape } \\
\text { B ( } \pm \text { SE) }\end{array}$} & \multirow[t]{2}{*}{$\begin{array}{c}\text { p-value for } \\
\text { Percent Building } \\
\text { Cover within a } \\
\text { 1 km-radius } \\
\text { Landscape } \mathbf{B} \\
0.0312\end{array}$} \\
\hline & 0.0032 & $( \pm 0.0048)$ & & 0.0592 & $( \pm 0.0275)$ & \\
\hline 0.05 & 0.0095 & $( \pm 0.0060)$ & 0.1132 & 0.0687 & $( \pm 0.0278)$ & 0.0135 \\
\hline 0.1 & 0.0160 & $( \pm 0.0071)$ & 0.0232 & 0.0835 & $( \pm 0.0288)$ & 0.0038 \\
\hline 0.15 & 0.0183 & $( \pm 0.0080)$ & 0.0217 & 0.0951 & $( \pm 0.0315)$ & 0.0025 \\
\hline 0.2 & 0.0182 & $( \pm 0.0082)$ & 0.0254 & 0.1009 & $( \pm 0.0333)$ & 0.0024 \\
\hline 0.25 & 0.0160 & $( \pm 0.0087)$ & 0.0668 & 0.0952 & $( \pm 0.0341)$ & 0.0052 \\
\hline 0.5 & 0.0132 & $( \pm 0.0104)$ & 0.2013 & 0.0889 & $( \pm 0.0365)$ & 0.0149 \\
\hline 0.75 & 0.0155 & $( \pm 0.0102)$ & 0.1266 & 0.0942 & $( \pm 0.0363)$ & 0.0094 \\
\hline 1 & 0.0167 & $( \pm 0.0103)$ & 0.1025 & 0.0944 & $( \pm 0.0354)$ & 0.0077 \\
\hline 1.25 & 0.0161 & $( \pm 0.0105)$ & 0.1247 & 0.0896 & $( \pm 0.0345)$ & 0.0095 \\
\hline 1.5 & 0.0148 & $( \pm 0.0104)$ & 0.1547 & 0.0834 & $( \pm 0.0331)$ & 0.0117 \\
\hline 1.75 & 0.0182 & $( \pm 0.0117)$ & 0.1198 & 0.0824 & $( \pm 0.0320)$ & 0.0099 \\
\hline 2 & 0.0169 & $( \pm 0.0104)$ & 0.1053 & 0.0797 & $( \pm 0.0308)$ & 0.0096 \\
\hline 2.25 & 0.0171 & $( \pm 0.0103)$ & 0.0964 & 0.0770 & $( \pm 0.0298)$ & 0.0099 \\
\hline 2.5 & 0.0179 & $( \pm 0.0104)$ & 0.0836 & 0.0754 & $( \pm 0.0293)$ & 0.0101 \\
\hline 2.75 & 0.0180 & $( \pm 0.0105)$ & 0.0862 & 0.0737 & $( \pm 0.0290)$ & 0.0111 \\
\hline 3 & 0.0182 & $( \pm 0.0106)$ & 0.0875 & 0.0727 & $( \pm 0.0288)$ & 0.0118 \\
\hline 3.25 & 0.0183 & $( \pm 0.0107)$ & 0.0886 & 0.0719 & $( \pm 0.0287)$ & 0.0123 \\
\hline 3.5 & 0.0183 & $( \pm 0.0111)$ & 0.0988 & 0.0715 & $( \pm 0.0288)$ & 0.0130 \\
\hline
\end{tabular}


Appendix 2. Continued.

(d) Little Brown Myotis/ Northern Myotis/ Tri-colored Bat

\begin{tabular}{|c|r|r|r|}
\hline $\begin{array}{c}\text { Scale } \\
\mathbf{( k m )}\end{array}$ & $\begin{array}{r}\text { Percent Tree Cover } \\
\mathbf{B}( \pm \mathbf{S E})\end{array}$ & $\begin{array}{r}\text { p-value for Percent } \\
\text { Tree Cover } \mathbf{B}\end{array}$ \\
\hline $\mathbf{0 . 0 2 5}$ & 0.0152 & $( \pm 0.009)$ & 0.0898 \\
\hline $\mathbf{0 . 0 5}$ & 0.0191 & $( \pm 0.0123)$ & 0.1184 \\
\hline $\mathbf{0 . 1}$ & 0.0168 & $( \pm 0.0149)$ & 0.2602 \\
\hline $\mathbf{0 . 1 5}$ & 0.0173 & $( \pm 0.0159)$ & 0.2762 \\
\hline $\mathbf{0 . 2}$ & 0.0172 & $( \pm 0.0162)$ & 0.2881 \\
\hline $\mathbf{0 . 2 5}$ & 0.0178 & $( \pm 0.0172)$ & 0.3003 \\
\hline $\mathbf{0 . 5}$ & 0.0064 & $( \pm 0.0183)$ & 0.7254 \\
\hline $\mathbf{0 . 7 5}$ & 0.0030 & $( \pm 0.0177)$ & 0.8665 \\
\hline $\mathbf{1}$ & 0.0029 & $( \pm 0.0175)$ & 0.8675 \\
\hline $\mathbf{1 . 2 5}$ & 0.0016 & $( \pm 0.0182)$ & 0.9294 \\
\hline $\mathbf{1 . 5}$ & 0.0013 & $( \pm 0.0205)$ & 0.9484 \\
\hline $\mathbf{1 . 7 5}$ & 0.0022 & $( \pm 0.0235)$ & 0.9267 \\
\hline $\mathbf{2}$ & 0.0020 & $( \pm 0.0229)$ & 0.9310 \\
\hline $\mathbf{2 . 2 5}$ & 0.0029 & $( \pm 0.0237)$ & 0.9034 \\
\hline $\mathbf{2 . 5}$ & 0.0029 & $( \pm 0.0247)$ & 0.9063 \\
\hline $\mathbf{2 . 7 5}$ & 0.0024 & $( \pm 0.0262)$ & 0.9259 \\
\hline $\mathbf{3}$ & 0.0001 & $( \pm 0.0278)$ & 0.9975 \\
\hline $\mathbf{3 . 2 5}$ & -0.0038 & $( \pm 0.0286)$ & 0.8951 \\
\hline $\mathbf{3 . 5}$ & -0.0062 & $( \pm 0.0294)$ & 0.8331 \\
\hline & & & \\
\hline
\end{tabular}


Appendix 2. Continued.

\begin{tabular}{|c|r|r|r|}
\hline \begin{tabular}{|c|} 
(e) Eastern Red Bat \\
Scale \\
$\mathbf{( k m )}$
\end{tabular} & $\begin{array}{r}\text { Percent Tree Cover } \\
\text { 及 ( } \pm \text { SE) }\end{array}$ & $\begin{array}{c}\text { p-value for Percent } \\
\text { Tree Cover B }\end{array}$ \\
\hline $\mathbf{0 . 0 2 5}$ & 0.0466 & $( \pm 0.0118)$ & 0.0001 \\
\hline $\mathbf{0 . 0 5}$ & 0.0499 & $( \pm 0.0172)$ & 0.0038 \\
\hline $\mathbf{0 . 1}$ & 0.0424 & $( \pm 0.0215)$ & 0.0483 \\
\hline $\mathbf{0 . 1 5}$ & 0.0298 & $( \pm 0.0215)$ & 0.1656 \\
\hline $\mathbf{0 . 2}$ & 0.0269 & $( \pm 0.0212)$ & 0.2047 \\
\hline $\mathbf{0 . 2 5}$ & 0.0254 & $( \pm 0.0219)$ & 0.2459 \\
\hline $\mathbf{0 . 5}$ & 0.0122 & $( \pm 0.0245)$ & 0.6185 \\
\hline $\mathbf{0 . 7 5}$ & 0.0130 & $( \pm 0.0256)$ & 0.6105 \\
\hline $\mathbf{1}$ & 0.0147 & $( \pm 0.0266)$ & 0.5814 \\
\hline $\mathbf{1 . 2 5}$ & 0.0119 & $( \pm 0.0277)$ & 0.6679 \\
\hline $\mathbf{1 . 5}$ & 0.0108 & $( \pm 0.0289)$ & 0.7098 \\
\hline $\mathbf{1 . 7 5}$ & 0.0139 & $( \pm 0.0342)$ & 0.6843 \\
\hline $\mathbf{2}$ & 0.0114 & $( \pm 0.0323)$ & 0.7240 \\
\hline $\mathbf{2 . 2 5}$ & 0.0101 & $( \pm 0.0332)$ & 0.7605 \\
\hline $\mathbf{2 . 5}$ & 0.0089 & $( \pm 0.0343)$ & 0.7955 \\
\hline $\mathbf{2 . 7 5}$ & 0.0070 & $( \pm 0.0353)$ & 0.8432 \\
\hline $\mathbf{3}$ & 0.0056 & $( \pm 0.0360)$ & 0.8775 \\
\hline $\mathbf{3 . 2 5}$ & 0.0030 & $( \pm 0.0364)$ & 0.9348 \\
\hline $\mathbf{3 . 5}$ & 0.0018 & $( \pm 0.0371)$ & 0.9614 \\
\hline & & & \\
\hline
\end{tabular}


Appendix 3. Additional results of generalized linear mixed models examining the relationship between percent tree cover measured within each of 19 circular landscape scales and (a) total bat activity and (b-e) species-specific activity. Regression coefficients $[\beta \pm$ standard error (SE) $]$ and $p$-values are shown for standardized temperature $\left({ }^{\circ} \mathrm{C}\right)$ and standardized Julian Date at each scale.

\begin{tabular}{|c|c|c|c|c|c|c|}
\hline \multicolumn{7}{|c|}{ (a) Total Bat Activity } \\
\hline \multirow{2}{*}{$\begin{array}{l}\text { Scale } \\
(\mathbf{k m}) \\
0.025\end{array}$} & \multicolumn{2}{|c|}{$\begin{array}{c}\text { Standardized } \\
\text { Temperature } \\
\mathbf{B}( \pm \text { SE) }\end{array}$} & \multirow[t]{2}{*}{$\begin{array}{c}\text { p-value for } \\
\text { Standardized } \\
\text { Temperature } \\
\text { B } \\
0.0977\end{array}$} & \multicolumn{2}{|c|}{$\begin{array}{c}\text { Standardized } \\
\text { Julian Date } \\
\text { B }( \pm \text { SE })\end{array}$} & \multirow[t]{2}{*}{$\begin{array}{c}\text { p-value for } \\
\text { Standardized } \\
\text { Julian Date } \\
\text { B } \\
0.0002\end{array}$} \\
\hline & 0.2079 & $( \pm 0.1255)$ & & 0.0183 & $( \pm 0.0049)$ & \\
\hline 0.05 & 0.2296 & $( \pm 0.1210)$ & 0.0577 & 0.0163 & $( \pm 0.0050)$ & 0.0010 \\
\hline 0.1 & 0.2401 & $( \pm 0.1175)$ & 0.0411 & 0.0160 & $( \pm 0.0050)$ & 0.0014 \\
\hline 0.15 & 0.2207 & $( \pm 0.1166)$ & 0.0585 & 0.0169 & $( \pm 0.0050)$ & 0.0006 \\
\hline 0.2 & 0.2108 & $( \pm 0.1170)$ & 0.0716 & 0.0169 & $( \pm 0.0050)$ & 0.0008 \\
\hline 0.25 & 0.1884 & $( \pm 0.1195)$ & 0.1151 & 0.0175 & $( \pm 0.0049)$ & 0.0004 \\
\hline 0.5 & 0.1952 & $( \pm 0.1264)$ & 0.1225 & 0.0184 & $( \pm 0.0050)$ & 0.0002 \\
\hline 0.75 & 0.2036 & $( \pm 0.1264)$ & 0.1073 & 0.0186 & $( \pm 0.0050)$ & 0.0002 \\
\hline 1 & 0.2105 & $( \pm 0.1256)$ & 0.0937 & 0.0185 & $( \pm 0.0050)$ & 0.0002 \\
\hline 1.25 & 0.2141 & $( \pm 0.1252)$ & 0.0873 & 0.0186 & $( \pm 0.0050)$ & 0.0002 \\
\hline 1.5 & 0.2176 & $( \pm 0.1249)$ & 0.0813 & 0.0186 & $( \pm 0.0050)$ & 0.0002 \\
\hline 1.75 & 0.2182 & $( \pm 0.1237)$ & 0.0777 & 0.0185 & $( \pm 0.0049)$ & 0.0002 \\
\hline 2 & 0.2167 & $( \pm 0.1236)$ & 0.0795 & 0.0184 & $( \pm 0.0049)$ & 0.0002 \\
\hline 2.25 & 0.2130 & $( \pm 0.1238)$ & 0.0852 & 0.0183 & $( \pm 0.0049)$ & 0.0002 \\
\hline 2.5 & 0.2126 & $( \pm 0.1236)$ & 0.0853 & 0.0182 & $( \pm 0.0049)$ & 0.0002 \\
\hline 2.75 & 0.2118 & $( \pm 0.1239)$ & 0.0875 & 0.0183 & $( \pm 0.0049)$ & 0.0002 \\
\hline 3 & 0.2085 & $( \pm 0.1242)$ & 0.0932 & 0.0184 & $( \pm 0.0049)$ & 0.0002 \\
\hline 3.25 & 0.2038 & $( \pm 0.1243)$ & 0.1010 & 0.0186 & $( \pm 0.0049)$ & 0.0001 \\
\hline 3.5 & 0.1978 & $( \pm 0.1245)$ & 0.1121 & 0.0188 & $( \pm 0.0049)$ & 0.0001 \\
\hline
\end{tabular}


Appendix 3. Continued.

(b) Big Brown Bat

\begin{tabular}{|c|c|c|c|c|c|c|}
\hline \multirow{2}{*}{\begin{tabular}{|c|} 
Scale \\
(km)
\end{tabular}} & \multicolumn{2}{|c|}{$\begin{array}{c}\text { Standardized } \\
\text { Temperature } \\
\text { 及 }( \pm \text { SE })\end{array}$} & \multirow[t]{2}{*}{$\begin{array}{c}\text { p-value for } \\
\text { Standardized } \\
\text { Temperature } \\
\text { B } \\
0.0461\end{array}$} & \multicolumn{2}{|c|}{$\begin{array}{c}\text { Standardized } \\
\text { Julian Date } \\
\text { B ( } \pm \text { SE })\end{array}$} & \multirow[t]{2}{*}{\begin{tabular}{|c|} 
p-value for \\
Standardized \\
Julian Date \\
B \\
0.0820
\end{tabular}} \\
\hline & 0.3028 & $( \pm 0.1518)$ & & 0.0102 & $( \pm 0.0059)$ & \\
\hline 0.05 & 0.3318 & $( \pm 0.1488)$ & 0.0257 & 0.0087 & $( \pm 0.0058)$ & 0.1345 \\
\hline 0.1 & 0.3321 & $( \pm 0.1472)$ & 0.0241 & 0.0087 & $( \pm 0$. & 0.1333 \\
\hline 0.15 & 0.3253 & $( \pm 0.1470)$ & 0.0269 & 0.0100 & $( \pm 0.0057)$ & 0.0814 \\
\hline 0.2 & 0.3187 & $( \pm 0.1471)$ & 0.0303 & 0.0100 & $( \pm 0$ & 0.0810 \\
\hline 0.25 & 0.2959 & $( \pm 0.1484)$ & & & & 0.0739 \\
\hline 0.5 & & $( \pm 0.1523)$ & & & & 0.0744 \\
\hline 0.75 & 0.2937 & $( \pm 0.1527)$ & 0.0545 & & $( \pm 0$ & 0.0747 \\
\hline 1 & 0.3028 & $( \pm 0.1522)$ & 0.0 & 0.0104 & $( \pm 0$ & 0.0767 \\
\hline 1.25 & 0.3042 & $( \pm 0.1519)$ & 0.0452 & 0.0104 & $( \pm 0.0059)$ & 0.0753 \\
\hline 1.5 & 0.3074 & $( \pm 0.1514)$ & 0.0423 & 0.0103 & $( \pm 0.0059)$ & 0.0796 \\
\hline 1.75 & 0.3083 & $( \pm 0.1506)$ & 0.0407 & 0.0101 & $( \pm 0.0058)$ & 0.0832 \\
\hline 2 & 0.3066 & $( \pm 0.1505)$ & 0.0417 & 0.0100 & $( \pm 0$ & 0.0873 \\
\hline 2.25 & 0.3025 & $( \pm 0.1506)$ & 0.0446 & 0.0099 & $( \pm 0.0058)$ & 0.0900 \\
\hline 2.5 & 0.3027 & $( \pm 0.1504)$ & 0.0441 & 0.0098 & $( \pm 0.0058)$ & 0.0933 \\
\hline 2.75 & 0.3021 & $( \pm 0.1506)$ & 0.0449 & 0.0098 & $( \pm 0.0058)$ & 0.0931 \\
\hline 3 & 0.2987 & $( \pm 0.1509)$ & 0.0477 & 0.0099 & $( \pm 0.0058)$ & 0.0883 \\
\hline 3.25 & 0.2922 & $( \pm 0.1511)$ & 0.0531 & 0.0102 & $( \pm 0.0058)$ & 0.0810 \\
\hline 3.5 & 0.2848 & $( \pm 0.1512)$ & 0.0596 & 0.0104 & $( \pm 0.0058)$ & 0.0746 \\
\hline
\end{tabular}


Appendix 3. Continued.

(c) Hoary Bat/ Silver-haired Bat

\begin{tabular}{|c|c|c|c|c|c|c|}
\hline \multirow{2}{*}{$\begin{array}{c}\text { Scale } \\
(\mathbf{k m}) \\
0.025\end{array}$} & \multicolumn{2}{|c|}{$\begin{array}{c}\text { Standardized } \\
\text { Temperature } \\
\text { B ( } \pm \text { SE) }\end{array}$} & \multirow[t]{2}{*}{$\begin{array}{c}\text { p-value for } \\
\text { Standardized } \\
\text { Temperature } \\
\text { B } \\
0.0359\end{array}$} & \multicolumn{2}{|c|}{$\begin{array}{c}\text { Standardized } \\
\text { Julian Date } \\
\text { B ( } \pm \text { SE })\end{array}$} & \multirow[t]{2}{*}{$\begin{array}{l}\text { p-value for } \\
\text { Standardized } \\
\text { Julian Date } \\
\text { B } \\
<0.0001 \\
\end{array}$} \\
\hline & 0.2841 & $( \pm 0.1355)$ & & 0.0296 & $( \pm 0.0063)$ & \\
\hline 0.05 & 0.2841 & $( \pm 0.1305)$ & 0.0295 & 0.0289 & $( \pm 0.0062)$ & $<0.0001$ \\
\hline 0.1 & 0.2893 & $( \pm 0.1285)$ & 0.0243 & 0.0284 & $( \pm 0.0061)$ & $<0.0001$ \\
\hline 0.15 & 0.2868 & $( \pm 0.1279)$ & 0.0250 & 0.0287 & $0.0061)$ & $<0.0001$ \\
\hline 0.2 & 0.2880 & $( \pm 0.1282)$ & 0.0246 & 0.0286 & $( \pm 0.0061)$ & $<0.0001$ \\
\hline 0.25 & 0.2767 & $( \pm 0.1302)$ & 0.0335 & 0.0290 & & $<0.0001$ \\
\hline 0.5 & 0.2675 & $( \pm 0.1$ & 0.0451 & 0.0293 & & $<0.0001$ \\
\hline 0.75 & 0.2534 & $( \pm 0.1334)$ & & & & $<0.0001$ \\
\hline 1 & & $( \pm 0.1328)$ & & & & $<0.0001$ \\
\hline 1.25 & 0.2553 & $( \pm 0.1327)$ & & & & $<0.0001$ \\
\hline 1.5 & 0.2630 & $( \pm 0.1349)$ & & & & $<0.0001$ \\
\hline 1.75 & 0.2655 & $( \pm 0.1338)$ & 0.0 & 0.0290 & $( \pm 0.00$ & $<0.0001$ \\
\hline 2 & 0.2632 & $( \pm 0.1334)$ & 0.0485 & 0.0290 & & $<0.0001$ \\
\hline 2.25 & 0.2602 & $( \pm 0.1316)$ & 0.0480 & 0.0289 & $( \pm 0.0062)$ & $<0.0001$ \\
\hline 2.5 & 0.2591 & $( \pm 0.1311)$ & 0.0482 & 0.0288 & $( \pm 0.0062)$ & $<0.0001$ \\
\hline 2.75 & 0.2579 & $( \pm 0.1312)$ & 0.0493 & 0.0289 & $( \pm 0.0062)$ & $<0.0001$ \\
\hline 3 & 0.2556 & $( \pm 0.1314)$ & 0.0518 & 0.0290 & $( \pm 0.0062)$ & $<0.0001$ \\
\hline 3.25 & 0.2527 & $( \pm 0.1317)$ & 0.0551 & 0.0291 & $( \pm 0.0062)$ & $<0.0001$ \\
\hline 3.5 & 0.2509 & $( \pm 0.1339)$ & 0.0609 & 0.0293 & $( \pm 0.0063)$ & $<0.0001$ \\
\hline
\end{tabular}


Appendix 3. Continued.

(d) Little Brown Myotis/ Northern Myotis/ Tri-colored Bat

\begin{tabular}{|c|c|c|c|c|c|c|}
\hline \multirow{2}{*}{$\begin{array}{c}\text { Scale } \\
(\mathbf{k m}) \\
0.025\end{array}$} & \multicolumn{2}{|c|}{$\begin{array}{c}\text { Standardized } \\
\text { Temperature } \\
\text { B }( \pm \text { SE })\end{array}$} & \multirow[t]{2}{*}{$\begin{array}{c}\text { p-value for } \\
\text { Standardized } \\
\text { Temperature } \\
\text { B } \\
0.7400\end{array}$} & \multicolumn{2}{|c|}{$\begin{array}{c}\text { Standardized } \\
\text { Julian Date } \\
\text { B }( \pm \text { SE })\end{array}$} & \multirow[t]{2}{*}{$\begin{array}{c}\text { p-value for } \\
\text { Standardized } \\
\text { Julian Date } \\
\text { B } \\
0.5242 \\
\end{array}$} \\
\hline & -0.1037 & $( \pm 0.3126)$ & & 0.0078 & $( \pm 0.0122)$ & \\
\hline 0.05 & -0.0717 & $( \pm 0.3148)$ & 0.8198 & 0.0056 & $( \pm 0.0127)$ & 0.6577 \\
\hline 0.1 & -0.0749 & $( \pm 0.3212)$ & 0.8157 & 0.0083 & $( \pm 0.0127)$ & 0.5112 \\
\hline 0.15 & -0.0902 & $( \pm 0.3201)$ & 0.7780 & 0.0093 & $( \pm 0.0125)$ & 0.4567 \\
\hline 0.2 & -0.0982 & $( \pm 0.3201)$ & 0.7591 & 0.0093 & $( \pm 0.0125)$ & 0.4552 \\
\hline 0.25 & -0.1147 & $( \pm 0.3198)$ & 0.7200 & 0.0094 & $( \pm 0.0125)$ & 0.4547 \\
\hline 0.5 & -0.1260 & $( \pm 0.3238)$ & 0.6972 & 0.0123 & $( \pm 0$ & 0.3258 \\
\hline 0.75 & -0.1260 & $( \pm 0.3246)$ & 0.6978 & 0.0131 & & 0.2933 \\
\hline 1 & -0.1262 & $( \pm 0.3245)$ & & 0.0131 & & 0.2927 \\
\hline 1.25 & -0.1264 & $( \pm 0.3249)$ & 0.6973 & 0.0134 & $( \pm 0.012$ & 0.2842 \\
\hline 1.5 & -0.1267 & $( \pm 0.3357)$ & & & & 0.2819 \\
\hline 1.75 & -0.1256 & $( \pm 0.3265)$ & 0.7 & 0.0134 & $( \pm 0.0$ & 0.2840 \\
\hline 2 & -0.1254 & $( \pm 0.3291)$ & 0.7031 & 0.0134 & $( \pm 0.0125)$ & 0.2836 \\
\hline 2.25 & -0.1238 & $( \pm 0.3262)$ & 0.7043 & 0.0132 & $( \pm 0.0125)$ & 0.2905 \\
\hline 2.5 & -0.1232 & $( \pm 0.3269)$ & 0.7064 & 0.0132 & $( \pm 0.0126)$ & 0.2927 \\
\hline 2.75 & -0.1238 & $( \pm 0.3335)$ & 0.7106 & 0.0133 & $( \pm 0.0126)$ & 0.2900 \\
\hline 3 & -0.1308 & $( \pm 0.3413)$ & 0.7015 & 0.0136 & $( \pm 0.0126)$ & 0.2797 \\
\hline 3.25 & -0.1406 & $( \pm 0.3427)$ & 0.6816 & 0.0140 & $( \pm 0.0126)$ & 0.2661 \\
\hline 3.5 & -0.1446 & $( \pm 0.3405)$ & 0.6712 & 0.0141 & $( \pm 0.0125)$ & 0.2598 \\
\hline
\end{tabular}


Appendix 3. Continued.

(e) Eastern Red Bat

\begin{tabular}{|c|c|c|c|c|c|c|}
\hline \multirow{2}{*}{\begin{tabular}{|c|}
$\begin{array}{c}\text { Scale } \\
(\mathbf{k m})\end{array}$ \\
$\mathbf{0 . 0 2 5}$ \\
\end{tabular}} & \multicolumn{2}{|c|}{$\begin{array}{c}\text { Standardized } \\
\text { Temperature } \\
\mathbf{B}( \pm \text { SE) }\end{array}$} & \multirow[t]{2}{*}{$\begin{array}{c}\text { p-value for } \\
\text { Standardized } \\
\text { Temperature } \\
\text { B } \\
0.1595\end{array}$} & \multicolumn{2}{|c|}{$\begin{array}{c}\text { Standardized } \\
\text { Julian Date } \\
\text { B ( } \pm \text { SE })\end{array}$} & \multirow[t]{2}{*}{\begin{tabular}{|c|} 
p-value for \\
Standardized \\
Julian Date \\
B \\
0.0069 \\
\end{tabular}} \\
\hline & -0.5735 & $( \pm 0.4077)$ & & 0.0413 & $( \pm 0.0153)$ & \\
\hline 0.05 & -0.4487 & $( \pm 0.4134)$ & 0.2777 & 0.0420 & & 0.0064 \\
\hline 0.1 & -0.4106 & $( \pm 0.4210)$ & 0.3295 & 0.0457 & $( \pm 0$ & 0.0032 \\
\hline 0.15 & -0.4240 & $( \pm 0.4280)$ & 0.3218 & 0.0476 & $( \pm 0.0157)$ & 0.0024 \\
\hline 0.2 & -0.4279 & $( \pm 0.4296)$ & 0.3192 & 0.0477 & $( \pm 0.0157)$ & 0.0024 \\
\hline 0.25 & -0.4409 & $( \pm 0.4306)$ & & & & 0.0024 \\
\hline 0.5 & -0.4614 & $( \pm 0.4353)$ & & & & 0.0024 \\
\hline 0.75 & -0.4699 & $( \pm 0.4355)$ & 6 & 0.0 & $( \pm$ & 0.0023 \\
\hline 1 & -0.4681 & $( \pm 0.4354)$ & 0.2823 & 0.0487 & $( \pm 0.0160)$ & 0.0024 \\
\hline 1.25 & -0.4689 & $( \pm 0.4356)$ & 0.2817 & 0.0491 & $( \pm 0.0160)$ & 0.0021 \\
\hline 1.5 & -0.4683 & $( \pm 0.4357)$ & 0.2825 & 0.0493 & $( \pm 0$. & 0.0020 \\
\hline 1.75 & -0.4676 & $( \pm 0.4356)$ & 0.2831 & 0.0493 & $( \pm 0$ & 0.0020 \\
\hline 2 & -0.4688 & $( \pm 0.4358)$ & 0.2821 & 0.0494 & $( \pm 0.0159)$ & 0.0019 \\
\hline 2.25 & -0.4699 & $( \pm 0.4361)$ & 0.2812 & 0.0496 & $( \pm 0.0159)$ & 0.0018 \\
\hline 2.5 & -0.4697 & $( \pm 0.4362)$ & 0.2815 & 0.0497 & $( \pm 0.0159)$ & 0.0018 \\
\hline 2.75 & -0.4701 & $( \pm 0.4363)$ & 0.2812 & 0.0498 & $( \pm 0.0159)$ & 0.0017 \\
\hline 3 & -0.4705 & $( \pm 0.4363)$ & 0.2809 & 0.0499 & $( \pm 0.0159)$ & 0.0017 \\
\hline 3.25 & -0.4708 & $( \pm 0.4364)$ & 0.2806 & 0.0500 & $( \pm 0.0159)$ & 0.0016 \\
\hline 3.5 & -0.4710 & $( \pm 0.4365)$ & 0.2806 & 0.0500 & $( \pm 0.0159)$ & 0.0016 \\
\hline
\end{tabular}


Appendix 4. AIC, $\triangle \mathrm{AIC}$, relative likelihood, and AIC weights from generalized linear mixed models (GLMM) examining the relationship between percent tree cover measured within each of 19 circular landscape scales and (a) total bat activity and (b - e) speciesspecific activity. AIC values are shown for GLMM without a statistical control for percent building cover, and with a statistical control for percent building cover included in models separately at the $0.5 \mathrm{~km}, 1 \mathrm{~km}$, or $1.5 \mathrm{~km}$-radius landscape scales. $\triangle \mathrm{AIC}$, relative likelihood, and AIC weights correspond to the best-fitting model, which is shaded (i.e., either with or without percent building cover at $1 \mathrm{~km}$ included as a statistical control).

\section{(a) Total Bat Activity}

\begin{tabular}{|c|c|c|c|c|c|c|c|}
\hline \multirow[b]{2}{*}{$\begin{array}{l}\text { Scale } \\
(\mathrm{km})\end{array}$} & \multicolumn{4}{|c|}{ AIC } & & \multirow[b]{2}{*}{ Relative } & \multirow[b]{2}{*}{$\begin{array}{c}\text { AIC } \\
\text { Weight }\end{array}$} \\
\hline & $\begin{array}{c}\text { No } \\
\text { Building } \\
\text { Control }\end{array}$ & $\begin{array}{l}\text { 0.5km } \\
\text { Building } \\
\text { Control }\end{array}$ & $\begin{array}{c}1 \mathrm{~km} \\
\text { Building } \\
\text { Control }\end{array}$ & $\begin{array}{c}1.5 \mathrm{~km} \\
\text { Building } \\
\text { Control }\end{array}$ & $\Delta \mathrm{AIC}$ & & \\
\hline 0.025 & 1079.102 & 1080.280 & 1076.176 & 1075.886 & 11.520 & 0.003 & 0.001 \\
\hline 0.05 & 1077.898 & 1077.196 & 1071.516 & 1071 & 6.860 & .032 & 0.013 \\
\hline 0.1 & 1078.478 & 1075.604 & 1067.232 & 1068 & 2.576 & 276 & 0.111 \\
\hline 0.15 & 1080.198 & 1075 & 1065. & $10 t$ & 0.542 & 63 & 0.307 \\
\hline 0.2 & 1081. & 1075 & 1064.656 & 107 & 0 & 00 & 0.403 \\
\hline 0.25 & 1082.018 & 1077.028 & 1066.594 & & 1.938 & & 0.153 \\
\hline 0.5 & 1085.124 & 1084.986 & 1076.318 & & 11.662 & 03 & 0.001 \\
\hline 0.75 & 1085.298 & 1086.134 & 1078.162 & 108 & 13.506 & 001 & \\
\hline 1 & 1085.228 & 1086.104 & 1078.262 & 107 & 13.606 & 0.001 & \\
\hline 1.25 & 1085.104 & 1085.912 & 1078.306 & 1079.028 & 13.650 & 0.001 & \\
\hline 1.5 & 1084.832 & 1085.492 & 1078.212 & 1078.222 & 13.556 & 0.001 & \\
\hline 1.75 & 1084.080 & 1084.302 & 1076.726 & 1076.436 & 12.070 & 0.002 & 0.001 \\
\hline 2 & 1083.478 & 1083.598 & 1076.346 & 1075.902 & 11.690 & .003 & 0.001 \\
\hline 2.25 & 1082 & 108 & 1076.282 & 107 & 11.626 & 03 & 0.001 \\
\hline 2.5 & & 108 & 1076.138 & 107 & 11.482 & 3 & 0.00 \\
\hline 2.75 & 1082.494 & 1082.788 & 1076.608 & 1075 & 11.952 & 0.003 & 0.001 \\
\hline 3 & 1082.338 & 1082.658 & 1076.598 & 1075.902 & 11.942 & 0.003 & 0.001 \\
\hline 3.25 & 1082.144 & 1082.482 & 1076.490 & 1075.762 & 11.834 & 0.003 & 0.001 \\
\hline 3.5 & 1081.896 & 1082.198 & 1076.168 & 1075.444 & 11.512 & 0.003 & 0.001 \\
\hline
\end{tabular}


Appendix 4. Continued.

(b) Big Brown Bat

\begin{tabular}{|c|c|c|c|c|c|c|c|}
\hline \multirow[b]{2}{*}{$\begin{array}{c}\text { Scale } \\
(\mathrm{km})\end{array}$} & \multicolumn{4}{|c|}{ AIC } & \multirow{2}{*}{\multicolumn{2}{|c|}{$\begin{array}{c}\text { Relative } \\
\text { Likelihoods }\end{array}$}} & \multirow[b]{2}{*}{$\begin{array}{c}\text { AIC } \\
\text { Weight }\end{array}$} \\
\hline & $\begin{array}{c}\text { No } \\
\text { Building } \\
\text { Control }\end{array}$ & $\begin{array}{c}\text { 0.5km } \\
\text { Building } \\
\text { Control }\end{array}$ & $\begin{array}{l}\text { 1km } \\
\text { Building } \\
\text { Control }\end{array}$ & $\begin{array}{c}\text { 1.5km } \\
\text { Building } \\
\text { Control }\end{array}$ & & & \\
\hline 0.025 & 904.862 & 906.540 & 903.202 & 903.752 & 8.648 & 0.013 & 0.004 \\
\hline 0.05 & 904.042 & 904.430 & 899.604 & 900.786 & 5.050 & 0.080 & 0.022 \\
\hline 0.1 & 904.296 & 902.740 & 895.128 & 898.280 & 0.574 & 0.751 & 0.205 \\
\hline 0.15 & 906.332 & 903.318 & 894.554 & 899.948 & 0 & 1.000 & 0.273 \\
\hline 0.2 & 907.682 & 904.442 & 894.686 & 900.956 & 0.132 & 0.936 & 0.255 \\
\hline 0.25 & 908.042 & 904.706 & 895.206 & 901.612 & 0.652 & 0.722 & 0.197 \\
\hline 0.5 & 911.204 & 911.316 & 902.686 & 907.464 & 8.132 & 0.017 & 0.005 \\
\hline 0.75 & 911.708 & 913.018 & 905.644 & 908.902 & 11.090 & 0.004 & 0.001 \\
\hline 1 & 911.7 & & 906.1 & & 11.5 & & 0.001 \\
\hline 1.25 & & & 905.694 & & 11.140 & 0.004 & 0.001 \\
\hline 1.5 & 910.992 & 912.108 & 905 & & 10.634 & 0.005 & 0.001 \\
\hline 1.75 & & 910.920 & 903.758 & 096 & 9.204 & 0.010 & 0.003 \\
\hline 2 & 909.366 & 910.070 & 903.214 & 388 & 8.660 & 0.013 & 0.004 \\
\hline 2.25 & 908.652 & 909.342 & 902.872 & 928 & 8.318 & 0.016 & 0.004 \\
\hline 2.5 & 907.946 & 908.642 & 902.526 & 903 & 7.972 & 0.019 & 0.005 \\
\hline 2.75 & 907.892 & 908.714 & 902.886 & 903.704 & 8.332 & 0.016 & 0.004 \\
\hline 3 & 907.692 & 908.540 & 902.832 & 903.584 & 8.278 & 0.016 & 0.004 \\
\hline 3.25 & 907.402 & 908.264 & 902.602 & 903.308 & 8.048 & 0.018 & 0.005 \\
\hline 3.5 & 906.924 & 907.732 & 901.982 & 902.698 & 7.428 & 0.024 & 0.007 \\
\hline
\end{tabular}


Appendix 4. Continued.

(c) Hoary Bat/ Silver-haired Bat

\begin{tabular}{|c|c|c|c|c|c|c|c|}
\hline \multirow[b]{2}{*}{$\begin{array}{l}\text { Scale } \\
(\mathbf{k m})\end{array}$} & \multicolumn{4}{|c|}{ AIC } & \multirow{2}{*}{\multicolumn{2}{|c|}{$\begin{array}{c}\text { Relative } \\
\text { Likelihoods }\end{array}$}} & \multirow[b]{2}{*}{$\begin{array}{c}\text { AIC } \\
\text { Weight }\end{array}$} \\
\hline & $\begin{array}{c}\text { No } \\
\text { Building } \\
\text { Control }\end{array}$ & $\begin{array}{c}\text { 0.5km } \\
\text { Building } \\
\text { Control }\end{array}$ & $\begin{array}{c}\text { 1km } \\
\text { Building } \\
\text { Control }\end{array}$ & $\begin{array}{c}1.5 \mathrm{~km} \\
\text { Building } \\
\text { Control }\end{array}$ & & & \\
\hline 0.025 & 741.774 & 741.866 & 739.440 & 739.354 & 4.730 & 0.094 & 0.014 \\
\hline 0.05 & 741. & 739.952 & 737.458 & & 2.748 & 0.253 & 0.036 \\
\hline 0.1 & 740. & 737.850 & 734.860 & & 0.150 & 0.928 & 0.134 \\
\hline 0.15 & 741. & 34 & 734.710 & 736.080 & 0 & 1.000 & 0.144 \\
\hline 0.2 & 741 & 738.438 & 734.996 & 736.602 & 0.286 & 0.867 & 0.125 \\
\hline 0.25 & 741. & 740.066 & 736.622 & 737.844 & 1.912 & 0.384 & 0.055 \\
\hline 0.5 & 741. & 74 & 738.330 & 28 & 3.620 & 0.164 & 0.024 \\
\hline 0.75 & 741.982 & 741.830 & 737.664 & 58 & 2.954 & 0.228 & 0.033 \\
\hline 1 & 742.024 & 741.684 & 737.330 & 738 & 2.620 & 0.270 & 0.039 \\
\hline 1.25 & 742.026 & 741.676 & 737.618 & 738.012 & 2.908 & 0.234 & 0.034 \\
\hline 1.5 & 742.014 & 741.626 & 737.924 & 844 & 3.214 & 0.200 & 0.029 \\
\hline 1.75 & 741.894 & 741.150 & 737.522 & 737.230 & 2.812 & 0.245 & 0.035 \\
\hline 2 & 741.706 & 740.804 & 737.324 & 736.902 & 2.614 & 0.271 & 0.039 \\
\hline 2.25 & 741.518 & 740.560 & 737.228 & 736.750 & 2.518 & 0.284 & 0.041 \\
\hline 2.5 & 741.258 & 740.210 & 737.002 & 736.468 & 2.292 & 0.318 & 0.046 \\
\hline 2.75 & 741.168 & 740.178 & 737.048 & 736.466 & 2.338 & 0.311 & 0.045 \\
\hline 3 & 741.084 & 740.126 & 737.070 & 736.456 & 2.360 & 0.307 & 0.044 \\
\hline 3.25 & 741.012 & 740.076 & 737.088 & 736.468 & 2.378 & 0.305 & 0.044 \\
\hline 3.5 & 741.062 & 740.186 & 737.226 & 736.642 & 2.516 & 0.284 & 0.041 \\
\hline
\end{tabular}


Appendix 4. Continued.

(d) Little Brown Myotis/ Northern Myotis/ Tri-colored Bat

\begin{tabular}{|c|c|c|c|c|c|c|c|}
\hline \multirow[b]{2}{*}{$\begin{array}{l}\text { Scale } \\
(\mathrm{km})\end{array}$} & \multicolumn{4}{|c|}{ AIC } & \multirow{2}{*}{\multicolumn{2}{|c|}{$\begin{array}{c}\text { Relative } \\
\text { Likelihoods }\end{array}$}} & \multirow[b]{2}{*}{$\begin{array}{c}\text { AIC } \\
\text { Weight }\end{array}$} \\
\hline & $\begin{array}{c}\text { No } \\
\text { Building } \\
\text { Control }\end{array}$ & $\begin{array}{c}\text { 0.5km } \\
\text { Building } \\
\text { Control }\end{array}$ & $\begin{array}{c}\text { 1km } \\
\text { Building } \\
\text { Control }\end{array}$ & $\begin{array}{c}1.5 \mathrm{~km} \\
\text { Building } \\
\text { Control }\end{array}$ & & & \\
\hline 0.025 & 190.802 & 192.699 & 192.723 & 192.337 & 0 & 1.000 & 0.146 \\
\hline 0.05 & 191.164 & 193.164 & 192.8 & 15 & 0.362 & 0.834 & 0.122 \\
\hline 0.1 & 192.337 & 194.308 & 194.101 & 61 & 1.535 & 0.464 & 0.068 \\
\hline 0.15 & 192.415 & 194.413 & 194.026 & 326 & 1.614 & 0.446 & 0.065 \\
\hline 0.2 & 192.473 & 194.473 & 194.019 & 04 & 1.672 & 0.434 & 0.063 \\
\hline 0.25 & 192.525 & 194.525 & 194. & 30 & 1.723 & 0.422 & 0.062 \\
\hline 0.5 & 19 & & & & 2.687 & 61 & 0.038 \\
\hline 0.75 & 193.584 & 194.632 & 195 & 195 & 2.782 & 0.249 & 0.036 \\
\hline 1 & 193.584 & 194.691 & 195.544 & 195.395 & 2.783 & 0.249 & 0.036 \\
\hline 1.25 & 193.604 & 194.592 & 195.520 & 195.451 & 2.803 & 0.246 & 0.036 \\
\hline 1.5 & 193.607 & 194.581 & 195.515 & 195.463 & 2.805 & 0.246 & 0.036 \\
\hline 1.75 & 193.604 & 194.625 & 195.528 & 195.445 & 2.802 & 0.246 & 0.036 \\
\hline 2 & 193.604 & 194.651 & 195.531 & 195.462 & 2.803 & 0.246 & 0.036 \\
\hline 2.25 & 193.597 & 194.731 & 195.542 & 195.444 & 2.796 & 0.247 & 0.036 \\
\hline 2.5 & 193.598 & 194.747 & 195.543 & 195.455 & 2.797 & 0.247 & 0.036 \\
\hline 2.75 & 193.603 & 194.740 & 195.540 & 195.476 & 2.801 & 0.246 & 0.036 \\
\hline 3 & 193.611 & 194.657 & 195.517 & 195.523 & 2.809 & 0.245 & 0.036 \\
\hline 3.25 & 193.594 & 194.483 & 195.445 & 195.549 & 2.792 & 0.248 & 0.036 \\
\hline 3.5 & 193.567 & 194.351 & 195.382 & 195.539 & 2.766 & 0.251 & 0.037 \\
\hline
\end{tabular}


Appendix 4. Continued.

(e) Eastern Red Bat

\begin{tabular}{|c|c|c|c|c|c|c|c|}
\hline \multirow[b]{2}{*}{$\begin{array}{c}\text { Scale } \\
(\mathrm{km})\end{array}$} & \multicolumn{4}{|c|}{ AIC } & & \multirow[b]{2}{*}{$\begin{array}{c}\text { Relative } \\
\text { Likelihoods }\end{array}$} & \multirow[b]{2}{*}{$\begin{array}{c}\text { AIC } \\
\text { Weight }\end{array}$} \\
\hline & $\begin{array}{c}\text { No } \\
\text { Building } \\
\text { Control }\end{array}$ & $\begin{array}{c}\text { 0.5km } \\
\text { Building } \\
\text { Control }\end{array}$ & $\begin{array}{c}\text { 1km } \\
\text { Building } \\
\text { Control }\end{array}$ & $\begin{array}{c}\text { 1.5km } \\
\text { Building } \\
\text { Control }\end{array}$ & $\Delta \mathrm{AIC}$ & & \\
\hline 0.025 & 383.172 & 384.746 & 385.102 & 384.716 & 0 & 1.000 & 0.921 \\
\hline 0.05 & 388.814 & 389.278 & 390.420 & 389.926 & 5.642 & 0.060 & 0.055 \\
\hline 0.1 & 393.154 & 393.666 & 394. & 132 & 9.982 & 0.007 & 0.006 \\
\hline 0.15 & 395.216 & 395.932 & 396.772 & 39 & 12.044 & 0.002 & 0.002 \\
\hline 0.2 & 395.536 & 396.210 & 397.064 & 39 & 12.364 & 0.002 & 0.002 \\
\hline 0.25 & 395.804 & 396.634 & 397.438 & 76 & 12.632 & 0.002 & 0.002 \\
\hline 0.5 & 396.914 & 398.798 & 398.892 & 39 & 13.742 & 0.001 & 0.001 \\
\hline 0.75 & 396.904 & 398.826 & 398.874 & 398 & 13.732 & .001 & 0.001 \\
\hline 1 & 396.860 & 398.782 & 398.816 & 08 & & 001 & 0.001 \\
\hline 1.25 & 396.978 & 398.952 & 398 & & 13.806 & 0.001 & 0.001 \\
\hline 1.5 & 397.024 & 399.014 & 399.024 & & 13.852 & 0.001 & 0.001 \\
\hline 1.75 & 396.996 & 84 & 398. & & 13.824 & 0.001 & 0.001 \\
\hline 2 & 397.038 & 399.034 & 399.036 & 16 & 13.866 & 0.001 & 0.001 \\
\hline 2.25 & 397.070 & 399.068 & 399.062 & 82 & 13.898 & 0.001 & 0.001 \\
\hline 2.5 & 397.096 & 399.096 & 399.082 & .030 & 13.924 & 0.001 & 0.001 \\
\hline 2.75 & 397.124 & 399.120 & 399.100 & 399.076 & 13.952 & 0.001 & 0.001 \\
\hline 3 & 397.138 & 399.132 & 399.106 & 399.104 & 13.966 & 0.001 & 0.001 \\
\hline 3.25 & 397.156 & 399.140 & 399.108 & 399.134 & 13.984 & 0.001 & 0.001 \\
\hline 3.5 & 397.160 & 399.138 & 399.104 & 399.142 & 13.988 & 0.001 & 0.001 \\
\hline
\end{tabular}


Appendix 5. Residual plots showing the spread of residuals relative to predicted values of total number of passes for (a) total bat activity and $(\mathbf{b}-\mathbf{e})$ species-specific activity at the $0.025 \mathrm{~km}, 1 \mathrm{~km}$, and $3.5 \mathrm{~km}$-radius landscape scales. I used these plots to assess the fit of the generalized linear mixed models and negative binomial link functions in estimating the relationship between percent tree cover and bat activity.

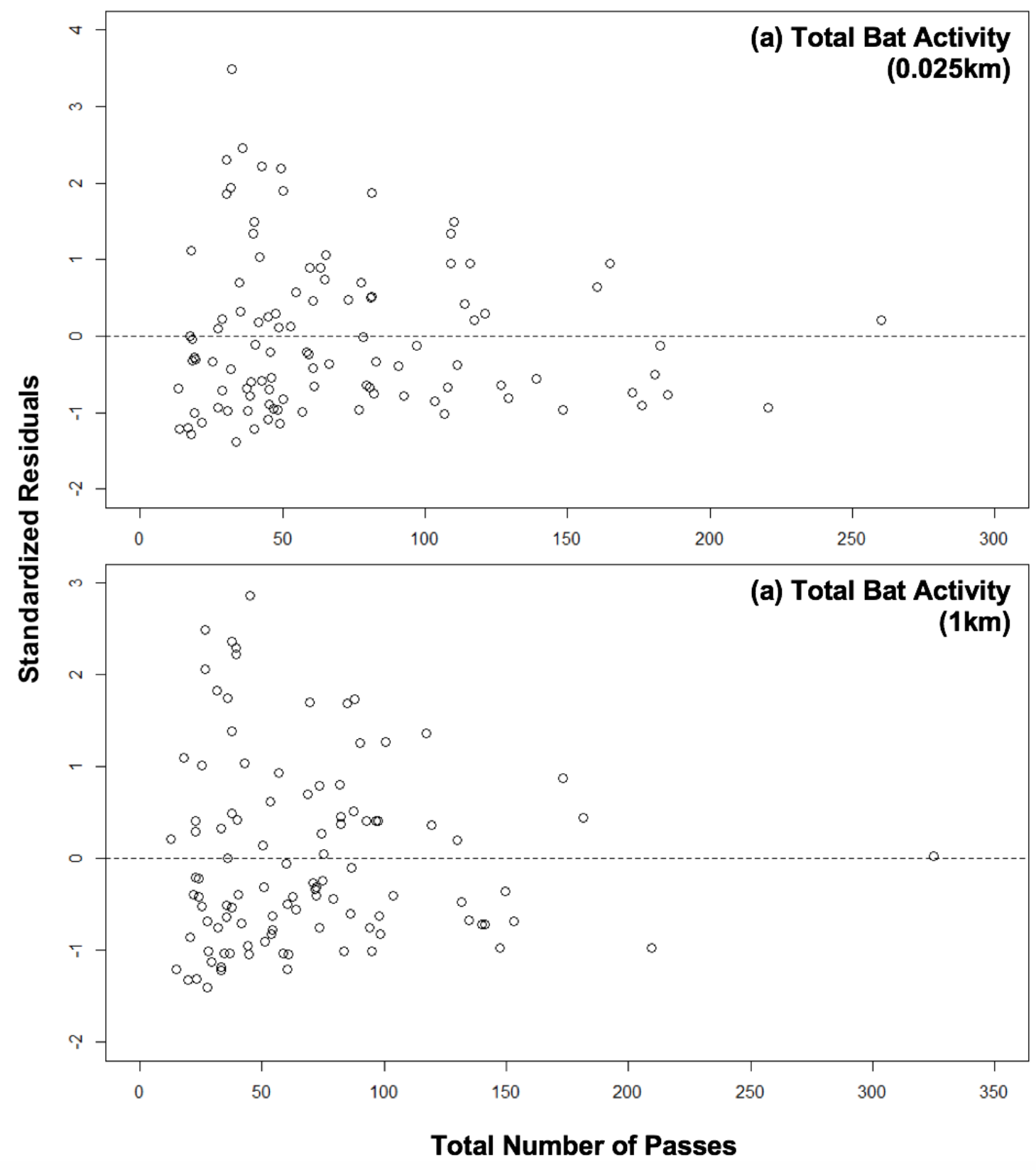


Appendix 5. Continued.

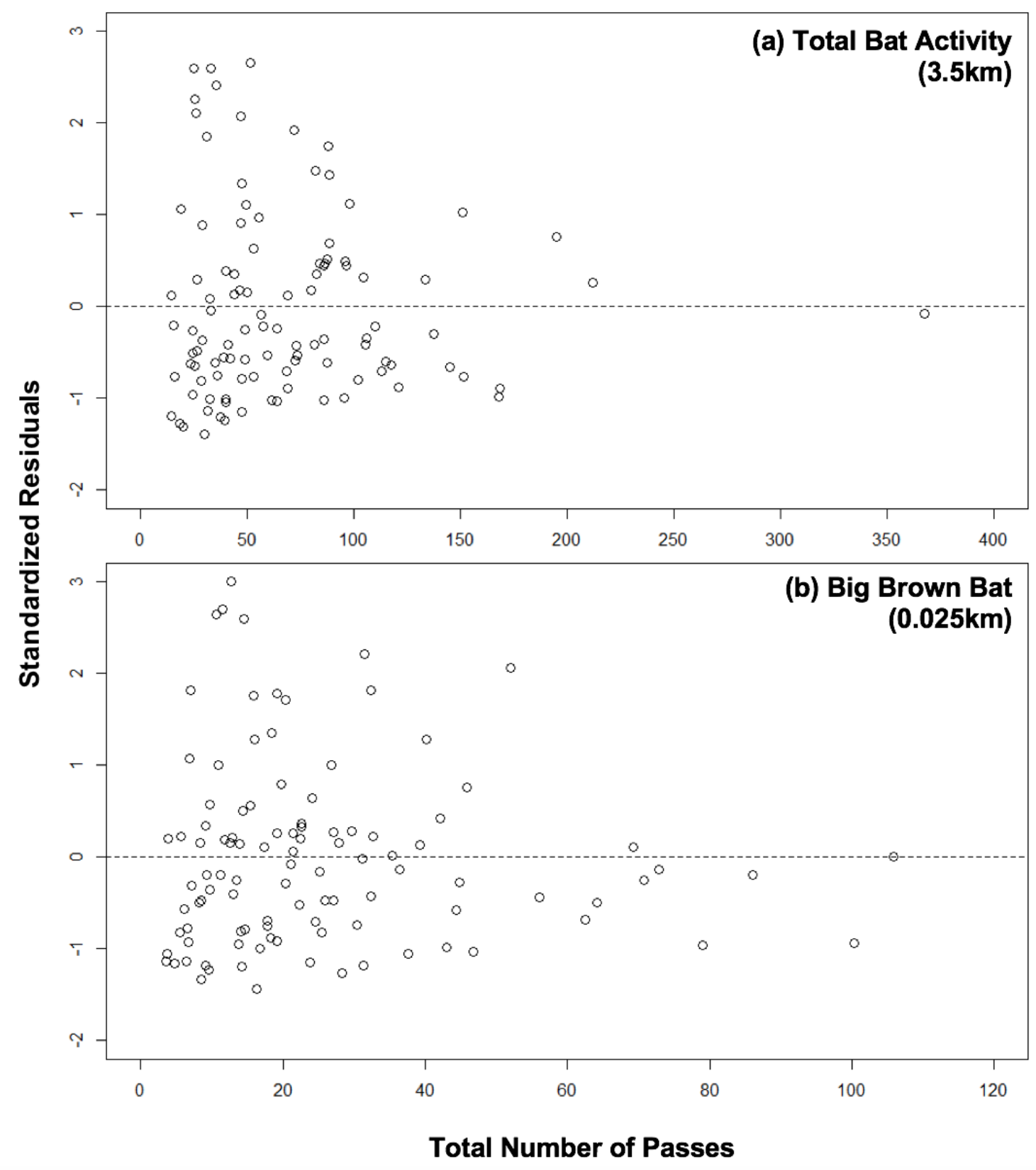


Appendix 5. Continued.

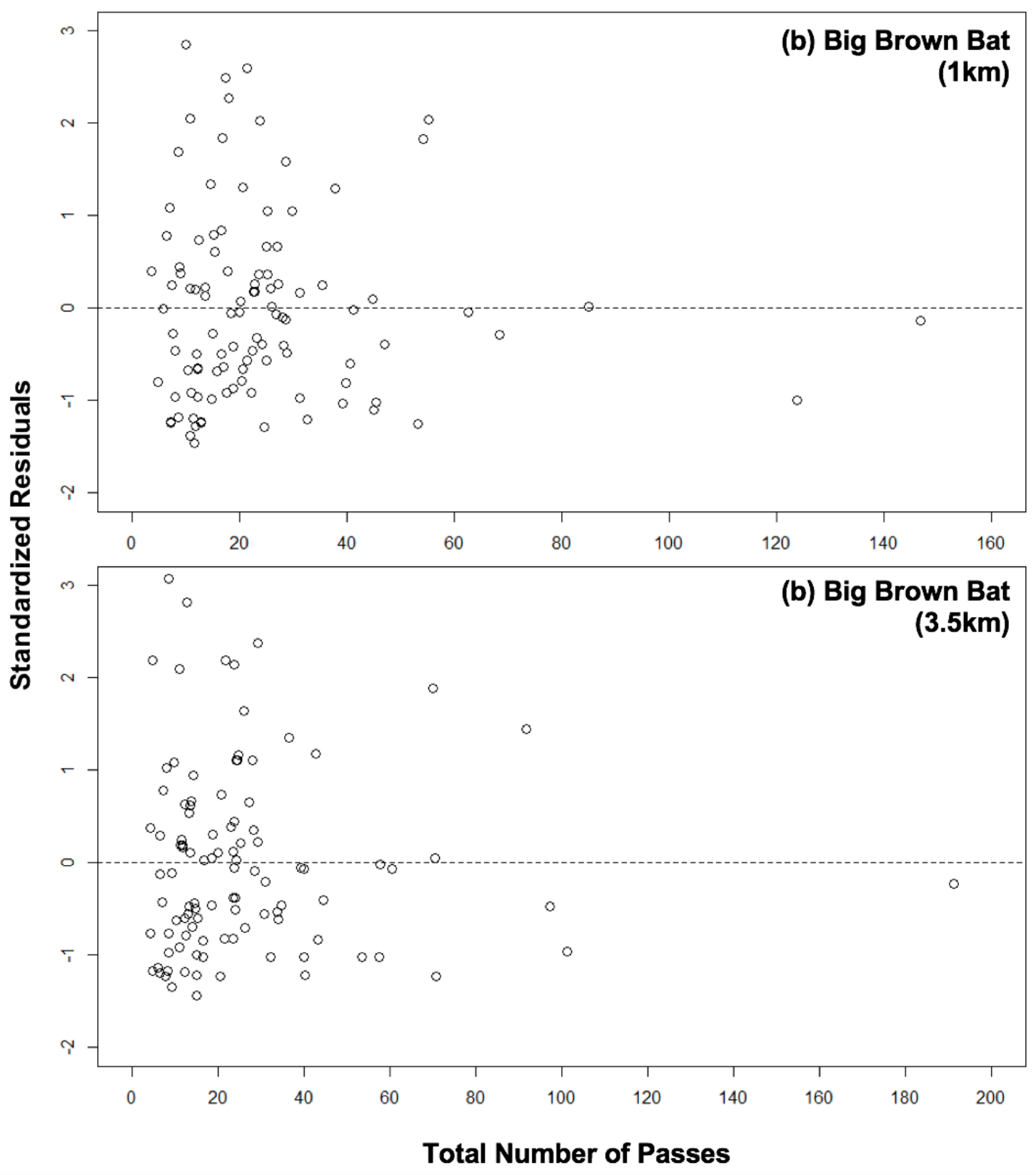


Appendix 5. Continued.

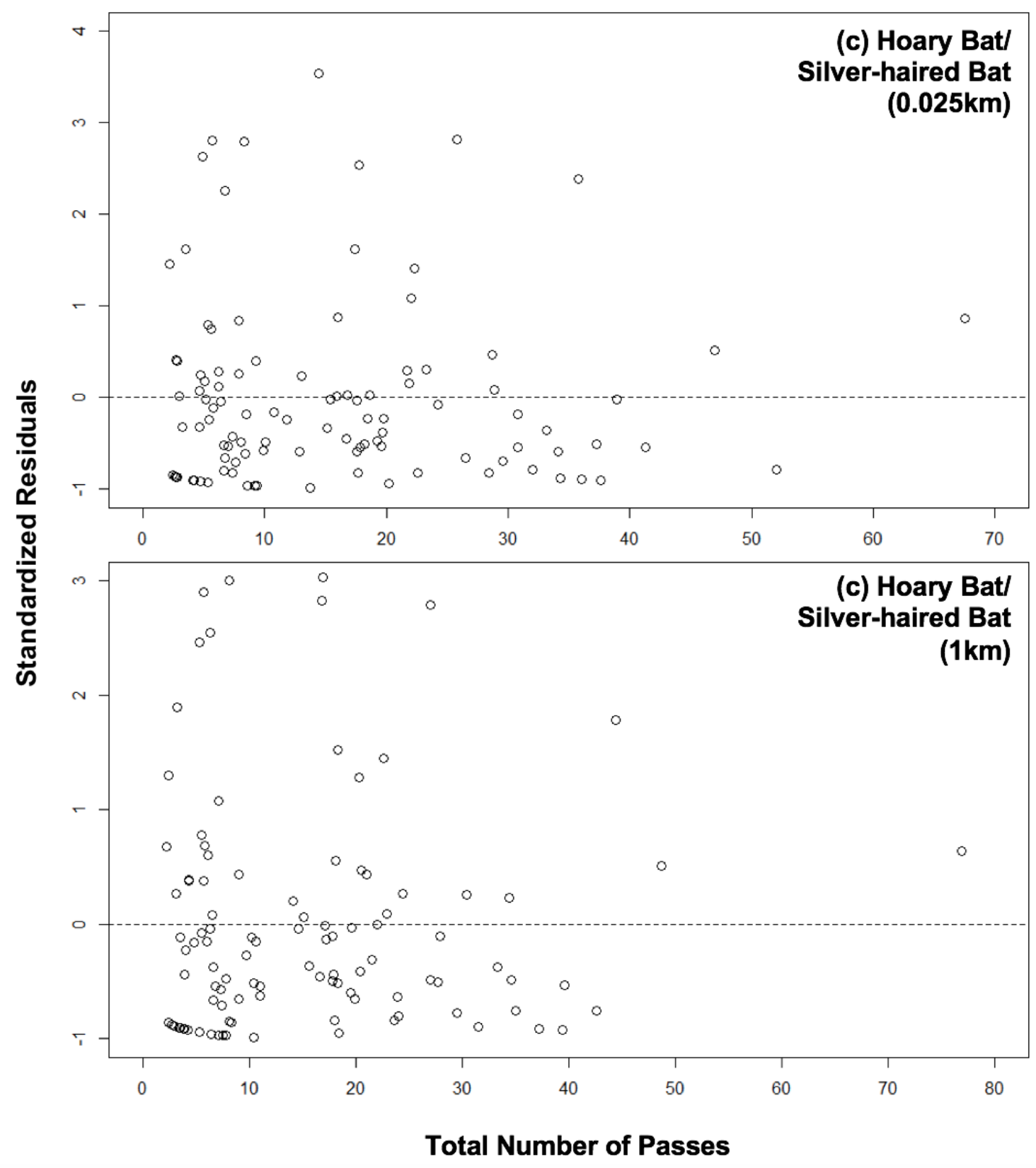


Appendix 5. Continued.

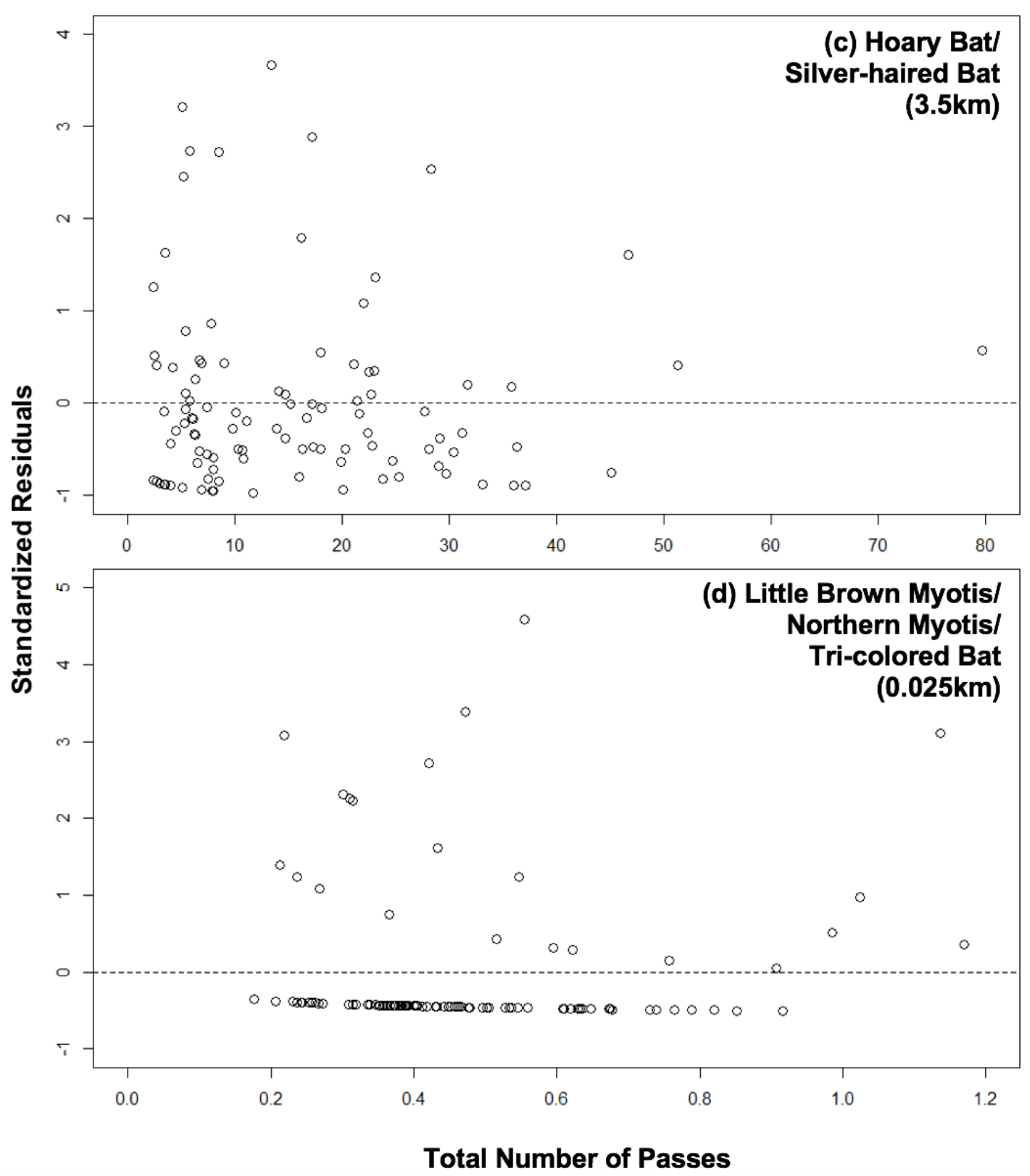


Appendix 5. Continued.

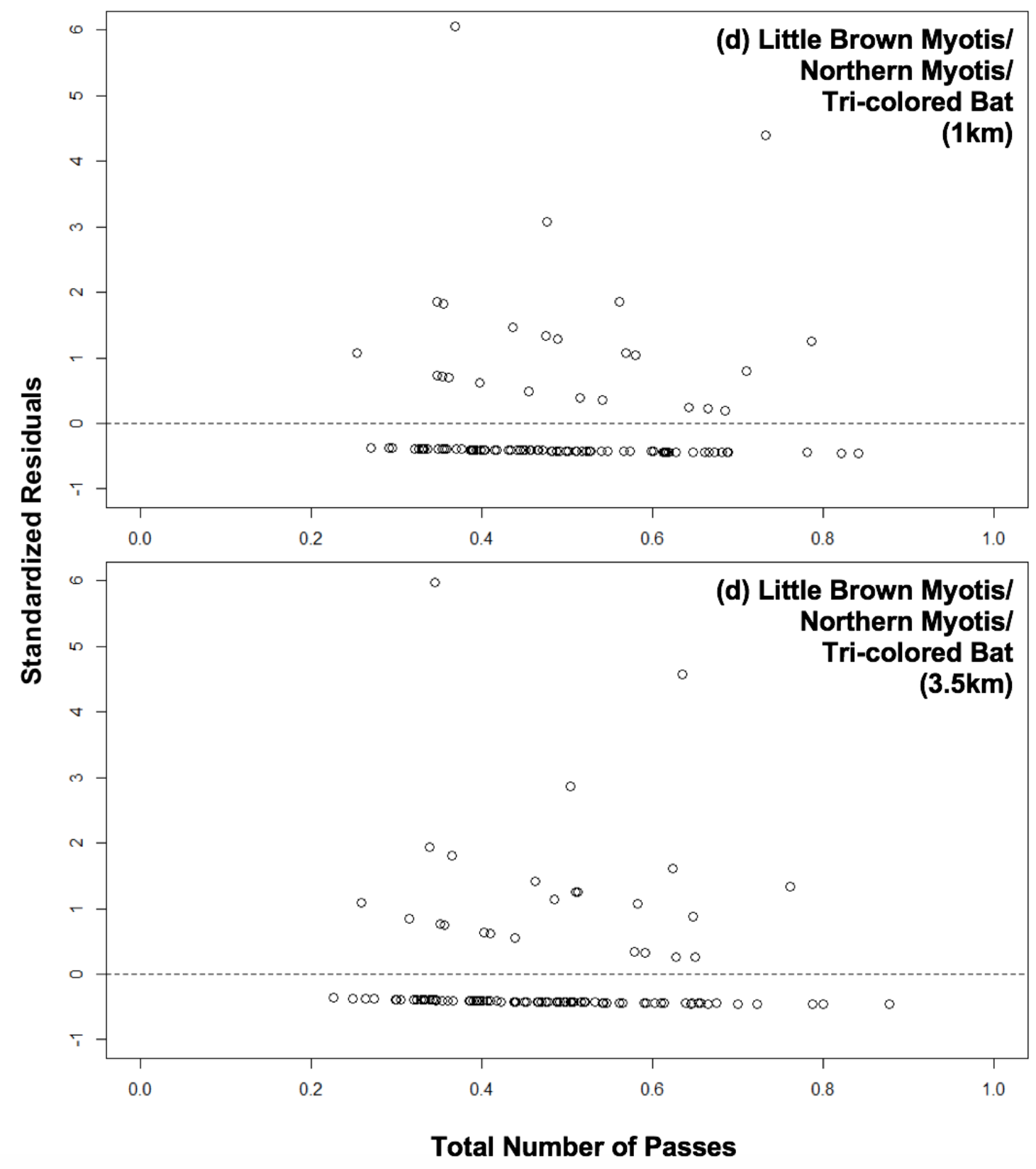


Appendix 5. Continued.

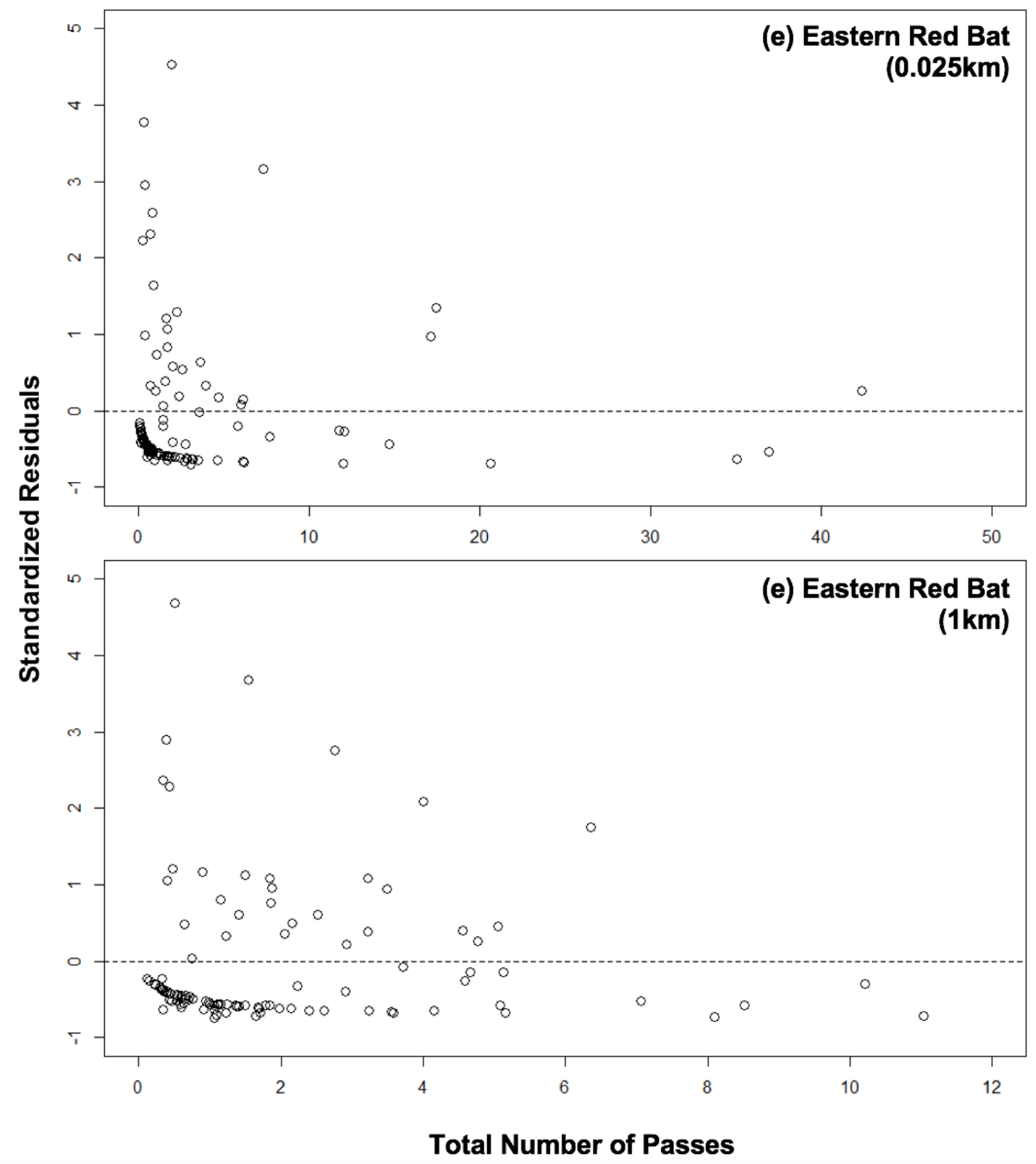


Appendix 5. Continued.

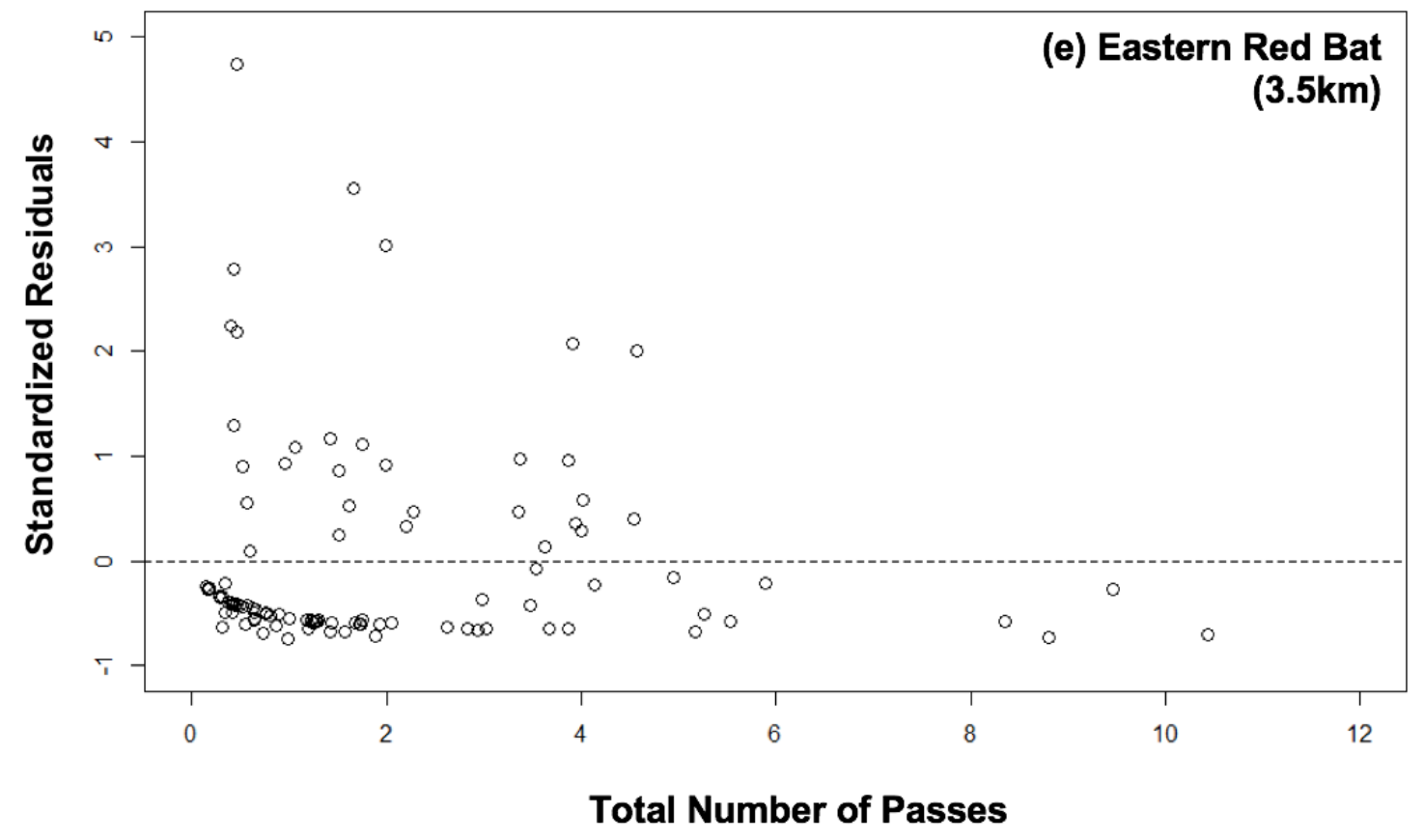


Appendix 6. Results of Moran's I tests [observed and expected values, standard deviation (sd), and p-values] for all 19 landscape scales measuring spatial autocorrelation in residuals of generalized linear mixed models that related percent tree cover to (a) total bat activity and $(\mathbf{b}-\mathbf{e})$ activity for each species. Moran's $I$ tests were performed separately for each round of sampling (i.e., round 1 or round 2).

\begin{tabular}{|c|c|c|c|c|c|c|c|c|c|c|}
\hline \multicolumn{11}{|c|}{ (a) Total Bat Activity } \\
\hline \multicolumn{11}{|c|}{ Round 1} \\
\hline & $0.025 \mathrm{~km}$ & $0.05 \mathrm{~km}$ & $0.1 \mathrm{~km}$ & $0.15 \mathrm{~km}$ & $0.2 \mathrm{~km}$ & $0.25 \mathrm{~km}$ & $0.5 \mathrm{~km}$ & $0.75 \mathrm{~km}$ & $1 \mathrm{~km}$ & $1.25 \mathrm{~km}$ \\
\hline observed & -0.0220 & -0.0230 & -0.0279 & -0.0234 & -0.0198 & -0.0165 & -0.0164 & -0.0205 & -0.0220 & -0.0223 \\
\hline expected & -0.0196 & -0.0196 & -0.0196 & -0.0196 & -0.0196 & -0.0196 & -0.0196 & -0.0196 & -0.0196 & -0.0196 \\
\hline sd & 0.0216 & 0.0217 & 0.0216 & 0.0216 & 0.0216 & 0.0217 & 0.0217 & 0.0218 & 0.0218 & 0.0218 \\
\hline \multirow[t]{2}{*}{ p-value } & 0.9134 & 0.8759 & 0.7002 & 0.8621 & 0.9927 & 0.8842 & 0.8824 & 0.9680 & 0.9114 & 0.9030 \\
\hline & $1.5 \mathrm{~km}$ & $1.75 \mathrm{~km}$ & $2 \mathrm{~km}$ & $2.25 \mathrm{~km}$ & $2.5 \mathrm{~km}$ & $2.75 \mathrm{~km}$ & $3 \mathbf{k m}$ & $3.25 \mathrm{~km}$ & $3.5 \mathrm{~km}$ & \\
\hline observed & -0.0219 & -0.0222 & -0.0224 & -0.0225 & -0.0227 & -0.0231 & -0.0235 & -0.0241 & -0.0246 & \\
\hline expected & -0.0196 & -0.0196 & -0.0196 & -0.0196 & -0.0196 & -0.0196 & -0.0196 & -0.0196 & -0.0196 & \\
\hline sd & 0.0218 & 0.0218 & 0.0218 & 0.0217 & 0.0217 & 0.0217 & 0.0217 & 0.0217 & 0.0218 & \\
\hline p-value & 0.9178 & 0.9069 & 0.8974 & 0.8948 & 0.8879 & 0.8741 & 0.8566 & 0.8378 & 0.8194 & \\
\hline \multicolumn{11}{|c|}{ Round 2} \\
\hline & $0.025 \mathrm{~km}$ & $0.05 \mathrm{~km}$ & $0.1 \mathrm{~km}$ & $0.15 \mathrm{~km}$ & $0.2 \mathrm{~km}$ & $0.25 \mathrm{~km}$ & $0.5 \mathrm{~km}$ & $0.75 \mathrm{~km}$ & $1 \mathrm{~km}$ & $1.25 \mathrm{~km}$ \\
\hline observed & -0.0263 & -0.0271 & -0.0294 & -0.0338 & -0.0343 & -0.0343 & -0.0299 & -0.0284 & -0.0270 & -0.0265 \\
\hline expected & -0.0196 & -0.0196 & -0.0196 & -0.0196 & -0.0196 & -0.0196 & -0.0196 & -0.0196 & -0.0196 & -0.0196 \\
\hline sd & 0.0219 & 0.0218 & 0.0218 & 0.0218 & 0.0218 & 0.0218 & 0.0219 & 0.0219 & 0.0219 & 0.0219 \\
\hline \multirow[t]{2}{*}{ p-value } & 0.7600 & 0.7324 & 0.6544 & 0.5156 & 0.5013 & 0.5010 & 0.6382 & 0.6900 & 0.7364 & 0.7527 \\
\hline & $1.5 \mathrm{~km}$ & $1.75 \mathrm{~km}$ & $2 \mathrm{~km}$ & $2.25 \mathrm{~km}$ & $2.5 \mathrm{~km}$ & $2.75 \mathrm{~km}$ & $3 \mathrm{~km}$ & $3.25 \mathrm{~km}$ & $3.5 \mathrm{~km}$ & \\
\hline observed & -0.0261 & -0.0263 & -0.0265 & -0.0266 & -0.0262 & -0.0262 & -0.0267 & -0.0277 & -0.0283 & \\
\hline expected & -0.0196 & -0.0196 & -0.0196 & -0.0196 & -0.0196 & -0.0196 & -0.0196 & -0.0196 & -0.0196 & \\
\hline sd & 0.0219 & 0.0219 & 0.0219 & 0.0219 & 0.0218 & 0.0218 & 0.0218 & 0.0218 & 0.0218 & \\
\hline p-value & 0.7677 & 0.7582 & 0.7544 & 0.7502 & 0.7635 & 0.7632 & 0.7450 & 0.7120 & 0.6902 & \\
\hline
\end{tabular}


Appendix 6. Continued.

\section{(b) Big Brown Bat}

\begin{tabular}{|c|c|c|c|c|c|c|c|c|c|c|}
\hline \multicolumn{11}{|c|}{ Round 1} \\
\hline & $0.025 \mathrm{~km}$ & $0.05 \mathrm{~km}$ & $0.1 \mathrm{~km}$ & $0.15 \mathrm{~km}$ & $0.2 \mathrm{~km}$ & $0.25 \mathrm{~km}$ & $0.5 \mathrm{~km}$ & $0.75 \mathrm{~km}$ & $1 \mathrm{~km}$ & $1.25 \mathrm{~km}$ \\
\hline observed & -0.0257 & -0.0246 & -0.0247 & -0.0220 & -0.0209 & -0.0191 & -0.0191 & -0.0240 & -0.0254 & -0.0253 \\
\hline expected & -0.0196 & -0.0196 & -0.0196 & -0.0196 & -0.0196 & -0.0196 & -0.0196 & -0.0196 & -0.0196 & -0.0196 \\
\hline sd & 0.0218 & 0.0218 & 0.0218 & 0.0218 & 0.0218 & 0.0218 & 0.0219 & 0.0219 & 0.0219 & 0.0219 \\
\hline p-value & 0.7792 & 0.8181 & 0.8168 & 0.9131 & 0.9538 & 0.9805 & 0.9831 & 0.8392 & 0.7919 & 0.7945 \\
\hline & $1.5 \mathrm{~km}$ & $1.75 \mathrm{~km}$ & $2 \mathrm{~km}$ & $2.25 \mathrm{~km}$ & $2.5 \mathrm{~km}$ & $2.75 \mathrm{~km}$ & $3 \mathrm{~km}$ & $3.25 \mathrm{~km}$ & $3.5 \mathrm{~km}$ & \\
\hline observed & -0.0247 & -0.0244 & -0.0239 & -0.0236 & -0.0235 & -0.0239 & -0.0240 & -0.0240 & -0.0238 & \\
\hline expected & -0.0196 & -0.0196 & -0.0196 & -0.0196 & -0.0196 & -0.0196 & -0.0196 & -0.0196 & -0.0196 & \\
\hline sd & 0.0219 & 0.0218 & 0.0218 & 0.0218 & 0.0218 & 0.0218 & 0.0218 & 0.0218 & 0.0218 & \\
\hline p-value & 0.8168 & 0.8267 & 0.8426 & 0.8548 & 0.8601 & 0.8454 & 0.8421 & 0.8423 & 0.8494 & \\
\hline \multicolumn{11}{|c|}{ Round 2} \\
\hline & $0.025 \mathrm{~km}$ & $0.05 \mathrm{~km}$ & $0.1 \mathrm{~km}$ & $0.15 \mathrm{~km}$ & $0.2 \mathrm{~km}$ & $0.25 \mathrm{~km}$ & $0.5 \mathrm{~km}$ & $0.75 \mathrm{~km}$ & $1 \mathrm{~km}$ & $1.25 \mathrm{~km}$ \\
\hline observed & -0.0317 & -0.0414 & & & -0.0 & -0.0513 & -0.0474 & -0.0 & -0.0396 & -0.0416 \\
\hline expected & -0.0196 & -0.0196 & -0.0196 & -0.0196 & -0.0196 & -0.0196 & -0.0196 & -0.0196 & -0.0196 & -0.0196 \\
\hline sd & & & & & & & 0.0 & 218 & 0.0218 & 0.0218 \\
\hline \multirow[t]{2}{*}{ p-value } & 0.5785 & 0.3169 & 0.2925 & 0.2133 & 0.1805 & 0.1465 & 0.2039 & 0.3169 & 0.3595 & 0.3139 \\
\hline & $1.5 \mathrm{~km}$ & $1.15 \mathrm{Km}$ & $2 \mathrm{~km}$ & $2.25 \mathrm{~km}$ & $2.5 \mathrm{~km}$ & $2.75 \mathrm{~km}$ & $3 \mathrm{~km}$ & $3.25 \mathrm{~km}$ & $3.5 \mathrm{~km}$ & \\
\hline observed & -0.0442 & -0.0474 & -0.0487 & -0.0491 & -0.0495 & -0.0490 & -0.0492 & -0.0494 & -0.0498 & \\
\hline expected & -0.0196 & -0.0196 & -0.0196 & -0.0196 & -0.0196 & -0.0196 & -0.0196 & -0.0196 & -0.0196 & \\
\hline sd & 0.0218 & & 0.0219 & & & 0.0218 & 0.0218 & 0.0218 & 0.0218 & \\
\hline p-value & 0.2605 & 0.2029 & 0.1832 & 0.1769 & 0.1714 & 0.1788 & 0.1757 & 0.1729 & 0.1665 & \\
\hline
\end{tabular}


Appendix 6. Continued.

(c) Hoary Bat/ Silver-haired Bat

\begin{tabular}{|c|c|c|c|c|c|c|c|c|c|c|}
\hline \multicolumn{11}{|c|}{ Round 1} \\
\hline & $0.025 \mathrm{~km}$ & $0.05 \mathrm{~km}$ & $0.1 \mathrm{~km}$ & $0.15 \mathrm{~km}$ & $0.2 \mathrm{~km}$ & $0.25 \mathrm{~km}$ & $0.5 \mathrm{~km}$ & $0.75 \mathrm{~km}$ & $1 \mathrm{~km}$ & $1.25 \mathrm{~km}$ \\
\hline observed & -0.0146 & -0.0156 & -0.0196 & -0.0161 & -0.0136 & 0.0118 & -0.0088 & -0.0091 & -0.0103 & -0.0109 \\
\hline expected & -0.0196 & -0.0196 & -0.0196 & -0.0196 & -0.0196 & -0.0196 & -0.0196 & -0.0196 & -0.0196 & -0.0196 \\
\hline sd & 0.0207 & 0.0209 & 0.0207 & 0.0210 & 0.0209 & 0.0208 & 0.0208 & 0.0209 & 0.0208 & 0.0208 \\
\hline \multirow[t]{2}{*}{ p-value } & 0.8092 & 0.8464 & 0.9995 & 0.8682 & 0.7719 & 0.7064 & 0.6032 & 0.6149 & 0.6532 & 0.6736 \\
\hline & & & & & $5 \mathrm{~km}$ & & $3 \mathbf{k m}$ & & $3.5 \mathrm{~km}$ & \\
\hline observed & -0.0107 & -0.0109 & -0.0112 & -0.0114 & -0.0118 & -0.0121 & -0.0127 & -0.0134 & -0.0141 & \\
\hline expected & -0.0196 & -0.0196 & -0.0196 & -0.0196 & -0.0196 & -0.0196 & -0.0196 & -0.0196 & -0.0196 & \\
\hline sd & 0.0207 & 0.0208 & 0.0208 & 0.0208 & 0.0208 & 0.0208 & 0.0208 & 0.0207 & 0.0207 & \\
\hline p-value & 0.6668 & 0.6731 & 0.6842 & 0.6940 & 0.7053 & & & & 0.7894 & \\
\hline \multicolumn{11}{|c|}{ Round 2} \\
\hline & $0.025 \mathrm{~km}$ & $0.05 \mathrm{~km}$ & $1 \mathbf{k m}$ & & $0.2 \mathrm{~km}$ & & $\mathbf{k m}$ & & $1 \mathrm{~km}$ & $1.25 \mathrm{~km}$ \\
\hline observed & -0.0137 & -0.0147 & -0.0141 & -0.0157 & -0.0155 & -0.0148 & -0.0119 & -0.0117 & -0.0112 & -0.0103 \\
\hline expected & -0.0196 & -0.0196 & -0.0196 & -0.0196 & -0.0196 & -0.0196 & -0.0196 & -0.0196 & -0.0196 & -0.0196 \\
\hline sd & 0.0217 & 0.0217 & 0.0217 & 0.0216 & 0.0215 & 0.0216 & 0.0217 & 0.0217 & 0.0217 & 0.0217 \\
\hline \multirow[t]{2}{*}{ p-value } & 0.7859 & 0.8216 & 0.7993 & 0.8569 & 0.8497 & & 0.7236 & & 0.6976 & 0.6673 \\
\hline & $5 \mathrm{~km}$ & $1.75 \mathrm{~km}$ & $2 \mathrm{~km}$ & $2.25 \mathrm{~km}$ & $2.5 \mathrm{~km}$ & $2.75 \mathrm{~km}$ & $3 \mathbf{k m}$ & $3.25 \mathrm{~km}$ & $3.5 \mathrm{~km}$ & \\
\hline & -0.0101 & -0.0097 & -0.0096 & -0.0095 & -0.0092 & -0.0092 & -0.0096 & -0.0102 & -0.0114 & \\
\hline expected & -0.0196 & -0.0196 & -0.0196 & -0.0196 & -0.0196 & -0.0196 & -0.0196 & -0.0196 & -0.0196 & \\
\hline sd & 0.0217 & 0.0217 & 0.0216 & 0.0216 & 0.0216 & 0.0216 & 0.0216 & 0.0216 & 0.0216 & \\
\hline p-value & 0.6606 & 0.6484 & 0.6432 & 0.6389 & 0.6316 & 0.6300 & 0.6413 & 0.6627 & 0.7021 & \\
\hline
\end{tabular}


Appendix 6. Continued.

(d) Little Brown Myotis/ Northern Myotis/ Tri-colored Bat

\begin{tabular}{|c|c|c|c|c|c|c|c|c|c|c|}
\hline \multicolumn{11}{|c|}{ Round 1} \\
\hline & $0.025 \mathrm{~km}$ & $0.05 \mathrm{~km}$ & $0.1 \mathrm{~km}$ & $0.15 \mathrm{~km}$ & $0.2 \mathrm{~km}$ & $0.25 \mathrm{~km}$ & $0.5 \mathrm{~km}$ & $0.75 \mathrm{~km}$ & $1 \mathrm{~km}$ & $1.25 \mathrm{~km}$ \\
\hline observed & -0.0437 & -0.0392 & -0.0382 & -0.0386 & -0.0386 & -0.0388 & -0.0410 & -0.0407 & -0.0407 & -0.0403 \\
\hline expected & -0.0196 & -0.0196 & -0.0196 & -0.0196 & -0.0196 & -0.0196 & -0.0196 & -0.0196 & -0.0196 & -0.0196 \\
\hline sd & 0.0205 & 0.0197 & 0.0188 & 0.0195 & 0.0197 & 0.0195 & 0.0193 & 0.0191 & 0.0191 & 0.0190 \\
\hline \multirow[t]{2}{*}{ p-value } & 0.2402 & 0.3211 & 0.3239 & 0.3296 & 0.3360 & 0.3235 & 0.2675 & 0.2684 & 0.2692 & 0.2750 \\
\hline & $1.5 \mathrm{~km}$ & $1.75 \mathrm{~km}$ & $2 \mathrm{~km}$ & $2.25 \mathrm{~km}$ & $2.5 \mathrm{~km}$ & $2.75 \mathrm{~km}$ & $3 \mathrm{~km}$ & $3.25 \mathrm{~km}$ & $3.5 \mathrm{~km}$ & \\
\hline observed & -0.0403 & -0.0402 & -0.0402 & -0.0402 & -0.0402 & -0.0402 & -0.0403 & -0.0404 & -0.0405 & \\
\hline expected & -0.0196 & -0.0196 & -0.0196 & -0.0196 & -0.0196 & -0.0196 & -0.0196 & -0.0196 & -0.0196 & \\
\hline sd & 0.0190 & 0.0190 & 0.0190 & 0.0190 & 0.0190 & 0.0190 & 0.0191 & 0.0192 & 0.0192 & \\
\hline p-value & 0.2765 & 0.2771 & 0.2776 & 0.2773 & 0.2775 & 0.2779 & 0.2784 & 0.2784 & 0.2768 & \\
\hline \multicolumn{11}{|c|}{ Round 2} \\
\hline & $0.025 \mathrm{~km}$ & $0.05 \mathrm{~km}$ & $1 \mathrm{~km}$ & & & $0.25 \mathrm{~km}$ & $0.5 \mathrm{~km}$ & & $1 \mathrm{~km}$ & $1.25 \mathrm{~km}$ \\
\hline observed & -0.0426 & -0.0412 & -0.0406 & -0.0397 & -0.0396 & -0.0389 & -0.0417 & -0.0431 & -0.0430 & -0.0435 \\
\hline expected & -0.0196 & & & & & & & & & \\
\hline sd & 0.0203 & 0.0201 & 0.0203 & 0.0200 & 0.0199 & 0.0196 & 0.0197 & 0.0199 & 0.0199 & 0.0200 \\
\hline \multirow[t]{2}{*}{ p-value } & 0.2572 & 0.2826 & 0.3002 & 0.3162 & 0.3151 & 0.3254 & 0.2626 & 0.2386 & 0.2410 & 0.2314 \\
\hline & $1.5 \mathrm{~km}$ & $1.75 \mathrm{~km}$ & $2 \mathrm{~km}$ & $2.25 \mathrm{~km}$ & $2.5 \mathrm{~km}$ & $2.75 \mathrm{~km}$ & $3 \mathrm{~km}$ & $3.25 \mathrm{~km}$ & $3.5 \mathrm{~km}$ & \\
\hline observed & -0.0437 & -0.0435 & -0.0435 & -0.0433 & -0.0433 & -0.0436 & -0.0443 & -0.0453 & -0.0457 & \\
\hline expected & -0.0196 & -0.0196 & -0.0196 & -0.0196 & -0.0196 & -0.0196 & -0.0196 & -0.0196 & -0.0196 & \\
\hline sd & 0.0200 & 0.0200 & 0.0200 & 0.0200 & 0.0200 & 0.0200 & 0.0201 & 0.0202 & 0.0203 & \\
\hline p-value & 0.2289 & 0.2322 & 0.2316 & 0.2360 & 0.2351 & 0.2314 & 0.2190 & 0.2042 & 0.1985 & \\
\hline
\end{tabular}


Appendix 6. Continued.

\begin{tabular}{|c|c|c|c|c|c|c|c|c|c|c|}
\hline \multicolumn{11}{|c|}{ (e) Eastern Red Bat } \\
\hline \multicolumn{11}{|c|}{ Round 1} \\
\hline & $0.025 \mathrm{~km}$ & $0.05 \mathrm{~km}$ & $0.1 \mathrm{~km}$ & $0.15 \mathrm{~km}$ & $0.2 \mathrm{~km}$ & $0.25 \mathrm{~km}$ & $0.5 \mathrm{~km}$ & $0.75 \mathrm{~km}$ & $1 \mathrm{~km}$ & $1.25 \mathrm{~km}$ \\
\hline observed & -0.0044 & -0.0022 & -0.0041 & -0.0024 & -0.0021 & -0.0007 & -0.0001 & -0.0003 & -0.0001 & 0.0004 \\
\hline expected & -0.0196 & -0.0196 & -0.0196 & -0.0196 & -0.0196 & -0.0196 & -0.0196 & -0.0196 & -0.0196 & -0.0196 \\
\hline sd & 0.0206 & 0.0203 & 0.0201 & 0.0203 & 0.0204 & 0.0203 & 0.0202 & 0.0203 & 0.0203 & 0.0202 \\
\hline \multirow[t]{2}{*}{ p-value } & 0.4589 & 0.3905 & 0.4415 & 0.3966 & 0.3906 & 0.3517 & 0.3351 & 0.3417 & 0.3358 & 0.3228 \\
\hline & $1.5 \mathrm{~km}$ & $1.75 \mathrm{~km}$ & $2 \mathrm{~km}$ & $2.25 \mathrm{~km}$ & $2.5 \mathrm{~km}$ & $2.75 \mathrm{~km}$ & $3 \mathbf{k m}$ & $3.25 \mathrm{~km}$ & $3.5 \mathrm{~km}$ & \\
\hline observed & 0.0006 & 0.0005 & 0.0005 & 0.0005 & 0.0006 & 0.0006 & 0.0006 & 0.0007 & 0.0007 & \\
\hline expected & -0.0196 & -0.0196 & -0.0196 & -0.0196 & -0.0196 & -0.0196 & -0.0196 & -0.0196 & -0.0196 & \\
\hline sd & 0.0202 & 0.0202 & 0.0202 & & 0.0201 & 0.0201 & 0.0201 & 0.0201 & 0.0201 & \\
\hline p-value & 0.3179 & 0.3193 & 0.3180 & 0.3172 & 0.3161 & 0.3156 & 0.3156 & 0.3133 & 0.3117 & \\
\hline \multicolumn{11}{|c|}{ Round 2} \\
\hline & $0.025 \mathrm{~km}$ & $0.05 \mathrm{~km}$ & $0.1 \mathrm{~km}$ & $0.15 \mathrm{~km}$ & $0.2 \mathrm{~km}$ & $0.25 \mathrm{~km}$ & $0.5 \mathrm{~km}$ & $0.75 \mathrm{~km}$ & $1 \mathrm{~km}$ & $1.25 \mathrm{~km}$ \\
\hline observed & -0.0373 & -0.0354 & -0.0402 & -0.0416 & -0.0421 & -0.0424 & -0.0439 & -0.0442 & -0.0442 & -0.0438 \\
\hline expected & -0.0196 & -0.0196 & -0.0196 & -0.0196 & -0.0196 & -0.0196 & -0.0196 & -0.0196 & -0.0196 & -0.0196 \\
\hline sd & 0.0209 & 0.0209 & 0.0207 & 0.0207 & 0.0208 & 0.0208 & 0.0208 & 0.0208 & 0.0208 & 0.0208 \\
\hline \multirow[t]{2}{*}{ p-value } & 0.3984 & 0.4495 & 0.3209 & 0.2893 & 0.2787 & 0.2721 & 0.2424 & 0.2365 & 0.2370 & 0.2454 \\
\hline & $1.5 \mathrm{~km}$ & $1.75 \mathrm{~km}$ & $2 \mathrm{~km}$ & $2.25 \mathrm{~km}$ & $2.5 \mathrm{~km}$ & $2.75 \mathrm{~km}$ & $3 \mathrm{~km}$ & $3.25 \mathrm{~km}$ & $3.5 \mathrm{~km}$ & \\
\hline observed & -0.0437 & -0.0437 & -0.0437 & -0.0437 & -0.0436 & -0.0435 & -0.0434 & -0.0433 & -0.0432 & \\
\hline expected & -0.0196 & -0.0196 & -0.0196 & -0.0196 & -0.0196 & -0.0196 & -0.0196 & -0.0196 & -0.0196 & \\
\hline sd & 0.0208 & 0.0209 & 0.0209 & 0.0209 & 0.0209 & 0.0209 & 0.0209 & 0.0209 & 0.0209 & \\
\hline p-value & 0.2482 & 0.2479 & 0.2484 & 0.2482 & 0.2495 & 0.2519 & 0.2540 & 0.2572 & 0.2588 & \\
\hline
\end{tabular}


Appendix 7. Mapped residuals of generalized linear mixed models relating (a) total bat activity and $(\mathbf{b}-\mathbf{e})$ species-specific activity to percent tree cover. These results are displayed for the scale of effect for each bat activity response (i.e., $0.2 \mathrm{~km}$ for Total Bat Activity and Big Brown Bat; 0.15km for Silver-haired Bat/ Hoary Bat; and $0.025 \mathrm{~km}$ for Little Brown Myotis/ Northern Myotis/ Tri-colored Bat and Eastern Red Bat), and at the $1 \mathrm{~km}$ and $3.5 \mathrm{~km}$-radius landscape scales. Results are shown separately for each round of sampling (i.e., round 1 or round 2). Red dots represent negative residuals, and blue dots represent positive residuals. Dot size reflects the absolute value of the residual. Overall, the residuals show an even spatial distribution for each response variable.

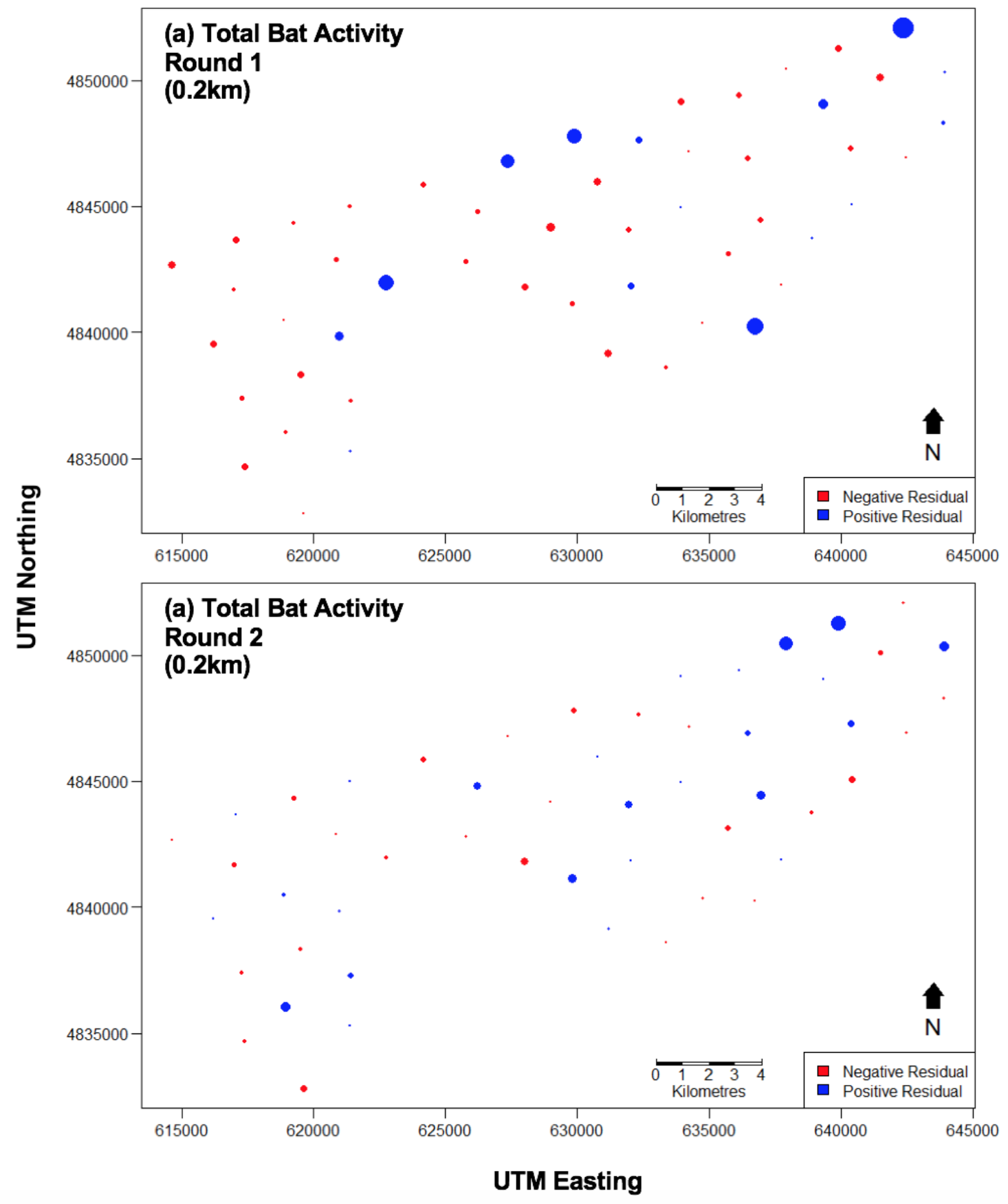


Appendix 7. Continued.

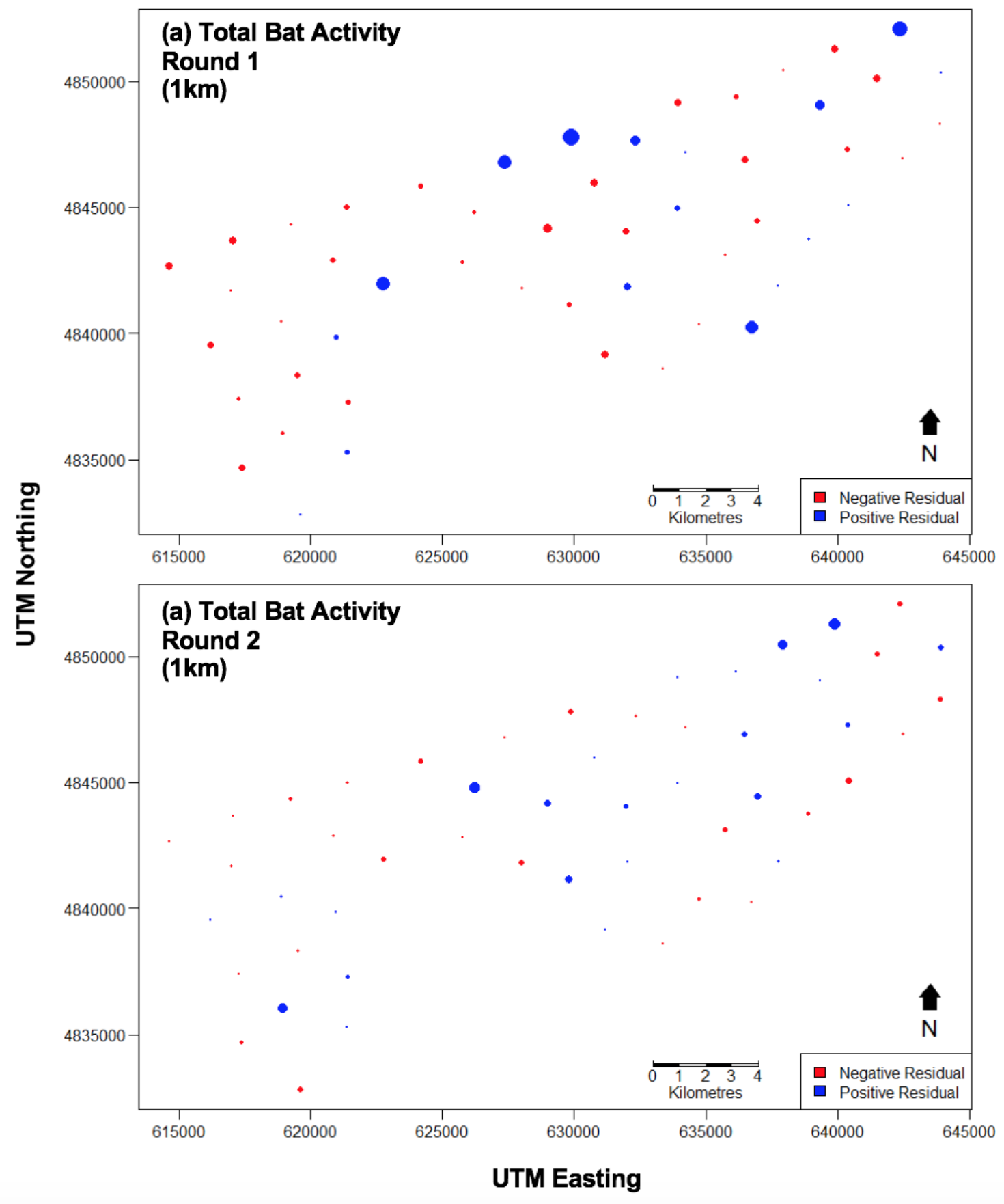


Appendix 7. Continued.

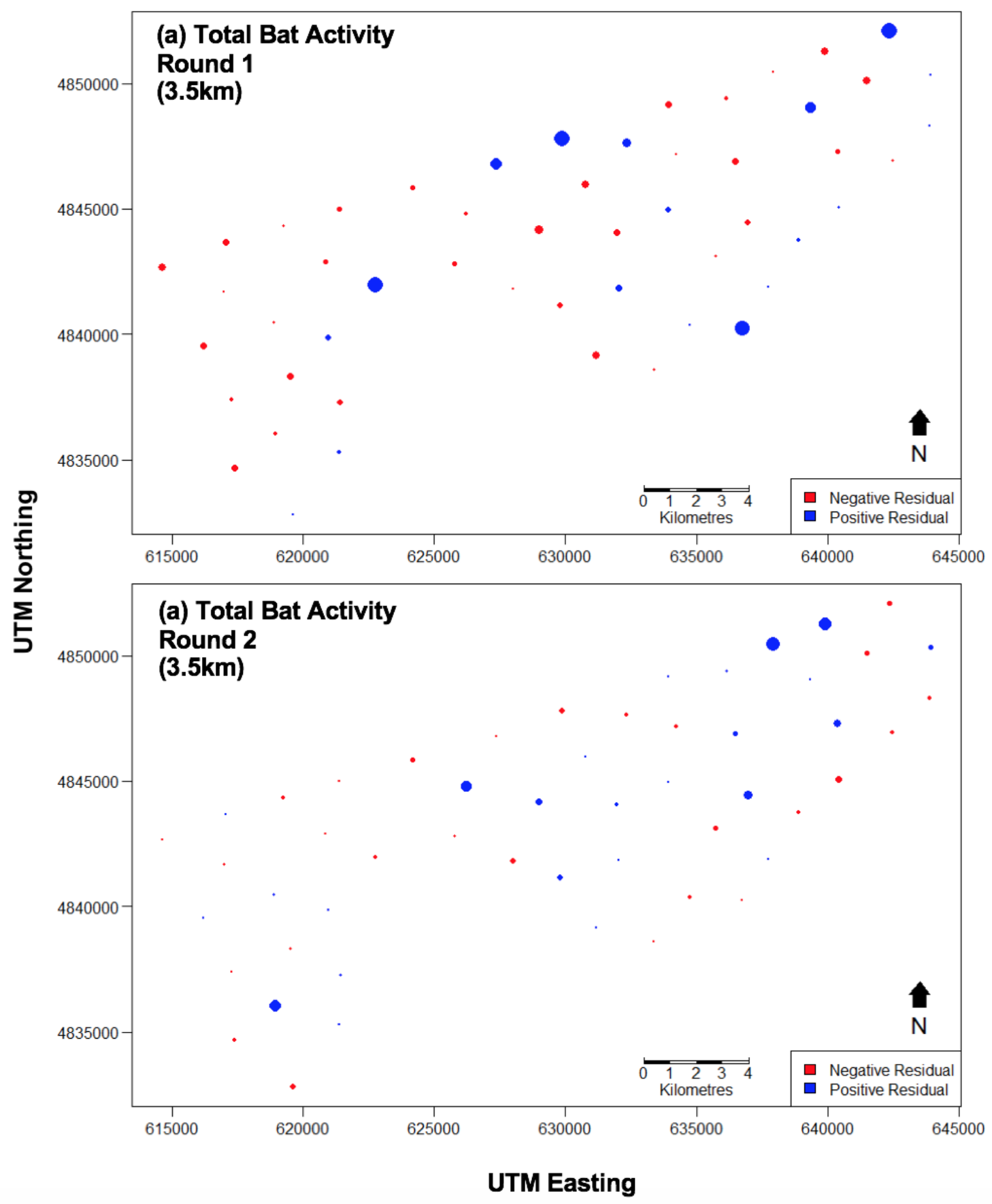


Appendix 7. Continued.

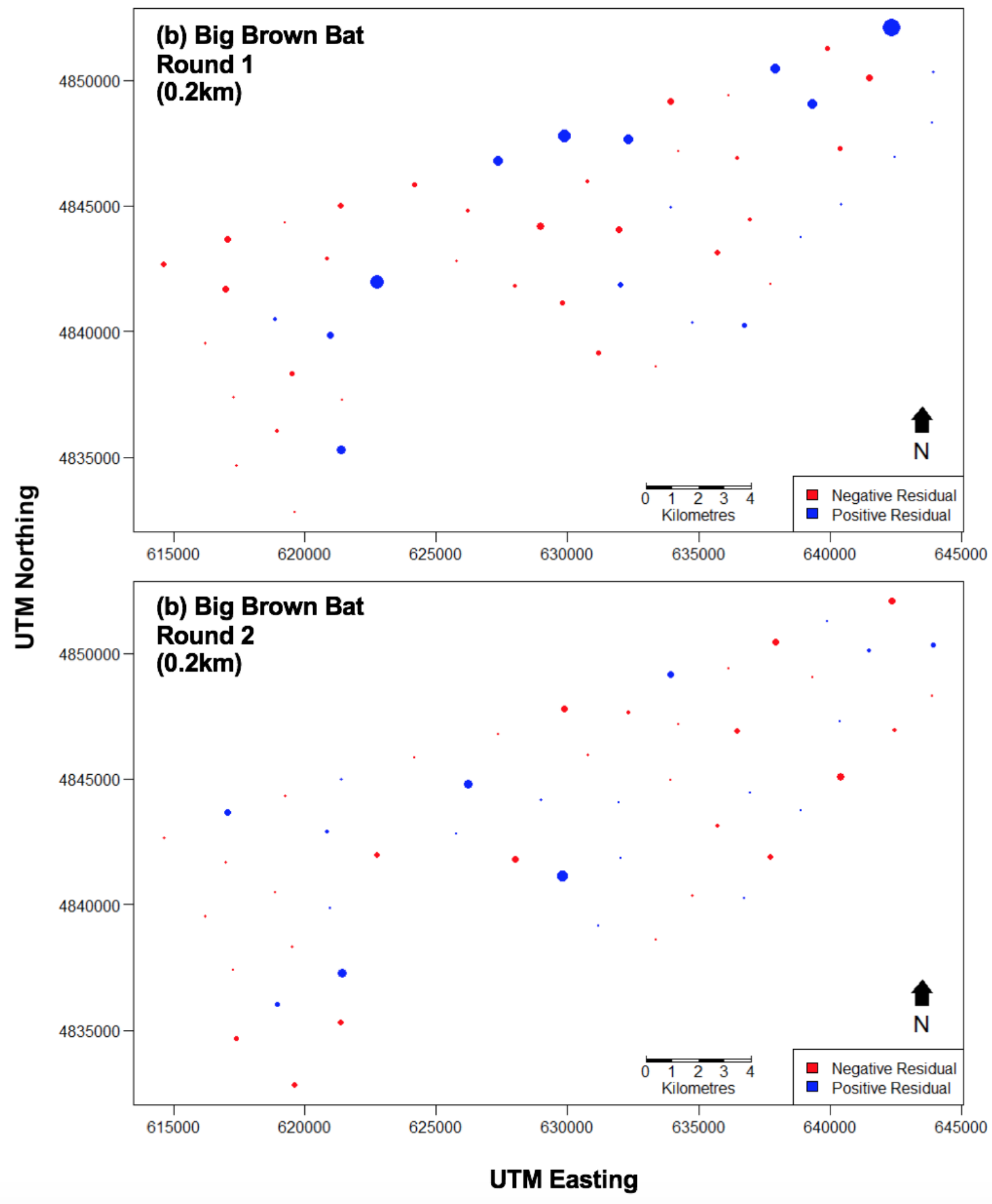


Appendix 7. Continued.

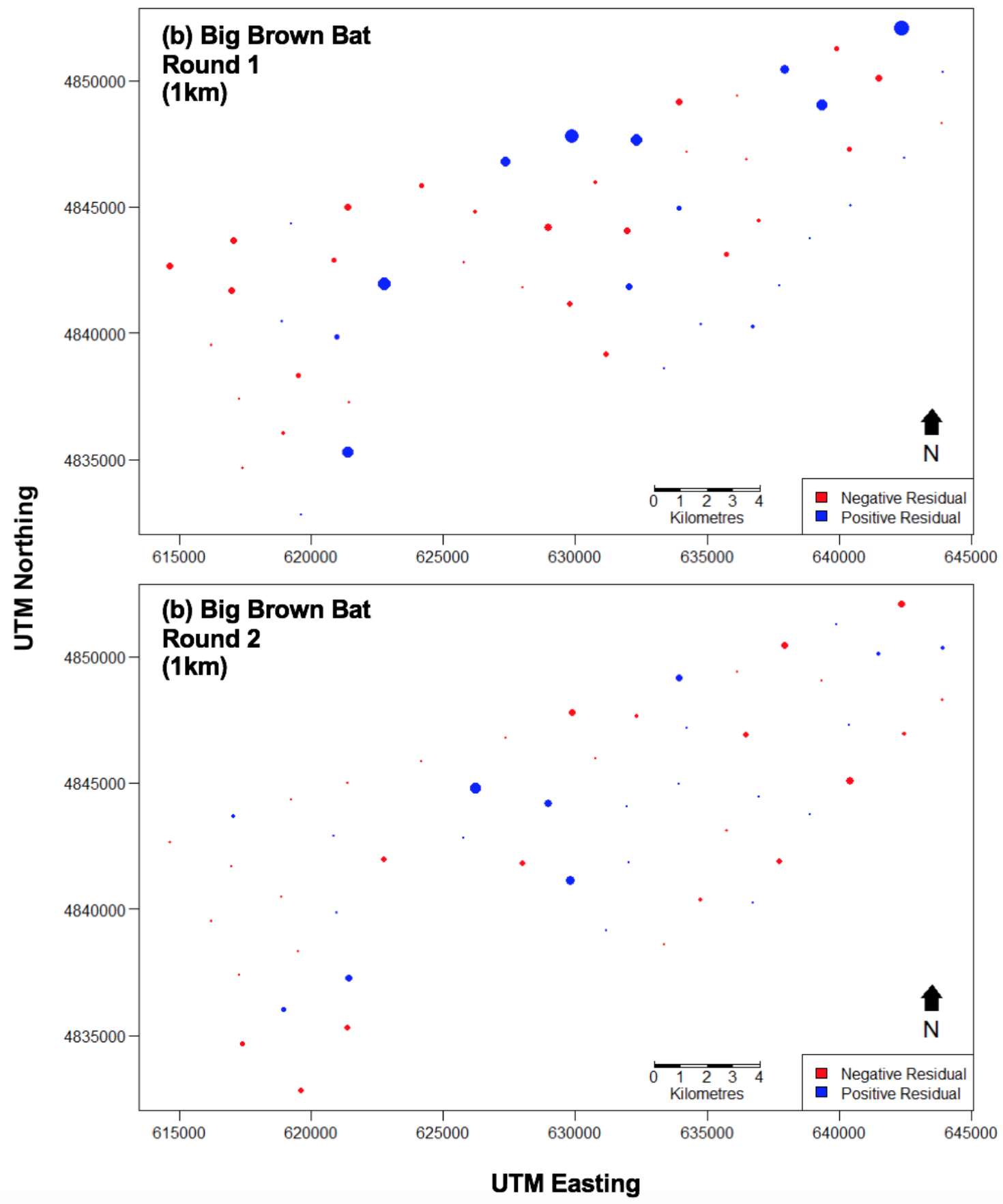


Appendix 7. Continued.

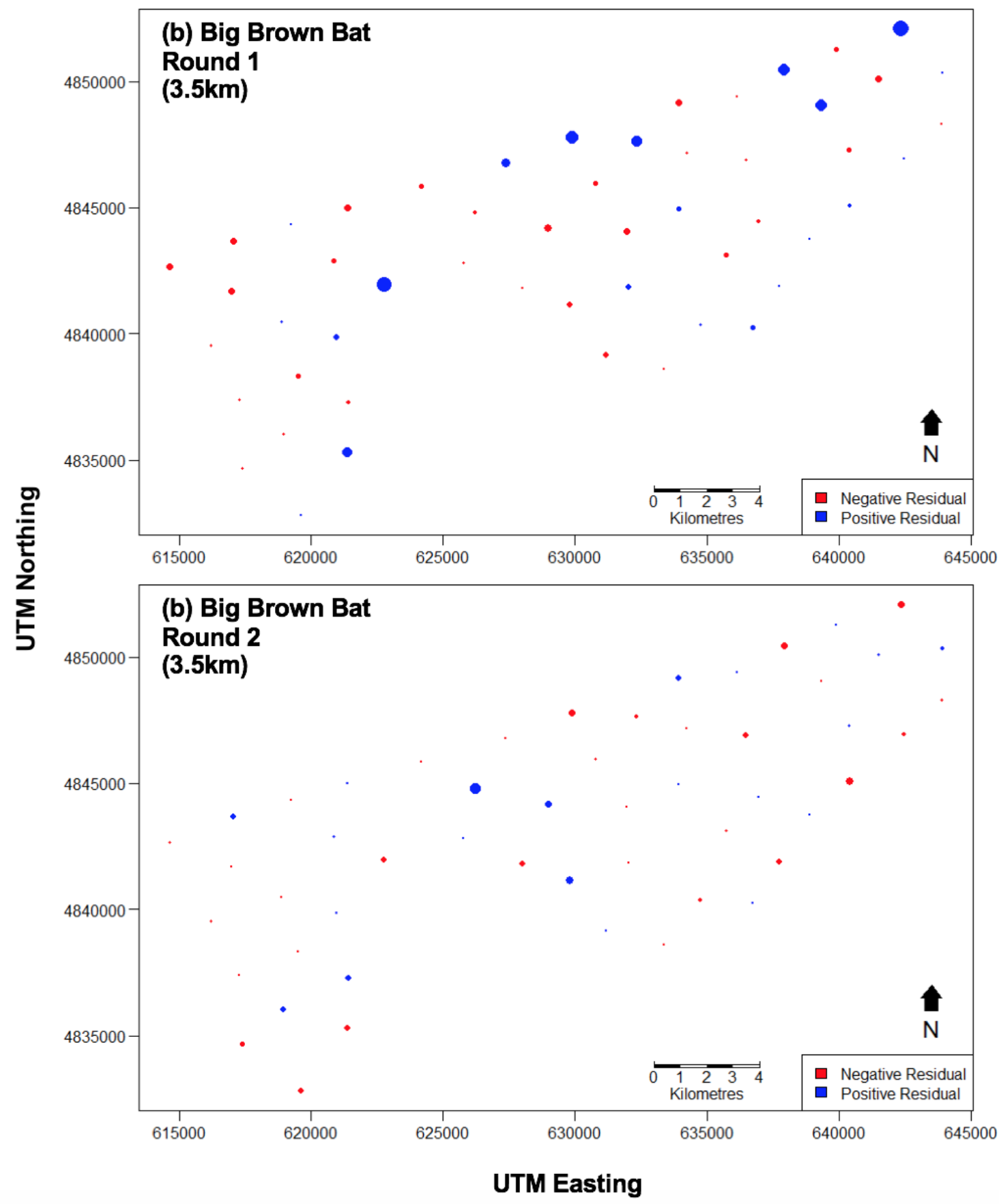


Appendix 7. Continued.

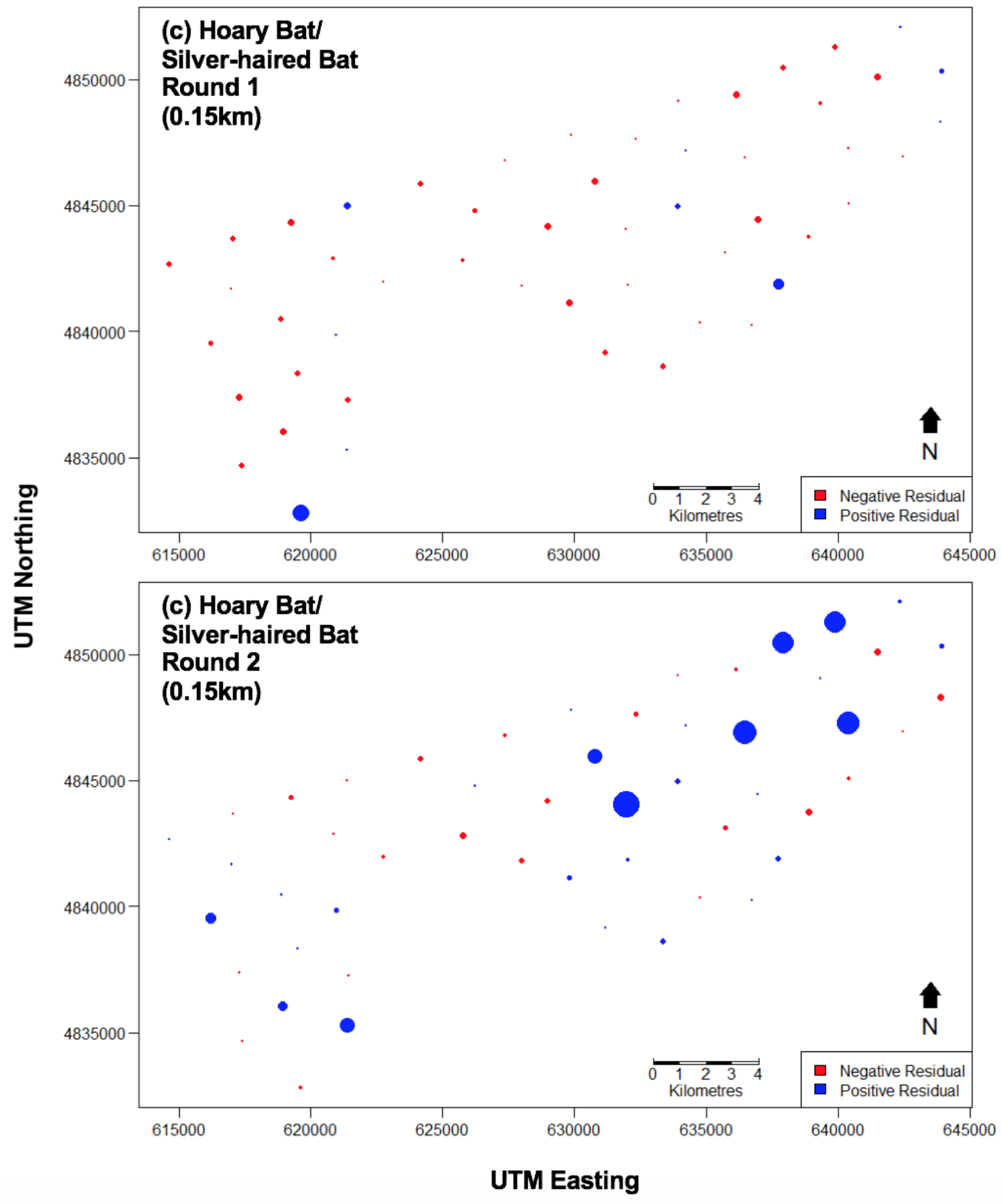


Appendix 7. Continued.

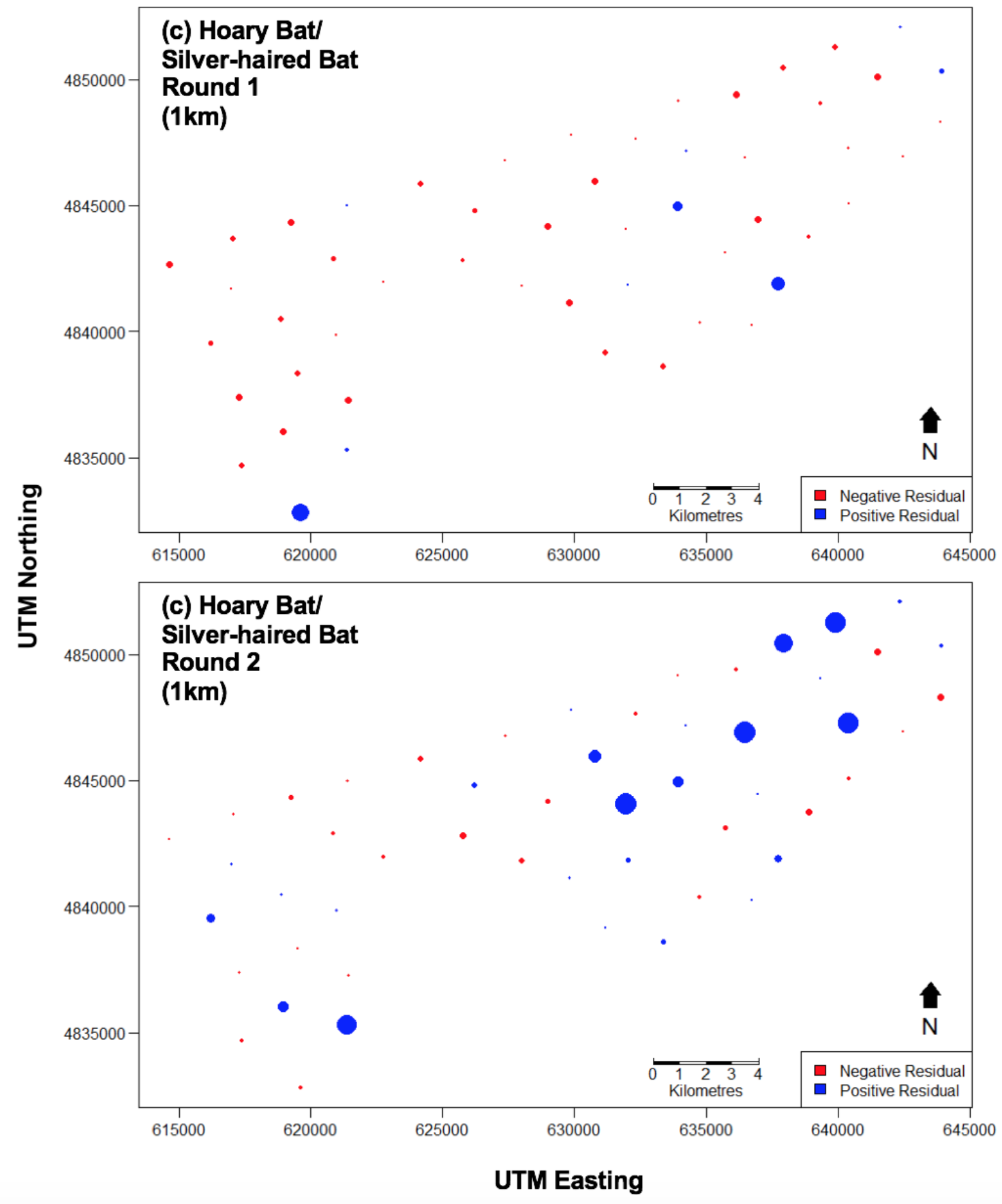


Appendix 7. Continued.

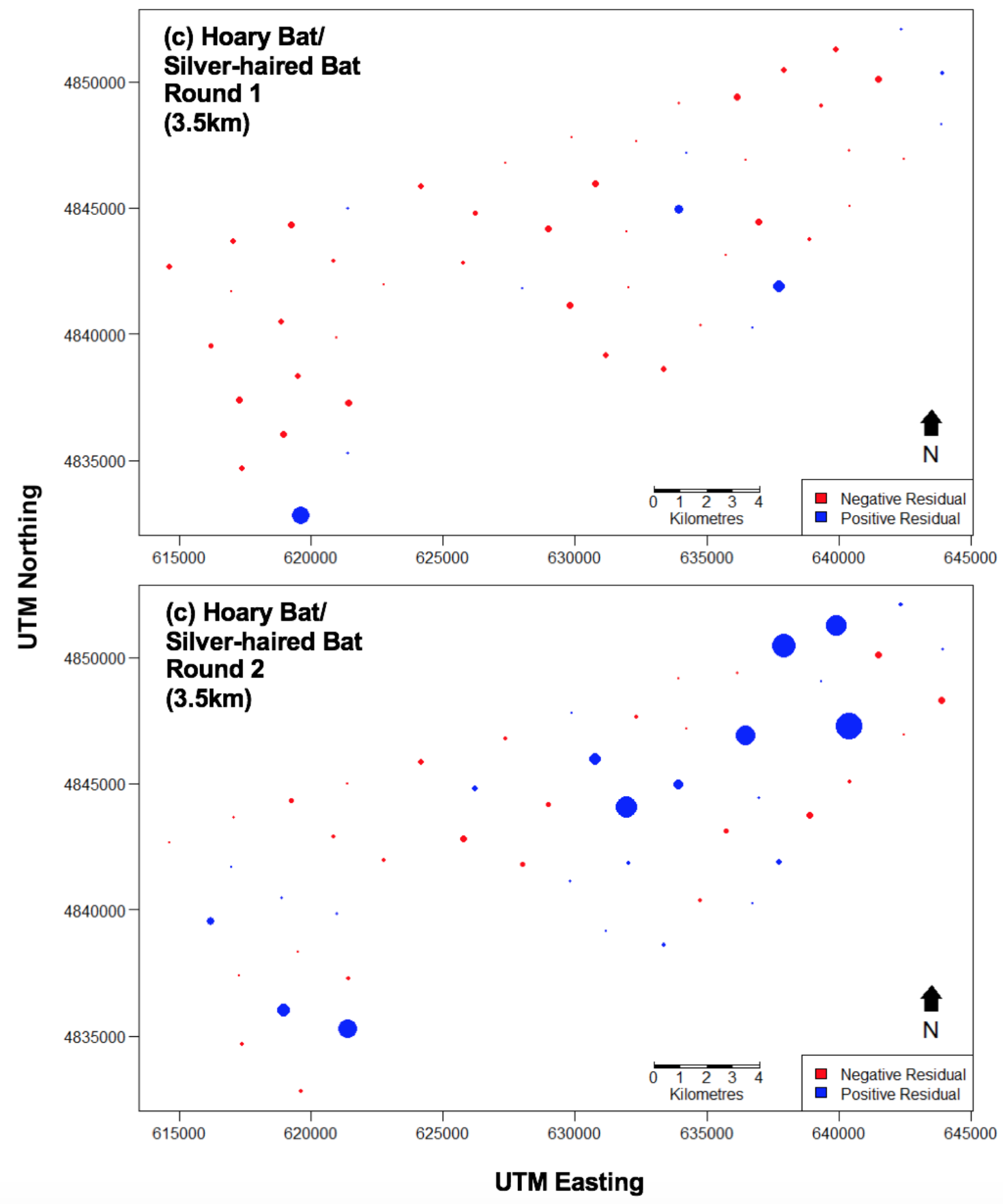


Appendix 7. Continued.

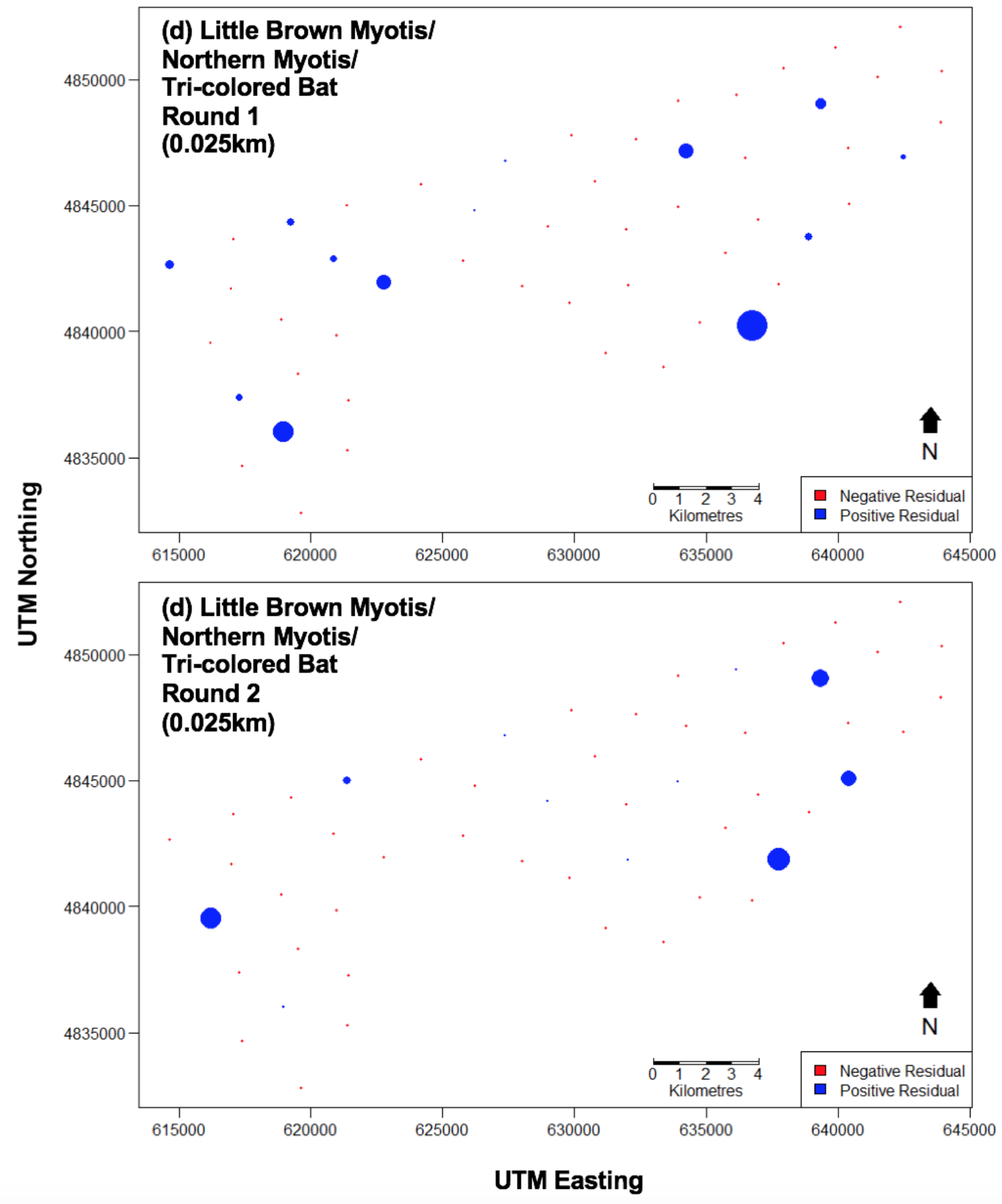


Appendix 7. Continued.

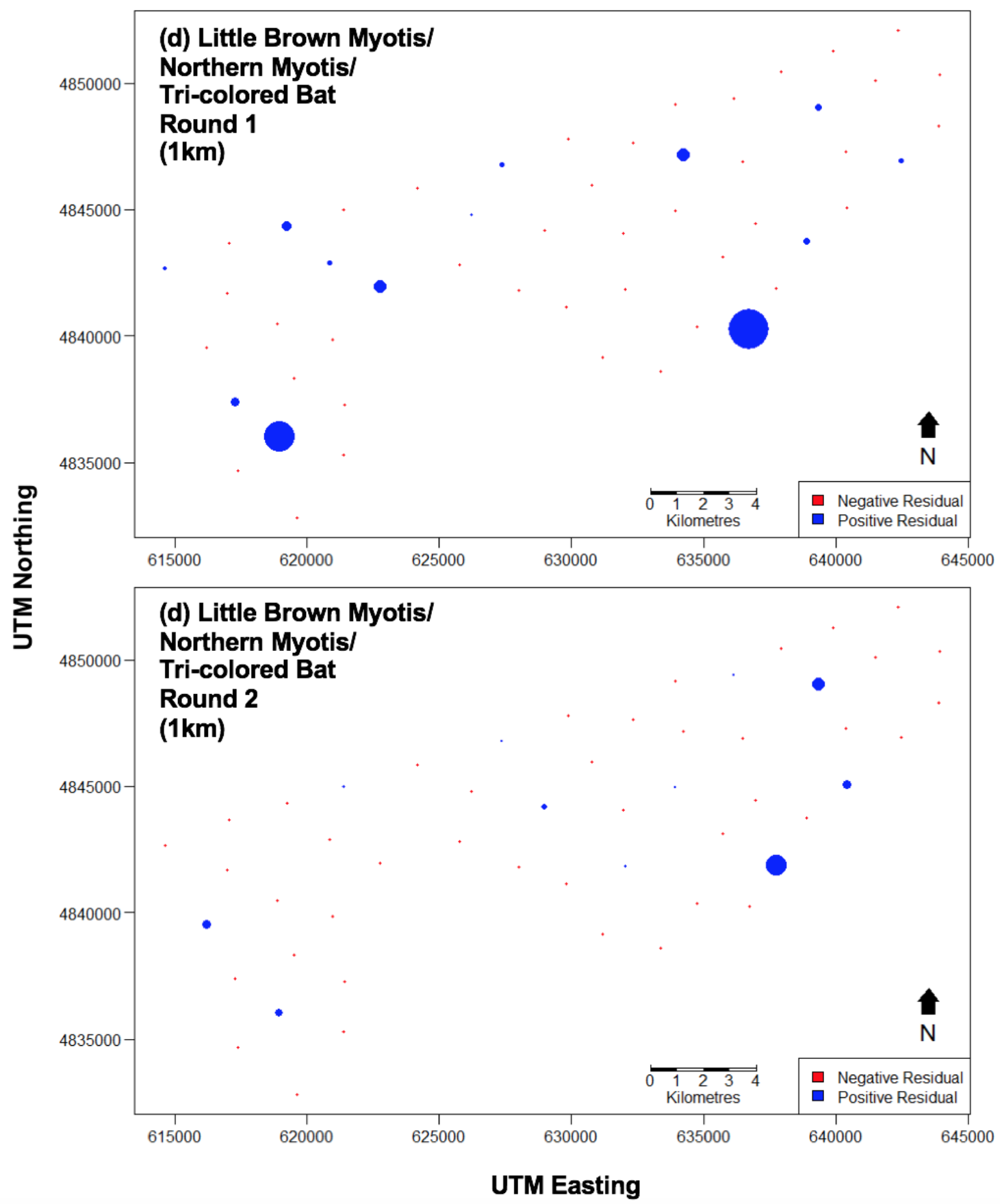


Appendix 7. Continued.

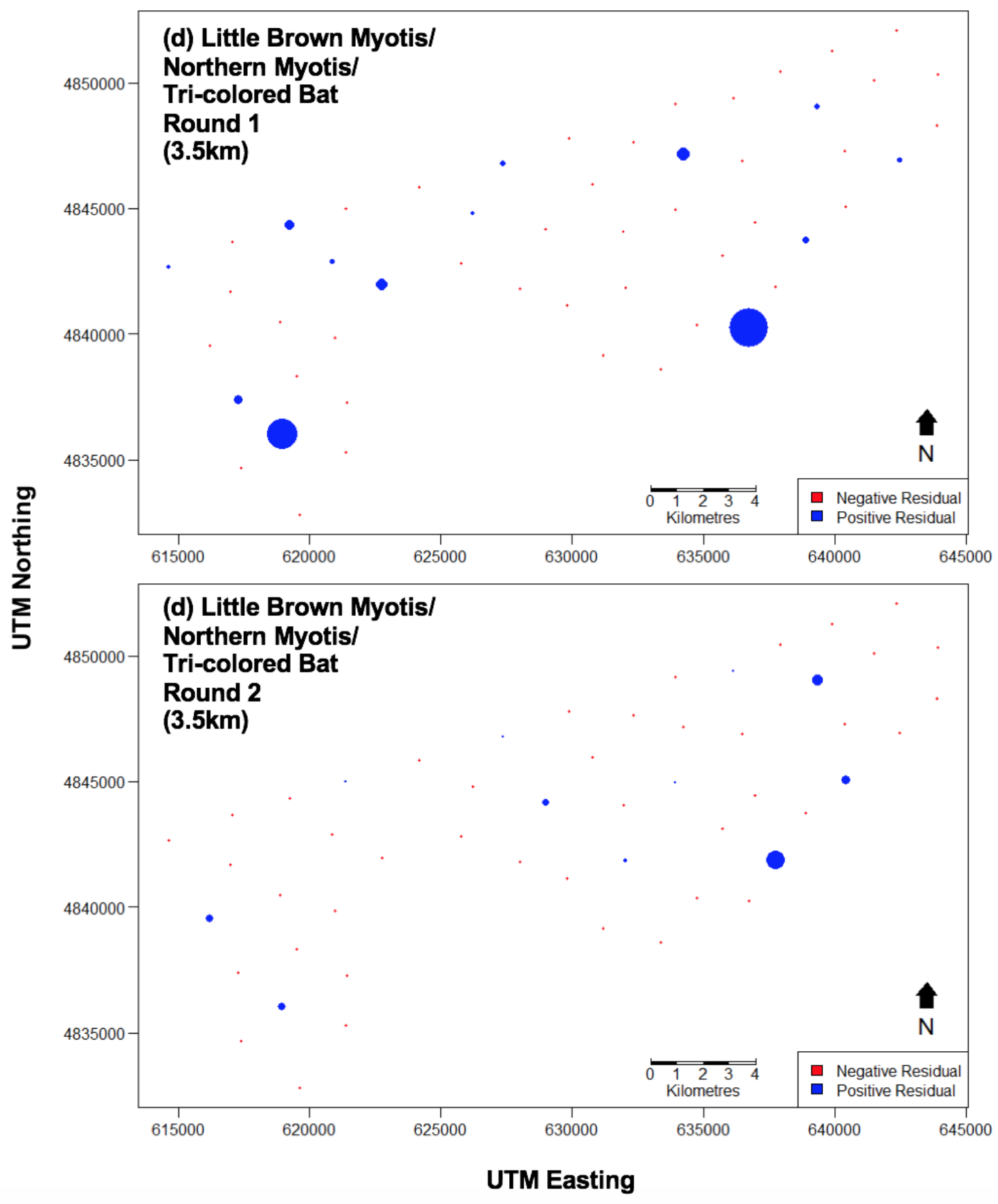


Appendix 7. Continued.

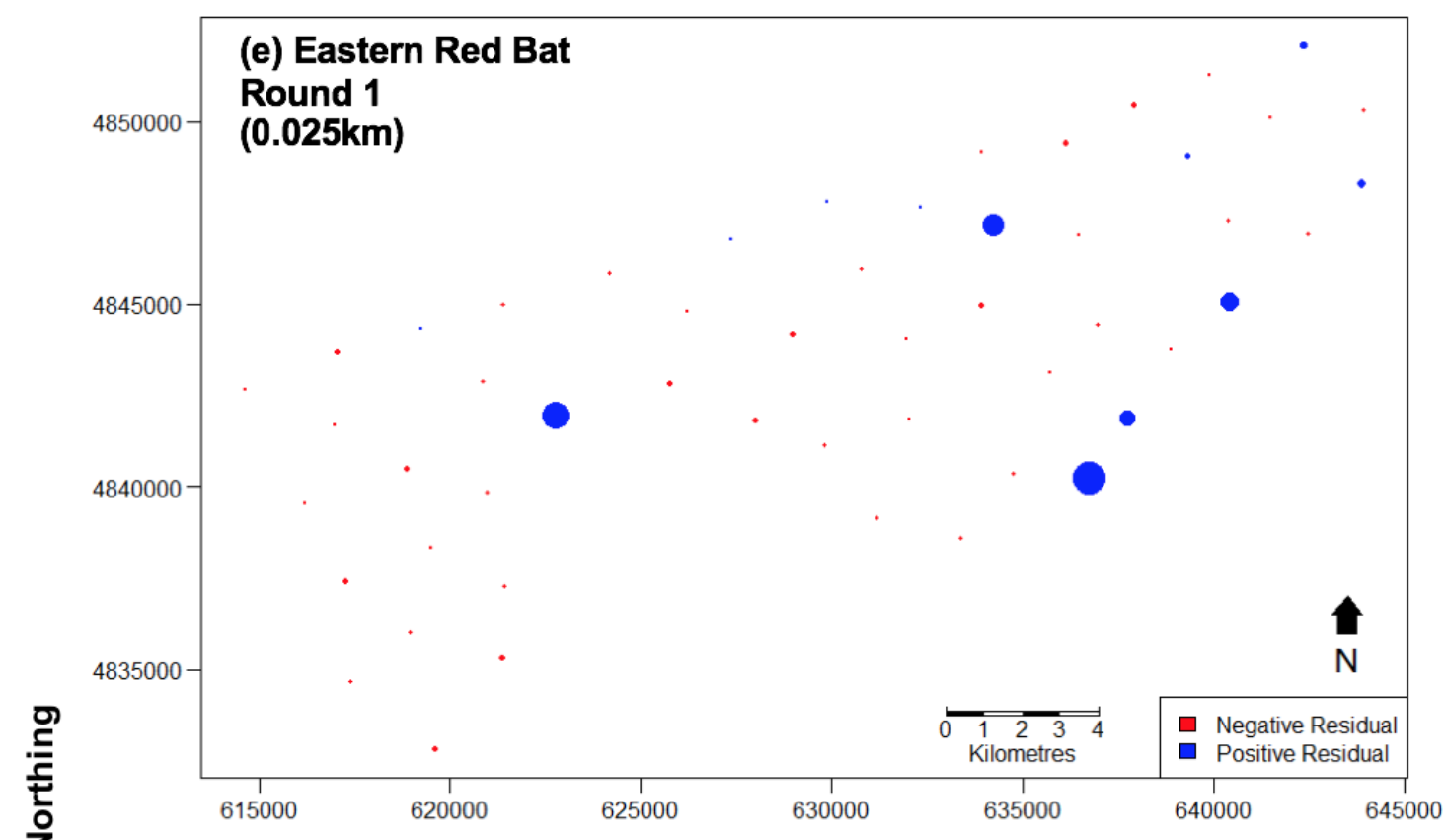

立

(e) Eastern Red Bat

Round 2

(0.025km)

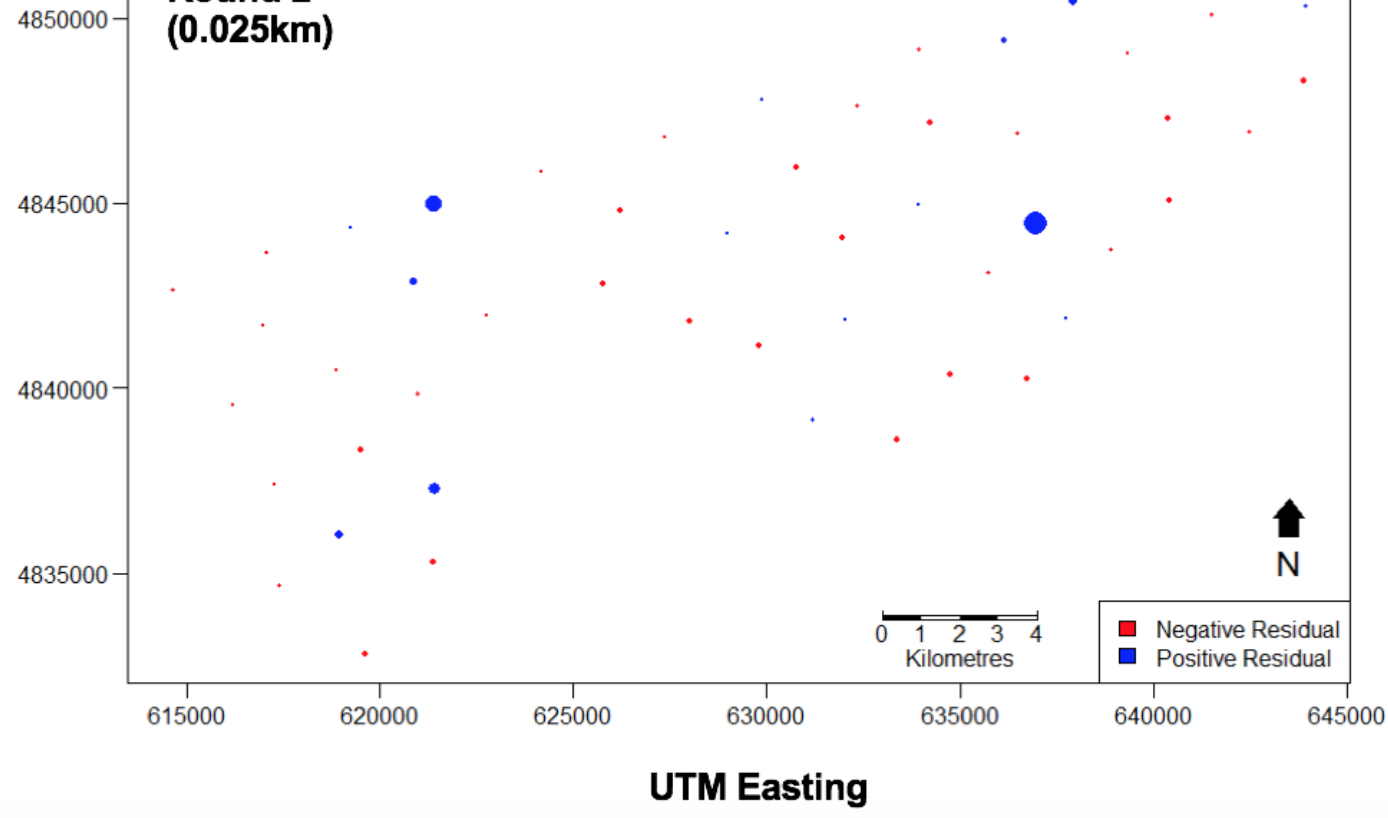


Appendix 7. Continued.

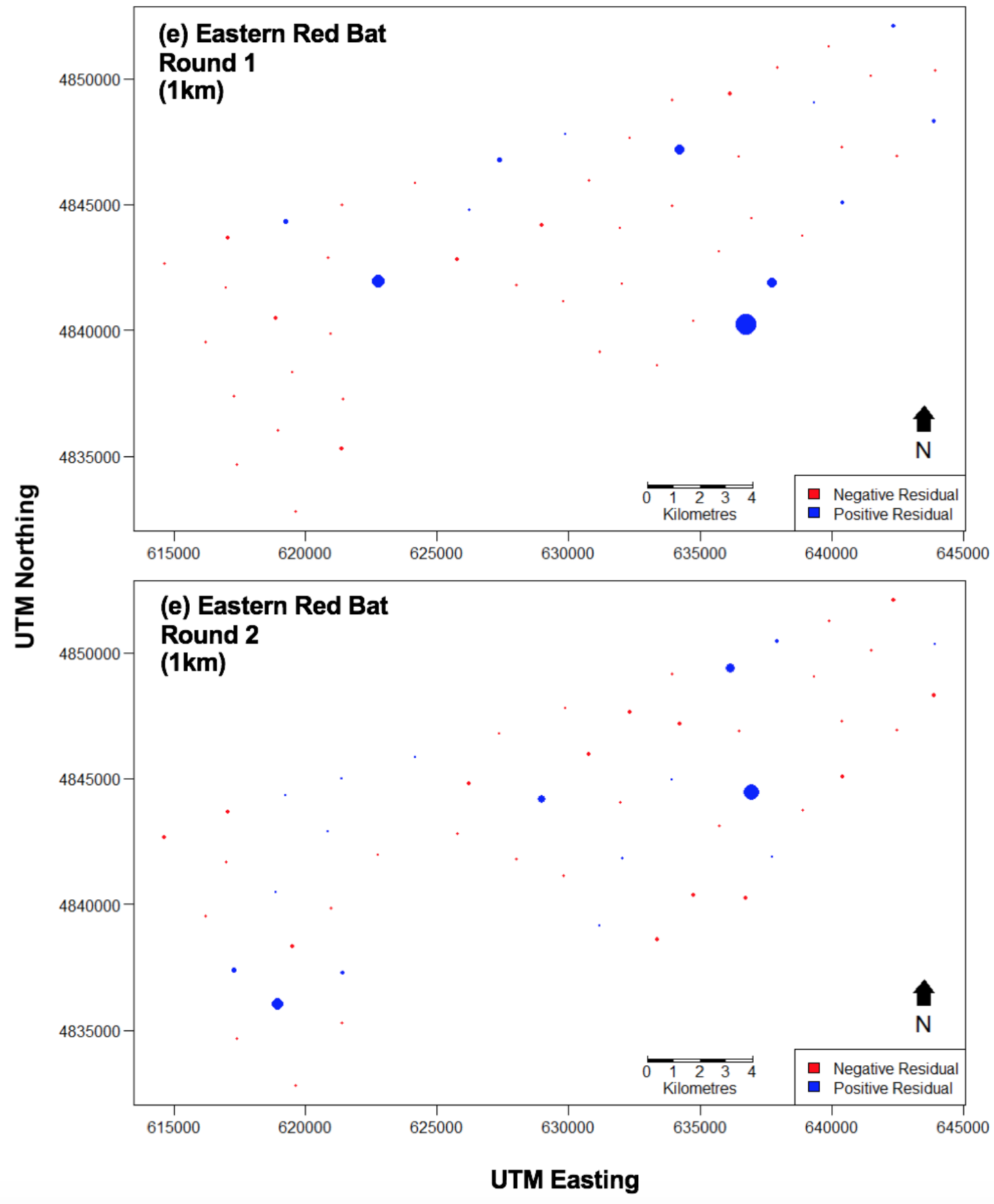


Appendix 7. Continued.

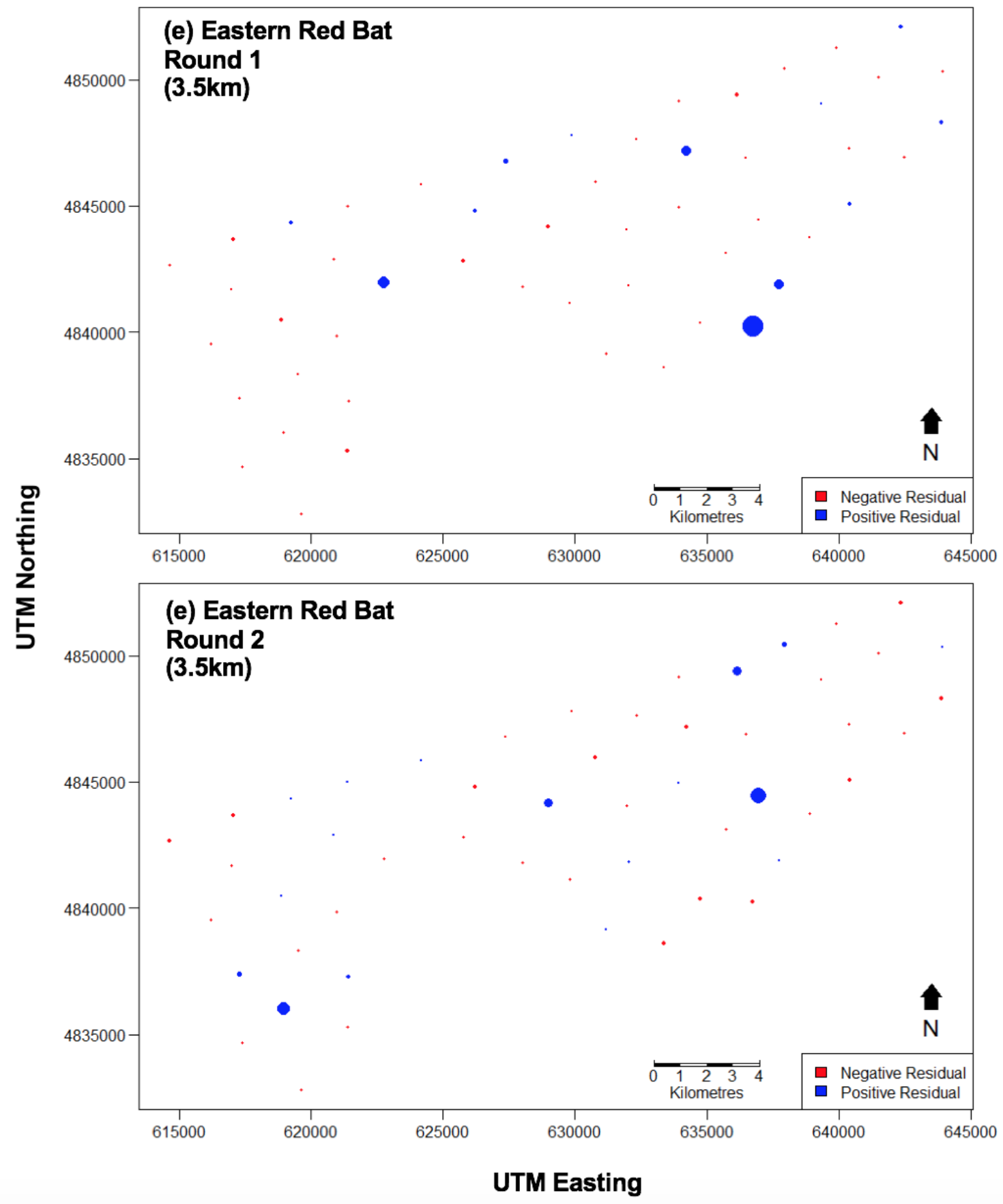


Appendix 8. Percent tree cover within 19 circular landscape scales $(0.025-3.5 \mathrm{~km})$ around each of 52 bat sampling sites, and percent cover of trees in parks within the $0.2 \mathrm{~km}$-radius landscape scale around each site.

\begin{tabular}{|c|c|c|c|c|c|c|c|c|c|c|}
\hline \multirow[t]{2}{*}{ Site } & \multicolumn{10}{|c|}{ Percent Tree Cover within Circular Landscapes } \\
\hline & $0.025 \mathrm{~km}$ & $0.05 \mathrm{~km}$ & $0.1 \mathrm{~km}$ & $0.15 \mathrm{~km}$ & $0.2 \mathrm{~km}$ & $0.25 \mathrm{~km}$ & $0.5 \mathrm{~km}$ & $0.75 \mathrm{~km}$ & $1 \mathrm{~km}$ & $1.25 \mathrm{~km}$ \\
\hline $\mathbf{0}$ & 32 & 20 & 15 & 19 & 16 & 15 & 17 & 14 & 13 & 12 \\
\hline 1 & 43 & 25 & 27 & 29 & 27 & 26 & 26 & 35 & 37 & 39 \\
\hline 2 & 20 & 22 & 19 & 21 & 20 & 19 & 16 & 14 & 13 & 13 \\
\hline 3 & 19 & 10 & 10 & 12 & 11 & 10 & 8 & 8 & 8 & 8 \\
\hline 4 & 37 & 35 & 26 & 29 & 33 & 36 & 26 & 18 & 14 & 13 \\
\hline 5 & 72 & 43 & 31 & 40 & 42 & 39 & 40 & 41 & 38 & 34 \\
\hline 6 & 33 & 16 & 23 & 25 & 22 & 25 & 20 & 18 & 16 & 16 \\
\hline 7 & 50 & 41 & 40 & 36 & 37 & 38 & 37 & 40 & 41 & 42 \\
\hline 8 & 96 & 82 & 67 & 64 & 62 & 59 & 54 & 55 & 57 & 55 \\
\hline 9 & 0 & 4 & 12 & 19 & 22 & 25 & 24 & 19 & 19 & 19 \\
\hline 10 & 73 & 53 & 33 & 28 & 25 & 24 & 23 & 21 & 19 & 20 \\
\hline 11 & 1 & 5 & 11 & 9 & 10 & 12 & 26 & 30 & 28 & 25 \\
\hline 12 & 46 & 41 & 43 & 43 & 42 & 39 & 49 & 48 & 47 & 47 \\
\hline 13 & 63 & 45 & 33 & 35 & 31 & 30 & 28 & 26 & 24 & 24 \\
\hline 14 & 35 & 29 & 29 & 28 & 28 & 26 & 21 & 19 & 22 & 26 \\
\hline 15 & 82 & 52 & 34 & 29 & 28 & 29 & 27 & 29 & 28 & 25 \\
\hline 16 & 84 & 48 & 43 & 38 & 39 & 40 & 42 & 36 & 36 & 35 \\
\hline 17 & 56 & 57 & 64 & 69 & 70 & 62 & 55 & 53 & 49 & 46 \\
\hline 18 & 63 & 56 & 50 & 58 & 62 & 64 & 59 & 51 & 48 & 47 \\
\hline 19 & 88 & 69 & 62 & 63 & 60 & 58 & 55 & 55 & 52 & 49 \\
\hline 20 & 98 & 91 & 84 & 82 & 81 & 80 & 70 & 64 & 59 & 57 \\
\hline
\end{tabular}


Appendix 8. Continued.

\begin{tabular}{|c|c|c|c|c|c|c|c|c|c|c|}
\hline \multirow[t]{2}{*}{ Site } & \multicolumn{10}{|c|}{ Percent Tree Cover within Circular Landscapes } \\
\hline & $0.025 \mathrm{~km}$ & $0.05 \mathrm{~km}$ & $0.1 \mathrm{~km}$ & $0.15 \mathrm{~km}$ & $0.2 \mathrm{~km}$ & $0.25 \mathrm{~km}$ & $0.5 \mathrm{~km}$ & $0.75 \mathrm{~km}$ & $1 \mathrm{~km}$ & $1.25 \mathrm{~km}$ \\
\hline 21 & 21 & 34 & 54 & 60 & 61 & 58 & 49 & 47 & 43 & 38 \\
\hline 22 & 43 & 40 & 42 & 46 & 49 & 46 & 35 & 36 & 40 & 40 \\
\hline 23 & 46 & 32 & 29 & 34 & 31 & 29 & 26 & 27 & 26 & 26 \\
\hline 24 & 68 & 49 & 52 & 51 & 48 & 48 & 39 & 37 & 38 & 41 \\
\hline 25 & 44 & 43 & 41 & 45 & 46 & 45 & 41 & 46 & 48 & 46 \\
\hline 26 & 62 & 37 & 25 & 27 & 25 & 24 & 22 & 19 & 19 & 19 \\
\hline 27 & 27 & 14 & 20 & 18 & 19 & 23 & 32 & 33 & 34 & 30 \\
\hline 28 & 34 & 28 & 28 & 27 & 26 & 30 & 23 & 22 & 22 & 21 \\
\hline 29 & 83 & 49 & 40 & 40 & 40 & 41 & 39 & 41 & 38 & 37 \\
\hline 30 & 25 & 22 & 25 & 26 & 30 & 33 & 45 & 40 & 39 & 37 \\
\hline 31 & 32 & 25 & 34 & 27 & 28 & 26 & 27 & 31 & 30 & 30 \\
\hline 32 & 46 & 27 & 19 & 21 & 23 & 23 & 30 & 28 & 26 & 27 \\
\hline 33 & 58 & 54 & 51 & 49 & 48 & 50 & 51 & 56 & 57 & 55 \\
\hline 34 & 51 & 44 & 45 & 46 & 49 & 52 & 54 & 54 & 52 & 52 \\
\hline 35 & 54 & 29 & 20 & 23 & 23 & 22 & 19 & 21 & 24 & 28 \\
\hline 36 & 68 & 37 & 36 & 45 & 50 & 53 & 62 & 55 & 49 & 44 \\
\hline 37 & 26 & 28 & 29 & 43 & 45 & 46 & 40 & 40 & 39 & 36 \\
\hline 38 & 32 & 26 & 27 & 23 & 23 & 24 & 22 & 21 & 20 & 22 \\
\hline 39 & 35 & 30 & 40 & 37 & 37 & 36 & 25 & 23 & 25 & 28 \\
\hline 40 & 15 & 26 & 31 & 28 & 28 & 32 & 31 & 31 & 28 & 28 \\
\hline
\end{tabular}


Appendix 8. Continued.

\begin{tabular}{|c|c|c|c|c|c|c|c|c|c|c|}
\hline \multirow[t]{2}{*}{ Site } & \multicolumn{10}{|c|}{ Percent Tree Cover within Circular Landscapes } \\
\hline & $0.025 \mathrm{~km}$ & $0.05 \mathrm{~km}$ & $0.1 \mathrm{~km}$ & $0.15 \mathrm{~km}$ & $0.2 \mathrm{~km}$ & $0.25 \mathrm{~km}$ & $0.5 \mathrm{~km}$ & $0.75 \mathrm{~km}$ & $1 \mathrm{~km}$ & $1.25 \mathrm{~km}$ \\
\hline 41 & 69 & 56 & 41 & 33 & 31 & 28 & 30 & 31 & 30 & 29 \\
\hline 42 & 3 & 11 & 17 & 25 & 24 & 24 & 29 & 32 & 33 & 32 \\
\hline 43 & 0 & 4 & 13 & 36 & 48 & 51 & 40 & 35 & 31 & 29 \\
\hline 44 & 58 & 51 & 58 & 52 & 50 & 47 & 42 & 37 & 36 & 36 \\
\hline 45 & 47 & 42 & 35 & 39 & 45 & 43 & 48 & 44 & 42 & 40 \\
\hline 46 & 19 & 25 & 22 & 24 & 25 & 25 & 24 & 24 & 21 & 20 \\
\hline 47 & 47 & 35 & 41 & 35 & 33 & 29 & 20 & 19 & 17 & 17 \\
\hline 48 & 44 & 28 & 30 & 27 & 22 & 20 & 14 & 15 & 18 & 21 \\
\hline 49 & 50 & 29 & 31 & 32 & 30 & 27 & 32 & 37 & 33 & 27 \\
\hline 50 & 39 & 28 & 32 & 36 & 36 & 34 & 33 & 35 & 34 & 31 \\
\hline 51 & 72 & 66 & 60 & 61 & 61 & 62 & 55 & 52 & 46 & 45 \\
\hline
\end{tabular}


Appendix 8. Continued.

\begin{tabular}{|c|c|c|c|c|c|c|c|c|c|c|}
\hline \multirow[t]{2}{*}{ Site } & \multicolumn{9}{|c|}{ Percent Tree Cover within Circular Landscapes } & \multirow[t]{2}{*}{$\begin{array}{c}\text { Percent Tree } \\
\text { Cover in Parks } \\
\text { within a } 0.2 \mathrm{~km}- \\
\text { radius Landscape }\end{array}$} \\
\hline & $1.5 \mathrm{~km}$ & $1.75 \mathrm{~km}$ & $2 \mathbf{k m}$ & $2.25 \mathrm{~km}$ & $2.5 \mathrm{~km}$ & $2.75 \mathrm{~km}$ & $3 \mathbf{k m}$ & $3.25 \mathrm{~km}$ & $3.5 \mathrm{~km}$ & \\
\hline $\mathbf{0}$ & 11 & 9 & 10 & 10 & 11 & 12 & 14 & 16 & 17 & 0 \\
\hline 1 & 36 & 31 & 34 & 31 & 29 & 29 & 28 & 28 & 28 & 0 \\
\hline 2 & 13 & 13 & 15 & 15 & 15 & 15 & 15 & 15 & 15 & 7 \\
\hline 3 & 11 & 10 & 12 & 13 & 14 & 14 & 15 & 16 & 17 & 0 \\
\hline 4 & 13 & 13 & 16 & 17 & 18 & 18 & 18 & 18 & 18 & 13 \\
\hline 5 & 32 & 29 & 32 & 31 & 30 & 30 & 30 & 30 & 31 & 25 \\
\hline 6 & 15 & 14 & 16 & 17 & 17 & 18 & 19 & 19 & 21 & 5 \\
\hline 7 & 43 & 40 & 45 & 46 & 47 & 47 & 47 & 47 & 48 & 19 \\
\hline 8 & 52 & 44 & 47 & 46 & 45 & 44 & 43 & 41 & 40 & 0 \\
\hline 9 & 19 & 18 & 21 & 22 & 22 & 22 & 23 & 23 & 23 & 0 \\
\hline 10 & 23 & 21 & 24 & 24 & 24 & 25 & 25 & 26 & 26 & 1 \\
\hline 11 & 25 & 21 & 23 & 21 & 20 & 20 & 19 & 19 & 19 & 1 \\
\hline 12 & 46 & 39 & 41 & 39 & 38 & 37 & 36 & 36 & 35 & 0 \\
\hline 13 & 26 & 25 & 29 & 29 & 29 & 30 & 30 & 30 & 29 & 18 \\
\hline 14 & 26 & 23 & 24 & 24 & 24 & 24 & 23 & 23 & 23 & 0 \\
\hline 15 & 23 & 20 & 23 & 23 & 23 & 24 & 24 & 25 & 25 & 0 \\
\hline 16 & 34 & 29 & 31 & 30 & 28 & 26 & 26 & 25 & 25 & 0 \\
\hline 17 & 44 & 39 & 42 & 40 & 40 & 40 & 39 & 39 & 39 & 65 \\
\hline 18 & 46 & 40 & 44 & 44 & 45 & 44 & 45 & 46 & 46 & 24 \\
\hline 19 & 48 & 40 & 44 & 44 & 44 & 43 & 43 & 43 & 43 & 0 \\
\hline 20 & 56 & 49 & 54 & 53 & 53 & 52 & 51 & 50 & 49 & 1 \\
\hline
\end{tabular}


Appendix 8. Continued.

\begin{tabular}{|c|c|c|c|c|c|c|c|c|c|c|}
\hline \multirow[t]{2}{*}{ Site } & \multicolumn{9}{|c|}{ Percent Tree Cover within Circular Landscapes } & \multirow[t]{2}{*}{$\begin{array}{c}\text { Percent Tree } \\
\text { Cover in Parks } \\
\text { within a } 0.2 \mathrm{~km}- \\
\text { radius Landscape }\end{array}$} \\
\hline & $1.5 \mathrm{~km}$ & $1.75 \mathrm{~km}$ & $2 \mathbf{k m}$ & $2.25 \mathrm{~km}$ & $2.5 \mathrm{~km}$ & $2.75 \mathrm{~km}$ & $3 \mathbf{k m}$ & $3.25 \mathrm{~km}$ & $3.5 \mathrm{~km}$ & \\
\hline 21 & 36 & 33 & 37 & 37 & 37 & 37 & 38 & 38 & 39 & 17 \\
\hline 22 & 43 & 40 & 44 & 43 & 42 & 42 & 42 & 42 & 42 & 28 \\
\hline 23 & 26 & 23 & 26 & 27 & 28 & 29 & 30 & 30 & 31 & 0 \\
\hline 24 & 43 & 40 & 44 & 44 & 44 & 43 & 42 & 42 & 42 & 23 \\
\hline 25 & 43 & 37 & 41 & 43 & 45 & 46 & 47 & 47 & 47 & 0 \\
\hline 26 & 19 & 18 & 22 & 23 & 24 & 24 & 24 & 23 & 23 & 0 \\
\hline 27 & 30 & 25 & 26 & 25 & 24 & 23 & 23 & 22 & 21 & 0 \\
\hline 28 & 20 & 17 & 19 & 19 & 20 & 20 & 20 & 20 & 20 & 1 \\
\hline 29 & 37 & 32 & 36 & 37 & 37 & 37 & 37 & 36 & 34 & 3 \\
\hline 30 & 35 & 28 & 30 & 28 & 27 & 26 & 25 & 24 & 23 & 25 \\
\hline 31 & 28 & 25 & 28 & 30 & 31 & 32 & 33 & 33 & 33 & 16 \\
\hline 32 & 28 & 26 & 30 & 30 & 29 & 28 & 28 & 27 & 27 & 3 \\
\hline 33 & 54 & 47 & 52 & 51 & 50 & 49 & 49 & 48 & 47 & 16 \\
\hline 34 & 50 & 43 & 44 & 42 & 40 & 39 & 39 & 39 & 39 & 9 \\
\hline 35 & 31 & 28 & 33 & 33 & 35 & 36 & 37 & 37 & 37 & 0 \\
\hline 36 & 40 & 34 & 36 & 34 & 32 & 32 & 33 & 34 & 34 & 28 \\
\hline 37 & 33 & 29 & 31 & 30 & 30 & 30 & 31 & 32 & 33 & 44 \\
\hline 38 & 22 & 21 & 24 & 25 & 25 & 24 & 25 & 25 & 26 & 0 \\
\hline 39 & 32 & 30 & 33 & 33 & 33 & 33 & 33 & 33 & 33 & 2 \\
\hline 40 & 28 & 25 & 28 & 29 & 30 & 31 & 31 & 32 & 32 & 7 \\
\hline
\end{tabular}


Appendix 8. Continued.

\begin{tabular}{|c|c|c|c|c|c|c|c|c|c|c|}
\hline \multirow[t]{2}{*}{ Site } & \multicolumn{9}{|c|}{ Percent Tree Cover within Circular Landscapes } & \multirow[t]{2}{*}{$\begin{array}{c}\text { Percent Tree } \\
\text { Cover in Parks } \\
\text { within a } 0.2 \mathrm{~km}- \\
\text { radius Landscape }\end{array}$} \\
\hline & $1.5 \mathrm{~km}$ & $1.75 \mathrm{~km}$ & $2 \mathbf{k m}$ & $2.25 \mathrm{~km}$ & $2.5 \mathrm{~km}$ & $2.75 \mathrm{~km}$ & $3 \mathbf{k m}$ & $3.25 \mathrm{~km}$ & $3.5 \mathrm{~km}$ & \\
\hline 41 & 29 & 26 & 30 & 30 & 29 & 29 & 28 & 29 & 29 & 1 \\
\hline 42 & 31 & 26 & 28 & 27 & 26 & 26 & 25 & 24 & 23 & 33 \\
\hline 43 & 30 & 26 & 27 & 26 & 25 & 26 & 27 & 27 & 26 & 54 \\
\hline 44 & 38 & 36 & 41 & 41 & 41 & 41 & 40 & 40 & 38 & 8 \\
\hline 45 & 38 & 34 & 38 & 38 & 38 & 38 & 37 & 36 & 35 & 27 \\
\hline 46 & 19 & 19 & 21 & 21 & 21 & 21 & 21 & 21 & 21 & 0 \\
\hline 47 & 18 & 17 & 20 & 21 & 23 & 25 & 26 & 26 & 26 & 0 \\
\hline 48 & 23 & 21 & 25 & 25 & 26 & 26 & 26 & 26 & 26 & 15 \\
\hline 49 & 22 & 17 & 17 & 17 & 17 & 17 & 17 & 17 & 18 & 6 \\
\hline 50 & 28 & 24 & 26 & 25 & 24 & 23 & 22 & 21 & 21 & 6 \\
\hline 51 & 44 & 38 & 41 & 39 & 38 & 37 & 37 & 36 & 36 & 0 \\
\hline
\end{tabular}


Appendix 9. Percent building cover within 19 circular landscape scales $(0.025-3.5 \mathrm{~km})$ around each of 52 bat sampling sites.

\begin{tabular}{|c|c|c|c|c|c|c|c|c|c|}
\hline \multirow[t]{2}{*}{ Site } & \multicolumn{9}{|c|}{ Percent Building Cover within Circular Landscapes } \\
\hline & $0.025 \mathrm{~km}$ & $0.05 \mathrm{~km}$ & $0.1 \mathrm{~km}$ & $0.15 \mathrm{~km}$ & $0.2 \mathrm{~km}$ & $0.25 \mathrm{~km}$ & $0.5 \mathrm{~km}$ & $0.75 \mathrm{~km}$ & $1 \mathrm{~km}$ \\
\hline $\mathbf{0}$ & 11 & 29 & 26 & 21 & 20 & 19 & 19 & 20 & 21 \\
\hline 1 & 19 & 24 & 21 & 22 & 22 & 23 & 20 & 16 & 13 \\
\hline 2 & 47 & 27 & 29 & 26 & 28 & 26 & 21 & 18 & 18 \\
\hline 3 & 41 & 26 & 22 & 24 & 25 & 26 & 21 & 19 & 19 \\
\hline 4 & 47 & 34 & 28 & 24 & 22 & 18 & 16 & 17 & 20 \\
\hline 5 & 4 & 21 & 20 & 17 & 16 & 16 & 17 & 16 & 16 \\
\hline 6 & 21 & 25 & 20 & 21 & 21 & 19 & 22 & 22 & 20 \\
\hline 7 & 32 & 22 & 21 & 22 & 26 & 24 & 21 & 20 & 21 \\
\hline 8 & 5 & 14 & 15 & 14 & 13 & 12 & 13 & 13 & 13 \\
\hline 9 & 24 & 32 & 26 & 25 & 24 & 22 & 20 & 19 & 18 \\
\hline 10 & 15 & 12 & 20 & 21 & 22 & 24 & 23 & 21 & 21 \\
\hline 11 & 41 & 38 & 29 & 31 & 32 & 31 & 21 & 18 & 17 \\
\hline 12 & 39 & 31 & 23 & 19 & 17 & 17 & 12 & 12 & 13 \\
\hline 13 & 30 & 29 & 26 & 22 & 19 & 20 & 21 & 22 & 23 \\
\hline 14 & 27 & 26 & 23 & 22 & 20 & 17 & 13 & 14 & 14 \\
\hline 15 & 13 & 22 & 23 & 21 & 22 & 22 & 21 & 20 & 19 \\
\hline 16 & 13 & 29 & 26 & 27 & 25 & 24 & 22 & 19 & 18 \\
\hline 17 & 14 & 18 & 13 & 11 & 7 & 5 & 8 & 10 & 12 \\
\hline 18 & 19 & 20 & 19 & 15 & 14 & 13 & 13 & 13 & 13 \\
\hline 19 & 3 & 24 & 25 & 19 & 18 & 17 & 17 & 19 & 21 \\
\hline 20 & 0 & 4 & 8 & 9 & 10 & 9 & 8 & 10 & 13 \\
\hline
\end{tabular}


Appendix 9. Continued.

\begin{tabular}{|c|c|c|c|c|c|c|c|c|c|}
\hline \multirow[t]{2}{*}{ Site } & \multicolumn{9}{|c|}{ Percent Building Cover within Circular Landscapes } \\
\hline & $0.025 \mathrm{~km}$ & $0.05 \mathrm{~km}$ & $0.1 \mathrm{~km}$ & $0.15 \mathrm{~km}$ & $0.2 \mathrm{~km}$ & $0.25 \mathrm{~km}$ & $0.5 \mathrm{~km}$ & $0.75 \mathrm{~km}$ & $1 \mathrm{~km}$ \\
\hline 21 & 19 & 27 & 20 & 18 & 16 & 14 & 11 & 11 & 12 \\
\hline 22 & 21 & 29 & 29 & 25 & 24 & 21 & 22 & 21 & 20 \\
\hline 23 & 10 & 29 & 30 & 24 & 24 & 24 & 22 & 18 & 18 \\
\hline 24 & 19 & 23 & 19 & 17 & 16 & 15 & 16 & 18 & 17 \\
\hline 25 & 19 & 30 & 24 & 24 & 22 & 21 & 20 & 19 & 18 \\
\hline 26 & 15 & 23 & 23 & 27 & 25 & 24 & 22 & 22 & 20 \\
\hline 27 & 22 & 21 & 17 & 21 & 22 & 22 & 19 & 17 & 17 \\
\hline 28 & 34 & 28 & 25 & 25 & 25 & 24 & 19 & 21 & 22 \\
\hline 29 & 10 & 32 & 25 & 24 & 20 & 19 & 19 & 20 & 20 \\
\hline 30 & 26 & 24 & 21 & 20 & 18 & 17 & 11 & 12 & 13 \\
\hline 31 & 39 & 30 & 29 & 27 & 27 & 27 & 20 & 17 & 16 \\
\hline 32 & 26 & 29 & 25 & 27 & 25 & 22 & 18 & 18 & 20 \\
\hline 33 & 25 & 22 & 15 & 13 & 17 & 17 & 14 & 13 & 12 \\
\hline 34 & 27 & 21 & 20 & 18 & 16 & 13 & 11 & 11 & 11 \\
\hline 35 & 16 & 33 & 31 & 30 & 30 & 30 & 29 & 29 & 27 \\
\hline 36 & 9 & 18 & 20 & 16 & 15 & 13 & 7 & 8 & 10 \\
\hline 37 & 33 & 31 & 26 & 21 & 20 & 20 & 16 & 15 & 15 \\
\hline 38 & 17 & 30 & 24 & 23 & 21 & 20 & 20 & 20 & 20 \\
\hline 39 & 20 & 22 & 21 & 22 & 22 & 20 & 15 & 15 & 15 \\
\hline 40 & 35 & 28 & 22 & 25 & 25 & 25 & 21 & 20 & 20 \\
\hline
\end{tabular}


Appendix 9. Continued.

\begin{tabular}{|c|c|c|c|c|c|c|c|c|c|}
\hline \multirow[t]{2}{*}{ Site } & \multicolumn{9}{|c|}{ Percent Building Cover within Circular Landscapes } \\
\hline & $0.025 \mathrm{~km}$ & $0.05 \mathrm{~km}$ & $0.1 \mathrm{~km}$ & $0.15 \mathrm{~km}$ & $0.2 \mathrm{~km}$ & $0.25 \mathrm{~km}$ & $0.5 \mathrm{~km}$ & $0.75 \mathrm{~km}$ & $1 \mathrm{~km}$ \\
\hline 41 & 5 & 20 & 22 & 25 & 24 & 22 & 22 & 21 & 18 \\
\hline 42 & 24 & 28 & 19 & 19 & 18 & 16 & 16 & 17 & 17 \\
\hline 43 & 8 & 36 & 26 & 20 & 15 & 12 & 12 & 13 & 11 \\
\hline 44 & 26 & 18 & 14 & 15 & 17 & 18 & 18 & 18 & 19 \\
\hline 45 & 33 & 32 & 29 & 22 & 18 & 16 & 14 & 14 & 14 \\
\hline 46 & 32 & 19 & 23 & 24 & 24 & 24 & 20 & 19 & 18 \\
\hline 47 & 14 & 21 & 19 & 19 & 20 & 22 & 22 & 22 & 21 \\
\hline 48 & 26 & 25 & 27 & 26 & 23 & 22 & 22 & 20 & 19 \\
\hline 49 & 21 & 29 & 20 & 20 & 20 & 20 & 21 & 17 & 17 \\
\hline 50 & 31 & 30 & 25 & 25 & 22 & 21 & 19 & 17 & 17 \\
\hline 51 & 14 & 18 & 18 & 15 & 16 & 16 & 14 & 13 & 13 \\
\hline
\end{tabular}


Appendix 9. Continued.

\begin{tabular}{|c|c|c|c|c|c|c|c|c|c|c|}
\hline \multirow[t]{2}{*}{ Site } & \multicolumn{10}{|c|}{ Percent Building Cover within Circular Landscapes } \\
\hline & $1.25 \mathrm{~km}$ & $1.5 \mathrm{~km}$ & $1.75 \mathrm{~km}$ & $2 \mathbf{k m}$ & $2.25 \mathrm{~km}$ & $2.5 \mathrm{~km}$ & $2.75 \mathrm{~km}$ & $3 \mathbf{k m}$ & $3.25 \mathrm{~km}$ & $3.5 \mathrm{~km}$ \\
\hline $\mathbf{0}$ & 21 & 20 & 17 & 18 & 17 & 17 & 17 & 16 & 15 & 15 \\
\hline 1 & 12 & 13 & 12 & 13 & 13 & 13 & 13 & 14 & 14 & 14 \\
\hline 2 & 18 & 18 & 16 & 18 & 19 & 19 & 19 & 19 & 19 & 19 \\
\hline 3 & 19 & 17 & 15 & 17 & 17 & 17 & 17 & 17 & 18 & 18 \\
\hline 4 & 20 & 20 & 17 & 20 & 20 & 20 & 20 & 19 & 19 & 19 \\
\hline 5 & 18 & 19 & 17 & 19 & 20 & 19 & 19 & 19 & 19 & 19 \\
\hline 6 & 20 & 20 & 17 & 19 & 19 & 19 & 19 & 19 & 19 & 19 \\
\hline 7 & 22 & 21 & 19 & 20 & 19 & 19 & 18 & 18 & 17 & 17 \\
\hline 8 & 12 & 13 & 12 & 14 & 14 & 15 & 15 & 15 & 15 & 16 \\
\hline 9 & 19 & 19 & 17 & 19 & 19 & 19 & 19 & 18 & 18 & 18 \\
\hline 10 & 20 & 18 & 15 & 17 & 16 & 16 & 16 & 16 & 16 & 17 \\
\hline 11 & 18 & 18 & 16 & 18 & 18 & 17 & 17 & 17 & 17 & 18 \\
\hline 12 & 14 & 15 & 14 & 15 & 15 & 15 & 16 & 16 & 17 & 16 \\
\hline 13 & 23 & 22 & 18 & 19 & 18 & 18 & 18 & 19 & 19 & 19 \\
\hline 14 & 12 & 12 & 11 & 12 & 13 & 13 & 14 & 14 & 14 & 15 \\
\hline 15 & 20 & 20 & 18 & 20 & 21 & 20 & 20 & 19 & 19 & 19 \\
\hline 16 & 18 & 18 & 16 & 18 & 18 & 19 & 19 & 19 & 19 & 19 \\
\hline 17 & 13 & 14 & 14 & 16 & 16 & 16 & 16 & 16 & 15 & 15 \\
\hline 18 & 14 & 14 & 13 & 15 & 15 & 14 & 14 & 14 & 14 & 14 \\
\hline 19 & 22 & 23 & 21 & 23 & 22 & 22 & 21 & 20 & 19 & 19 \\
\hline 20 & 14 & 15 & 13 & 15 & 15 & 15 & 15 & 16 & 16 & 16 \\
\hline
\end{tabular}


Appendix 9. Continued.

\begin{tabular}{|c|c|c|c|c|c|c|c|c|c|c|}
\hline \multirow[t]{2}{*}{ Site } & \multicolumn{10}{|c|}{ Percent Building Cover within Circular Landscapes } \\
\hline & $1.25 \mathrm{~km}$ & $1.5 \mathrm{~km}$ & $1.75 \mathrm{~km}$ & $2 \mathrm{~km}$ & $2.25 \mathrm{~km}$ & $2.5 \mathrm{~km}$ & $2.75 \mathrm{~km}$ & $3 \mathbf{k m}$ & $3.25 \mathrm{~km}$ & $3.5 \mathrm{~km}$ \\
\hline 21 & 14 & 15 & 14 & 16 & 16 & 16 & 17 & 16 & 16 & 16 \\
\hline 22 & 19 & 18 & 15 & 17 & 17 & 17 & 17 & 17 & 17 & 17 \\
\hline 23 & 19 & 20 & 18 & 20 & 20 & 20 & 20 & 19 & 19 & 19 \\
\hline 24 & 17 & 16 & 13 & 15 & 15 & 15 & 16 & 16 & 16 & 16 \\
\hline 25 & 17 & 18 & 16 & 18 & 17 & 16 & 16 & 15 & 15 & 15 \\
\hline 26 & 20 & 20 & 18 & 19 & 18 & 18 & 18 & 18 & 18 & 18 \\
\hline 27 & 17 & 17 & 15 & 16 & 16 & 17 & 18 & 18 & 18 & 18 \\
\hline 28 & 21 & 22 & 19 & 22 & 21 & 20 & 19 & 19 & 19 & 19 \\
\hline 29 & 19 & 19 & 16 & 18 & 17 & 17 & 16 & 15 & 15 & 15 \\
\hline 30 & 14 & 15 & 14 & 16 & 16 & 17 & 17 & 17 & 18 & 18 \\
\hline 31 & 16 & 16 & 14 & 17 & 17 & 18 & 18 & 19 & 19 & 19 \\
\hline 32 & 19 & 19 & 16 & 17 & 17 & 18 & 18 & 18 & 19 & 19 \\
\hline 33 & 13 & 13 & 12 & 13 & 13 & 14 & 14 & 14 & 14 & 14 \\
\hline 34 & 12 & 12 & 12 & 15 & 17 & 18 & 18 & 19 & 19 & 19 \\
\hline 35 & 24 & 22 & 18 & 20 & 19 & 19 & 19 & 19 & 19 & 19 \\
\hline 36 & 11 & 13 & 14 & 17 & 17 & 18 & 19 & 19 & 18 & 18 \\
\hline 37 & 17 & 17 & 15 & 17 & 18 & 18 & 18 & 18 & 17 & 17 \\
\hline 38 & 21 & 20 & 18 & 20 & 20 & 20 & 20 & 20 & 20 & 19 \\
\hline 39 & 14 & 14 & 13 & 16 & 16 & 17 & 17 & 17 & 18 & 18 \\
\hline 40 & 20 & 19 & 17 & 18 & 18 & 18 & 17 & 17 & 17 & 17 \\
\hline
\end{tabular}


Appendix 9. Continued.

\begin{tabular}{|c|c|c|c|c|c|c|c|c|c|c|}
\hline \multirow[t]{2}{*}{ Site } & \multicolumn{10}{|c|}{ Percent Building Cover within Circular Landscapes } \\
\hline & $1.25 \mathrm{~km}$ & $1.5 \mathrm{~km}$ & $1.75 \mathrm{~km}$ & $2 \mathbf{k m}$ & $2.25 \mathrm{~km}$ & $2.5 \mathrm{~km}$ & $2.75 \mathrm{~km}$ & $3 \mathbf{k m}$ & $3.25 \mathrm{~km}$ & $3.5 \mathrm{~km}$ \\
\hline 41 & 16 & 15 & 14 & 16 & 16 & 16 & 17 & 17 & 16 & 16 \\
\hline 42 & 17 & 17 & 16 & 17 & 17 & 16 & 16 & 16 & 16 & 17 \\
\hline 43 & 12 & 13 & 12 & 15 & 16 & 17 & 17 & 17 & 17 & 17 \\
\hline 44 & 19 & 19 & 16 & 17 & 18 & 18 & 17 & 17 & 17 & 17 \\
\hline 45 & 15 & 16 & 14 & 16 & 16 & 16 & 16 & 16 & 16 & 16 \\
\hline 46 & 18 & 17 & 16 & 18 & 18 & 18 & 19 & 19 & 19 & 19 \\
\hline 47 & 20 & 20 & 17 & 19 & 19 & 19 & 18 & 18 & 18 & 18 \\
\hline 48 & 18 & 17 & 15 & 17 & 17 & 16 & 16 & 16 & 16 & 16 \\
\hline 49 & 18 & 19 & 18 & 20 & 20 & 20 & 20 & 19 & 19 & 19 \\
\hline 50 & 17 & 18 & 17 & 19 & 19 & 18 & 18 & 19 & 19 & 19 \\
\hline 51 & 13 & 15 & 13 & 15 & 15 & 15 & 16 & 16 & 16 & 17 \\
\hline
\end{tabular}


Appendix 10. Date, Start and End Recording Time, and Mean Nightly Temperature $\left({ }^{\circ} \mathrm{C}\right)$ from sampling round 1 (R1) and round 2 (R2) of bat recording at each sampling site.

\begin{tabular}{|c|c|c|c|c|c|c|c|c|}
\hline \multirow[t]{2}{*}{ Site } & \multicolumn{2}{|c|}{ Date } & \multicolumn{2}{|c|}{ Start Time } & \multicolumn{2}{|c|}{ End Time } & \multicolumn{2}{|c|}{ Mean Temperature $\left({ }^{\circ} \mathrm{C}\right)$} \\
\hline & R1 & $\mathbf{R 2}$ & R1 & $\mathbf{R 2}$ & R1 & $\mathbf{R 2}$ & R1 & $\mathbf{R 2}$ \\
\hline $\mathbf{0}$ & June 7, 2017 & July 11,2017 & $20: 57$ & $20: 59$ & $5: 36$ & $5: 47$ & 11.905 & 20.132 \\
\hline 1 & July 30, 2017 & June 27,2017 & $20: 43$ & $21: 03$ & $6: 06$ & $5: 38$ & 19.485 & 12.261 \\
\hline 2 & June 1, 2017 & June 27,2017 & $20: 52$ & $21: 03$ & $5: 38$ & $5: 38$ & 9.614 & 12.548 \\
\hline 3 & June 19, 2017 & July 4, 2017 & 21:02 & $21: 02$ & $5: 36$ & $5: 42$ & 18.938 & 19.005 \\
\hline 4 & July 30, 2017 & July 31,2017 & $20: 43$ & $20: 41$ & $6: 06$ & $6: 07$ & 19.932 & 20.950 \\
\hline 5 & June 13, 2017 & July 6, 2017 & 21:00 & $21: 01$ & $5: 35$ & $5: 43$ & 16.145 & 20.203 \\
\hline 6 & June 12,2017 & June 27,2017 & $21: 00$ & $21: 03$ & $5: 35$ & $5: 38$ & 26.399 & 12.981 \\
\hline 7 & May 31, 2017 & July 5, 2017 & $20: 51$ & $21: 02$ & $5: 39$ & $5: 42$ & 14.059 & 17.727 \\
\hline 8 & August 8, 2017 & July 17, 2017 & $20: 31$ & $20: 55$ & $6: 16$ & $5: 53$ & 19.241 & 19.092 \\
\hline 9 & June 25,2017 & July 19, 2017 & 21:03 & $20: 54$ & $5: 38$ & $5: 55$ & 16.029 & 20.275 \\
\hline 10 & August 8, 2017 & July 25, 2017 & $20: 31$ & $20: 48$ & $6: 16$ & $6: 00$ & 19.016 & 15.511 \\
\hline 11 & June 6,2017 & July 17,2017 & $20: 56$ & $20: 55$ & $5: 36$ & $5: 53$ & 9.592 & 17.812 \\
\hline 12 & June 25, 2017 & July 5, 2017 & 21:03 & $21: 02$ & $5: 38$ & $5: 42$ & 16.166 & 17.407 \\
\hline 13 & June 6,2017 & July 5, 2017 & $20: 56$ & $21: 02$ & $5: 36$ & $5: 42$ & 10.446 & 16.346 \\
\hline 14 & June 7, 2017 & July 4, 2017 & $20: 57$ & $21: 02$ & $5: 36$ & $5: 42$ & 10.080 & 14.789 \\
\hline 15 & May 30, 2017 & July 18,2017 & $20: 50$ & $20: 54$ & $5: 39$ & $5: 54$ & 12.236 & 20.740 \\
\hline 16 & May 31, 2017 & August 1, 2017 & $20: 51$ & $20: 40$ & $5: 39$ & $6: 08$ & 13.575 & 19.428 \\
\hline 17 & May 30, 2017 & July 31,2017 & $20: 50$ & $20: 41$ & $5: 39$ & $6: 07$ & 11.510 & 19.148 \\
\hline 18 & June 19, 2017 & June 26,2017 & 21:02 & $21: 03$ & $5: 36$ & $5: 38$ & 17.390 & 11.246 \\
\hline 19 & June 18,2017 & July 6, 2017 & 21:02 & $21: 01$ & $5: 36$ & $5: 43$ & 20.086 & 21.827 \\
\hline 20 & June 6, 2017 & July 25, 2017 & $20: 56$ & $20: 48$ & $5: 36$ & $6: 00$ & 10.134 & 14.378 \\
\hline 21 & July 30, 2017 & July 4, 2017 & $20: 43$ & $21: 02$ & $6: 06$ & $5: 42$ & 17.327 & 13.745 \\
\hline 22 & June 8, 2017 & July 27,2017 & $20: 57$ & $20: 46$ & $5: 36$ & $6: 03$ & 12.793 & 17.462 \\
\hline 23 & July 30, 2017 & July 17,2017 & $20: 43$ & $20: 55$ & $6: 06$ & $5: 53$ & 19.193 & 18.119 \\
\hline 24 & June 8, 2017 & July 25, 2017 & $20: 57$ & $20: 48$ & $5: 36$ & $6: 00$ & 13.204 & 14.487 \\
\hline 25 & June 1, 2017 & July 31,2017 & $20: 52$ & $20: 41$ & $5: 38$ & $6: 07$ & 10.242 & 20.742 \\
\hline
\end{tabular}


Appendix 10. Continued.

\begin{tabular}{|c|c|c|c|c|c|c|c|c|}
\hline \multirow[t]{2}{*}{ Site } & \multicolumn{2}{|c|}{ Date } & \multicolumn{2}{|c|}{ Start Time } & \multicolumn{2}{|c|}{ End Time } & \multicolumn{2}{|c|}{ Mean Temperature $\left({ }^{\circ} \mathrm{C}\right)$} \\
\hline & R1 & $\mathbf{R 2}$ & R1 & $\mathbf{R 2}$ & R1 & $\mathbf{R 2}$ & R1 & $\mathbf{R 2}$ \\
\hline 26 & June 25, 2017 & July 27, 2017 & 21:03 & $20: 46$ & $5: 38$ & $6: 03$ & 13.848 & 17.913 \\
\hline 27 & June 18, 2017 & July 25, 2017 & 21:02 & $20: 48$ & $5: 36$ & $6: 00$ & 19.998 & 15.114 \\
\hline 28 & June 8, 2017 & August 1, 2017 & $20: 57$ & $20: 40$ & $5: 36$ & $6: 08$ & 14.248 & 19.483 \\
\hline 29 & August 7, 2017 & July 18,2017 & $20: 33$ & $20: 54$ & $6: 15$ & $5: 54$ & 14.869 & 21.495 \\
\hline 30 & August 7, 2017 & July 27,2017 & $20: 33$ & $20: 46$ & $6: 15$ & $6: 03$ & 13.585 & 17.358 \\
\hline 31 & August 8, 2017 & July 19, 2017 & $20: 31$ & $20: 54$ & $6: 16$ & $5: 55$ & 19.591 & 19.935 \\
\hline 32 & June 18, 2017 & June 21, 2017 & 21:02 & $21: 03$ & $5: 36$ & $5: 36$ & 20.002 & 15.696 \\
\hline 33 & June 12, 2017 & July 11,2017 & 21:00 & $20: 59$ & $5: 35$ & $5: 47$ & 25.871 & 20.697 \\
\hline 34 & May 31,2017 & August 1, 2017 & $20: 51$ & $20: 40$ & $5: 39$ & $6: 08$ & 13.827 & 19.541 \\
\hline 35 & May 31,2017 & July 31, 2017 & $20: 51$ & $20: 41$ & $5: 39$ & $6: 07$ & & 22.212 \\
\hline 36 & June 12,2017 & July 27,2017 & 21:00 & $20: 46$ & $5: 35$ & $6: 03$ & 24.914 & 19.488 \\
\hline 37 & May 30, 2017 & July 4, 2017 & $20: 50$ & $21: 02$ & $5: 39$ & $5: 42$ & 12.587 & 16.210 \\
\hline 38 & June 12,2017 & June 26, 2017 & $21: 00$ & $21: 03$ & $5: 35$ & $5: 38$ & 25.134 & 11.088 \\
\hline 39 & June 13, 2017 & July 18, 2017 & 21:00 & $20: 54$ & $5: 35$ & $5: 54$ & 16.782 & 19.379 \\
\hline 40 & June 1, 2017 & July 11,2017 & $20: 52$ & $20: 59$ & $5: 38$ & $5: 47$ & 8.546 & 19.937 \\
\hline 41 & August 7, 2017 & July 19, 2017 & $20: 33$ & $20: 54$ & $6: 15$ & $5: 55$ & 13.998 & 18.014 \\
\hline 42 & June 6,2017 & July 19, 2017 & $20: 56$ & $20: 54$ & $5: 36$ & $5: 55$ & 9.744 & 17.282 \\
\hline 43 & June 18, 2017 & July 5, 2017 & 21:02 & $21: 02$ & $5: 36$ & $5: 42$ & 19.681 & 14.736 \\
\hline 44 & August 8, 2017 & July 18, 2017 & $20: 31$ & $20: 54$ & $6: 16$ & $5: 54$ & 19.866 & 20.737 \\
\hline 45 & August 7, 2017 & July 17, 2017 & $20: 33$ & $20: 55$ & $6: 15$ & $5: 53$ & 14.392 & 18.304 \\
\hline 46 & August 1, 2017 & June 27, 2017 & $20: 40$ & $21: 03$ & $6: 08$ & $5: 38$ & 19.022 & 12.068 \\
\hline 47 & May 30, 2017 & June 26, 2017 & $20: 50$ & $21: 03$ & $5: 39$ & $5: 38$ & 11.988 & 11.035 \\
\hline 48 & June 7, 2017 & July 6, 2017 & $20: 57$ & 21:01 & $5: 36$ & $5: 43$ & 11.827 & 22.058 \\
\hline 49 & June 19, 2017 & July 11, 2017 & 21:02 & $20: 59$ & $5: 36$ & $5: 47$ & 17.727 & 20.467 \\
\hline 50 & June 1, 2017 & June 26, 2017 & $20: 52$ & $21: 03$ & $5: 38$ & $5: 38$ & 8.652 & 10.369 \\
\hline 51 & June 25, 2017 & June 21, 2017 & 21:03 & $21: 03$ & $5: 38$ & $5: 36$ & 14.747 & 14.881 \\
\hline
\end{tabular}


Appendix 11. Total number of bat passes, passes with more than one bat, feeding buzzes, and duration of bat passes from sampling round 1 (R1) and round 2 (R2) of bat recording at each sampling site.

\begin{tabular}{|c|c|c|c|c|c|c|c|c|}
\hline \multirow[t]{2}{*}{ Site } & \multicolumn{2}{|c|}{ Number of Passes } & \multicolumn{2}{|c|}{$\begin{array}{l}\text { Number of Passes that } \\
\text { Contain more than One Bat } \\
\text { ( }+1 \text { to Number of Passes) }\end{array}$} & \multicolumn{2}{|c|}{$\begin{array}{c}\text { Number of } \\
\text { Feeding Buzzes }\end{array}$} & \multicolumn{2}{|c|}{$\begin{array}{l}\text { Total Duration of } \\
\text { Passes (Seconds) }\end{array}$} \\
\hline & R1 & $\mathbf{R 2}$ & R1 & $\mathbf{R 2}$ & R1 & $\mathbf{R 2}$ & R1 & $\mathbf{R 2}$ \\
\hline $\mathbf{0}$ & 116 & 60 & 11 & 3 & 11 & 9 & 1567.827 & 632.717 \\
\hline 1 & 59 & 11 & 2 & 0 & 1 & 0 & 369.192 & 28.921 \\
\hline 2 & 3 & 79 & 0 & 3 & 0 & 2 & 13.698 & 288.114 \\
\hline 3 & 3 & 11 & 0 & 3 & 0 & 0 & 15.130 & 30.806 \\
\hline 4 & 356 & 232 & 24 & 21 & 59 & 26 & 2141.219 & 1346.675 \\
\hline 5 & 170 & 99 & 10 & 3 & 15 & 19 & 1748.310 & 777.31 \\
\hline 6 & 72 & 23 & 3 & 0 & 4 & 3 & 371.587 & 134.869 \\
\hline 7 & 27 & 249 & 0 & 15 & 0 & 19 & 122.428 & 1767.016 \\
\hline 8 & 97 & 233 & 6 & 17 & 5 & 8 & 348.758 & 1393.357 \\
\hline 9 & 8 & 64 & 0 & 10 & 0 & 5 & 45.025 & 734.845 \\
\hline 10 & 42 & 27 & 1 & 1 & 1 & 8 & 261.887 & 128.377 \\
\hline 11 & 5 & 28 & 0 & 1 & 0 & 5 & 41.876 & 522.658 \\
\hline 12 & 7 & 17 & 0 & 0 & 1 & 0 & 31.780 & 68.853 \\
\hline 13 & 39 & 24 & 0 & 0 & 0 & 1 & 338.632 & 180.891 \\
\hline 14 & 20 & 59 & 0 & 3 & 0 & 12 & 120.906 & 248.611 \\
\hline 15 & 9 & 190 & 0 & 4 & 0 & 33 & 77.140 & 1029.189 \\
\hline 16 & 12 & 115 & 0 & 9 & 0 & 8 & 64.843 & 518.783 \\
\hline 17 & 48 & 165 & 2 & 10 & 1 & 15 & 338.577 & 1026.647 \\
\hline 18 & 118 & 66 & 0 & 0 & 7 & 1 & 861.883 & 450.056 \\
\hline 19 & 52 & 43 & 5 & 5 & 12 & 2 & 330.097 & 276.322 \\
\hline 20 & 1 & 149 & 0 & 14 & 0 & 12 & 4.166 & 1143.613 \\
\hline 21 & 203 & 32 & 6 & 0 & 26 & 2 & 1384.565 & 183.585 \\
\hline 22 & 225 & 90 & 27 & 9 & 8 & 16 & 1445.527 & 808.344 \\
\hline 23 & 40 & 44 & 3 & 2 & 24 & 2 & 463.847 & 304.533 \\
\hline 24 & 188 & 156 & 8 & 14 & 7 & 18 & 1431.710 & 869.168 \\
\hline 25 & 4 & 172 & 0 & 11 & 0 & 10 & 54.004 & 1558.075 \\
\hline
\end{tabular}


Appendix 11. Continued.

\begin{tabular}{|c|c|c|c|c|c|c|c|c|}
\hline \multirow[t]{2}{*}{ Site } & \multicolumn{2}{|c|}{ Number of Passes } & \multicolumn{2}{|c|}{$\begin{array}{c}\text { Number of Passes that } \\
\text { Contain more than One Bat } \\
\text { ( }+1 \text { to Number of Passes) }\end{array}$} & \multicolumn{2}{|c|}{$\begin{array}{c}\text { Number of } \\
\text { Feeding Buzzes }\end{array}$} & \multicolumn{2}{|c|}{$\begin{array}{l}\text { Total Duration of } \\
\text { Passes (Seconds) }\end{array}$} \\
\hline & R1 & $\mathbf{R 2}$ & R1 & $\mathbf{R 2}$ & R1 & $\mathbf{R 2}$ & R1 & $\mathbf{R 2}$ \\
\hline 26 & 20 & 35 & 0 & 0 & 7 & 3 & 216.953 & 303.134 \\
\hline 27 & 12 & 34 & 0 & 0 & 0 & 1 & 70.820 & 173.645 \\
\hline 28 & 155 & 116 & 0 & 5 & 3 & 8 & 1433.980 & 742.3492 \\
\hline 29 & 56 & 76 & 0 & 7 & 1 & 2 & 265.418 & 388.391 \\
\hline 30 & 7 & 36 & 0 & 2 & 0 & 5 & 53.179 & 292.127 \\
\hline 31 & 40 & 90 & 0 & 4 & 1 & 3 & 230.365 & 410.685 \\
\hline 32 & 122 & 73 & 3 & 3 & 19 & 5 & 1419.461 & 537.857 \\
\hline 33 & 16 & 109 & 0 & 3 & 0 & 2 & 111.912 & 836.396 \\
\hline 34 & 1 & 72 & 0 & 5 & 0 & 2 & 6.334 & 407.658 \\
\hline 35 & 47 & 280 & 2 & 1 & 4 & 5 & 268.722 & 2856.634 \\
\hline 36 & 28 & 31 & 0 & 1 & 1 & 2 & 171.727 & 125.537 \\
\hline 37 & 10 & 16 & 1 & 1 & 0 & 0 & 67.977 & 69.382 \\
\hline 38 & 17 & 68 & 0 & 0 & 0 & 0 & 110.713 & 169.358 \\
\hline 39 & 25 & 37 & 1 & 3 & 1 & 3 & 181.305 & 201.533 \\
\hline 40 & 5 & 93 & 0 & 4 & 0 & 26 & 31.759 & 704.144 \\
\hline 41 & 73 & 113 & 9 & 2 & 68 & 31 & 1198.235 & 1261.311 \\
\hline 42 & 1 & 33 & 0 & 2 & 0 & 1 & 5.857 & 224.562 \\
\hline 43 & 15 & 13 & 0 & 1 & 1 & 6 & 99.951 & 180.92 \\
\hline 44 & 384 & 208 & 53 & 24 & 50 & 4 & 2359.738 & 1776.725 \\
\hline 45 & 16 & 31 & 0 & 1 & 0 & 2 & 72.329 & 277.987 \\
\hline 46 & 90 & 8 & 6 & 0 & 4 & 0 & 729.463 & 14.573 \\
\hline 47 & 36 & 62 & 1 & 2 & 0 & 3 & 216.087 & 235.452 \\
\hline 48 & 15 & 30 & 1 & 0 & 0 & 0 & 62.312 & 242.507 \\
\hline 49 & 14 & 100 & 1 & 6 & 1 & 7 & 72.219 & 661.829 \\
\hline 50 & 23 & 113 & 0 & 1 & 0 & 4 & 82.829 & 301.997 \\
\hline 51 & 28 & 96 & 0 & 12 & 6 & 38 & 306.654 & 502.155 \\
\hline
\end{tabular}


Appendix 12. Total number of passes identified to each species or species group and unidentified passes (unknown) from sampling round 1 (R1) and round 2 (R2) of bat recording at each sampling site.

\begin{tabular}{|c|c|c|c|c|c|c|c|c|c|c|}
\hline \multirow[t]{2}{*}{ Site } & \multicolumn{2}{|c|}{ Big Brown Bat } & \multicolumn{2}{|c|}{$\begin{array}{c}\text { Hoary Bat/ } \\
\text { Silver-haired Bat }\end{array}$} & \multicolumn{2}{|c|}{$\begin{array}{c}\text { Little Brown Myotis/ } \\
\text { Northern Myotis/ } \\
\text { Tri-colored Bat }\end{array}$} & \multicolumn{2}{|c|}{ Eastern Red Bat } & \multicolumn{2}{|c|}{ Unknown } \\
\hline & R1 & $\mathbf{R 2}$ & R1 & $\mathbf{R 2}$ & R1 & $\mathbf{R 2}$ & R1 & $\mathbf{R 2}$ & $\mathbf{R} 1$ & $\mathbf{R} 2$ \\
\hline $\mathbf{0}$ & 97 & 14 & 6 & 28 & 0 & 0 & 1 & 0 & 12 & 18 \\
\hline 1 & 11 & 3 & 22 & 0 & 0 & 0 & 7 & 0 & 19 & 8 \\
\hline 2 & 1 & 5 & 0 & 23 & 0 & 0 & 0 & 0 & 2 & 51 \\
\hline 3 & 1 & 11 & 0 & 0 & 0 & 0 & 0 & 0 & 2 & 0 \\
\hline 4 & 277 & 129 & 14 & 38 & 2 & 3 & 4 & 1 & 59 & 61 \\
\hline 5 & 59 & 73 & 6 & 16 & 6 & 0 & 73 & 0 & 26 & 10 \\
\hline 6 & 44 & 19 & 5 & 0 & 1 & 0 & 0 & 0 & 22 & 4 \\
\hline 7 & 21 & 218 & 0 & 30 & 0 & 0 & 0 & 0 & 6 & 1 \\
\hline 8 & 31 & 63 & 4 & 46 & 8 & 2 & 10 & 59 & 44 & 63 \\
\hline 9 & 3 & 6 & 2 & 46 & 0 & 2 & 0 & 0 & 3 & 10 \\
\hline 10 & 7 & 10 & 11 & 5 & 0 & 0 & 3 & 4 & 21 & 8 \\
\hline 11 & 0 & 6 & 4 & 10 & 0 & 1 & 0 & 2 & 1 & 9 \\
\hline 12 & 3 & 2 & 1 & 5 & 0 & 0 & 0 & 0 & 3 & 10 \\
\hline 13 & 11 & 6 & 19 & 9 & 0 & 0 & 0 & 0 & 9 & 9 \\
\hline 14 & 11 & 23 & 4 & 10 & 0 & 0 & 0 & 2 & 5 & 24 \\
\hline 15 & 4 & 25 & 0 & 31 & 0 & 0 & 3 & 121 & 2 & 13 \\
\hline 16 & 8 & 27 & 0 & 18 & 0 & 1 & 0 & 38 & 4 & 31 \\
\hline 17 & 31 & 66 & 6 & 55 & 0 & 1 & 0 & 4 & 11 & 39 \\
\hline 18 & 93 & 42 & 7 & 10 & 0 & 1 & 1 & 5 & 17 & 8 \\
\hline 19 & 30 & 15 & 16 & 9 & 0 & 0 & 0 & 0 & 6 & 19 \\
\hline 20 & 0 & 58 & 0 & 7 & 0 & 2 & 0 & 37 & 1 & 45 \\
\hline 21 & 161 & 21 & 19 & 3 & 0 & 0 & 1 & 0 & 22 & 8 \\
\hline 22 & 163 & 29 & 5 & 42 & 0 & 0 & 1 & 3 & 56 & 16 \\
\hline 23 & 17 & 24 & 14 & 1 & 0 & 0 & 0 & 0 & 9 & 19 \\
\hline 24 & 168 & 119 & 5 & 12 & 1 & 1 & 2 & 6 & 12 & 18 \\
\hline 25 & 3 & 21 & 0 & 122 & 0 & 0 & 0 & 0 & 1 & 29 \\
\hline
\end{tabular}


Appendix 12. Continued.

\begin{tabular}{|c|c|c|c|c|c|c|c|c|c|c|}
\hline \multirow[t]{2}{*}{ Site } & \multicolumn{2}{|c|}{ Big Brown Bat } & \multicolumn{2}{|c|}{$\begin{array}{c}\text { Hoary Bat/ } \\
\text { Silver-haired Bat }\end{array}$} & \multicolumn{2}{|c|}{$\begin{array}{c}\text { Little Brown Myotis/ } \\
\text { Northern Myotis/ } \\
\text { Tri-colored Bat }\end{array}$} & \multicolumn{2}{|c|}{ Eastern Red Bat } & \multicolumn{2}{|c|}{ Unknown } \\
\hline & R1 & $\mathbf{R 2}$ & R1 & $\mathbf{R 2}$ & R1 & $\mathbf{R 2}$ & R1 & $\mathbf{R 2}$ & R1 & R2 \\
\hline 26 & 10 & 12 & 0 & 9 & 2 & 0 & 5 & 8 & 3 & 6 \\
\hline 27 & 4 & 13 & 3 & 8 & 1 & 0 & 0 & 5 & 4 & 8 \\
\hline 28 & 133 & 38 & 5 & 19 & 2 & 0 & 10 & 7 & 5 & 52 \\
\hline 29 & 20 & 35 & 4 & 21 & 3 & 0 & 2 & 4 & 27 & 16 \\
\hline 30 & 1 & 14 & 3 & 9 & 0 & 0 & 0 & 0 & 3 & 13 \\
\hline 31 & 26 & 63 & 4 & 10 & 0 & 0 & 1 & 4 & 9 & 13 \\
\hline 32 & 98 & 49 & 9 & 13 & 0 & 0 & 0 & 0 & 15 & 11 \\
\hline 33 & 2 & 12 & 7 & 68 & 0 & 0 & 0 & 0 & 7 & 29 \\
\hline 34 & 1 & 12 & 0 & 25 & 0 & 0 & 0 & 6 & 0 & 29 \\
\hline 35 & 39 & 110 & 1 & 125 & 0 & 0 & 0 & 0 & 7 & 45 \\
\hline 36 & 18 & 8 & 4 & 9 & 0 & 0 & 0 & 0 & 6 & 14 \\
\hline 37 & 1 & 4 & 3 & 4 & 0 & 0 & 0 & 0 & 6 & 8 \\
\hline 38 & 5 & 1 & 9 & 33 & 0 & 0 & 0 & 0 & 3 & 34 \\
\hline 39 & 5 & 13 & 6 & 17 & 2 & 0 & 4 & 0 & 8 & 7 \\
\hline 40 & 2 & 66 & 2 & 15 & 0 & 0 & 0 & 0 & 1 & 14 \\
\hline 41 & 53 & 36 & 7 & 30 & 0 & 0 & 0 & 2 & 13 & 45 \\
\hline 42 & 0 & 3 & 0 & 15 & 1 & 0 & 0 & 0 & 0 & 15 \\
\hline 43 & 0 & 2 & 4 & 8 & 0 & 0 & 0 & 0 & 11 & 3 \\
\hline 44 & 274 & 33 & 73 & 101 & 0 & 0 & 0 & 0 & 37 & 74 \\
\hline 45 & 3 & 6 & 4 & 17 & 0 & 0 & 2 & 0 & 7 & 8 \\
\hline 46 & 18 & 0 & 25 & 3 & 0 & 2 & 8 & 0 & 39 & 3 \\
\hline 47 & 6 & 2 & 10 & 15 & 0 & 4 & 9 & 11 & 11 & 30 \\
\hline 48 & 8 & 8 & 3 & 14 & 1 & 0 & 0 & 0 & 3 & 8 \\
\hline 49 & 3 & 14 & 4 & 64 & 0 & 0 & 0 & 0 & 7 & 22 \\
\hline 50 & 22 & 2 & 0 & 23 & 0 & 0 & 0 & 5 & 1 & 83 \\
\hline 51 & 21 & 76 & 2 & 10 & 1 & 0 & 2 & 0 & 2 & 10 \\
\hline
\end{tabular}


Appendix 13. Total number of feeding buzzes identified to each species or species group and unidentified feeding buzzes (unknown) from sampling round 1 (R1) and round 2 (R2) of bat recording at each sampling site.

\begin{tabular}{|c|c|c|c|c|c|c|c|c|c|c|}
\hline \multirow[t]{2}{*}{ Site } & \multicolumn{2}{|c|}{ Big Brown Bat } & \multicolumn{2}{|c|}{$\begin{array}{c}\text { Hoary Bat/ } \\
\text { Silver-haired Bat }\end{array}$} & \multicolumn{2}{|c|}{$\begin{array}{l}\text { Little Brown Myotis/ } \\
\text { Northern Myotis/ } \\
\text { Tri-colored Bat }\end{array}$} & \multicolumn{2}{|c|}{ Eastern Red Bat } & \multicolumn{2}{|c|}{ Unknown } \\
\hline & R1 & $\mathbf{R 2}$ & R1 & $\mathbf{R 2}$ & $\mathbf{R 1}$ & $\mathbf{R 2}$ & R1 & $\mathbf{R 2}$ & R1 & $\mathbf{R 2}$ \\
\hline $\mathbf{0}$ & 11 & 4 & 0 & 1 & 0 & 0 & 0 & 0 & 0 & 4 \\
\hline 1 & 0 & 0 & 0 & 0 & 0 & 0 & 0 & 0 & 1 & 0 \\
\hline 2 & 0 & 2 & 0 & 0 & 0 & 0 & 0 & 0 & 0 & 0 \\
\hline 3 & 0 & 0 & 0 & 0 & 0 & 0 & 0 & 0 & 0 & 0 \\
\hline 4 & 57 & 22 & 2 & 1 & 0 & 0 & 0 & 0 & 0 & 3 \\
\hline 5 & 6 & 16 & 0 & 2 & 0 & 0 & 7 & 0 & 2 & 1 \\
\hline 6 & 2 & 3 & 0 & 0 & 2 & 0 & 0 & 0 & 0 & 0 \\
\hline 7 & 0 & 18 & 0 & 0 & 0 & 0 & 0 & 0 & 0 & 1 \\
\hline 8 & 0 & 4 & 0 & 1 & 1 & 0 & 3 & 0 & 0 & 3 \\
\hline 9 & 0 & 1 & 0 & 3 & 0 & 0 & 0 & 0 & 0 & 1 \\
\hline 10 & 0 & 1 & 0 & 0 & 0 & 0 & 0 & 0 & 1 & 7 \\
\hline 11 & 0 & 2 & 0 & 3 & 0 & 0 & 0 & 0 & 0 & 0 \\
\hline 12 & 0 & 0 & 0 & 0 & 0 & 0 & 0 & 0 & 1 & 0 \\
\hline 13 & 0 & 1 & 0 & 0 & 0 & 0 & 0 & 0 & 0 & 0 \\
\hline 14 & 0 & 6 & 0 & 0 & 0 & 0 & 0 & 0 & 0 & 6 \\
\hline 15 & 0 & 0 & 0 & 4 & 0 & 0 & 0 & 28 & 0 & 1 \\
\hline 16 & 0 & 1 & 0 & 2 & 0 & 0 & 0 & 5 & 0 & 0 \\
\hline 17 & 1 & 9 & 0 & 4 & 0 & 0 & 0 & 0 & 0 & 2 \\
\hline 18 & 4 & 1 & 1 & 0 & 0 & 0 & 1 & 0 & 1 & 0 \\
\hline 19 & 7 & 1 & 2 & 0 & 0 & 0 & 0 & 0 & 3 & 1 \\
\hline 20 & 0 & 6 & 0 & 0 & 0 & 0 & 0 & 3 & 0 & 3 \\
\hline 21 & 19 & 2 & 0 & 0 & 0 & 0 & 0 & 0 & 7 & 0 \\
\hline 22 & 6 & 10 & 0 & 1 & 0 & 0 & 0 & 0 & 2 & 5 \\
\hline 23 & 23 & 1 & 0 & 0 & 0 & 0 & 0 & 0 & 1 & 1 \\
\hline 24 & 7 & 18 & 0 & 0 & 0 & 0 & 0 & 0 & 0 & 0 \\
\hline 25 & 0 & 0 & 0 & 8 & 0 & 0 & 0 & 0 & 0 & 2 \\
\hline
\end{tabular}


Appendix 13. Continued.

\begin{tabular}{|c|c|c|c|c|c|c|c|c|c|c|}
\hline \multirow[t]{2}{*}{ Site } & \multicolumn{2}{|c|}{ Big Brown Bat } & \multicolumn{2}{|c|}{$\begin{array}{c}\text { Hoary Bat/ } \\
\text { Silver-haired Bat }\end{array}$} & \multicolumn{2}{|c|}{$\begin{array}{c}\text { Little Brown Myotis/ } \\
\text { Northern Myotis/ } \\
\text { Tri-colored Bat }\end{array}$} & \multicolumn{2}{|c|}{ Eastern Red Bat } & \multicolumn{2}{|c|}{ Unknown } \\
\hline & R1 & $\mathbf{R 2}$ & R1 & $\mathbf{R 2}$ & R1 & $\mathbf{R 2}$ & R1 & $\mathbf{R 2}$ & R1 & $\mathbf{R 2}$ \\
\hline 26 & 6 & 0 & 0 & 2 & 1 & 0 & 0 & 0 & 0 & 1 \\
\hline 27 & 0 & 1 & 0 & 0 & 0 & 0 & 0 & 0 & 0 & 0 \\
\hline 28 & 3 & 4 & 0 & 1 & 0 & 0 & 0 & 0 & 0 & 3 \\
\hline 29 & 0 & 1 & 0 & 0 & 0 & 0 & 0 & 0 & 1 & 1 \\
\hline 30 & 0 & 5 & 0 & 0 & 0 & 0 & 0 & 0 & 0 & 0 \\
\hline 31 & 1 & 2 & 0 & 0 & 0 & 0 & 0 & 0 & 0 & 1 \\
\hline 32 & 18 & 4 & 1 & 0 & 0 & 0 & 0 & 0 & 0 & 1 \\
\hline 33 & 0 & 0 & 0 & 2 & 0 & 0 & 0 & 0 & 0 & 0 \\
\hline 34 & 0 & 0 & 0 & 1 & 0 & 0 & 0 & 0 & 0 & 1 \\
\hline 35 & 4 & 5 & 0 & 0 & 0 & 0 & 0 & 0 & 0 & 0 \\
\hline 36 & 0 & 0 & 0 & 1 & 0 & 0 & 0 & 0 & 1 & 1 \\
\hline 37 & 0 & 0 & 0 & 0 & 0 & 0 & 0 & 0 & 0 & 0 \\
\hline 38 & 0 & 0 & 0 & 0 & 0 & 0 & 0 & 0 & 0 & 0 \\
\hline 39 & 0 & 3 & 0 & 0 & 0 & 0 & 1 & 0 & 0 & 0 \\
\hline 40 & 0 & 26 & 0 & 0 & 0 & 0 & 0 & 0 & 0 & 0 \\
\hline 41 & 68 & 29 & 0 & 1 & 0 & 0 & 0 & 0 & 0 & 1 \\
\hline 42 & 0 & 0 & 0 & 0 & 0 & 0 & 0 & 0 & 0 & 1 \\
\hline 43 & 0 & 0 & 0 & 6 & 0 & 0 & 0 & 0 & 1 & 0 \\
\hline 44 & 44 & 2 & 3 & 0 & 0 & 0 & 0 & 0 & 3 & 2 \\
\hline 45 & 0 & 1 & 0 & 1 & 0 & 0 & 0 & 0 & 0 & 0 \\
\hline 46 & 1 & 0 & 1 & 0 & 0 & 0 & 0 & 0 & 2 & 0 \\
\hline 47 & 0 & 0 & 0 & 0 & 0 & 0 & 0 & 0 & 0 & 3 \\
\hline 48 & 0 & 0 & 0 & 0 & 0 & 0 & 0 & 0 & 0 & 0 \\
\hline 49 & 0 & 0 & 0 & 5 & 0 & 0 & 0 & 0 & 1 & 2 \\
\hline 50 & 0 & 2 & 0 & 1 & 0 & 0 & 0 & 1 & 0 & 0 \\
\hline 51 & 6 & 38 & 0 & 0 & 0 & 0 & 0 & 0 & 0 & 0 \\
\hline
\end{tabular}




\section{References}

Avila-Flores, R., and M.B. Fenton. 2005. Use of spatial features by foraging insectivorous bats in a large urban landscape. Journal of Mammalogy 86:11931204.

Bazelman, T.C. 2016. Effects of urbanization on bat habitat use in the Phoenix Metropolitan Region, Arizona, USA: a multi-scale landscape analysis. M.S. thesis, Arizona State University, Phoenix, Arizona, 117 pp.

Belaire, J.A., C.J. Whelan, and E.S. Minor. 2014. Having our yards and sharing them too: the collective effects of yards on native bird species in an urban landscape. Ecological Applications 24:2132-2143.

Beninde, J., M. Veith, and A. Hochkirch. 2015. Biodiversity in cities needs space: a meta-analysis of factors determining intra-urban biodiversity variation. Ecology Letters 18:581-592.

Bennett, V.J., and A.A. Zurcher. 2013. When corridors collide: road-related disturbance in commuting bats. The Journal of Wildlife Management 77:93-101.

Bivand, R., N. Lewin-Koh, E. Pebesma, E. Archer, A. Baddeley, N. Bearman, H-J., Bibiko, S. Brey, J. Callahan, G. Carrillo, S. Dray, D. Forrest, M. Friendly, P. Giraudoux, D. Golicher, V. Gómez Rubio, P. Hausmann, K. Ove Hufthammer, T. Jagger, K. Johnson, S. Luque, D. MacQueen, A. Niccolai, E. Pebesma, O. Perpiñán Lamigueiro, T. Short, G. Snow, B. Stabler, M. Stokely, and R. Turner. 2017. maptools: Tools for Reading and Handling Spatial Objects. Written for R package version 3.4.4.

Blair, R.B., and A.E. Launer. 1997. Butterfly diversity and human land use: species assemblages along an urban gradient. Biological Conservation 80:113-125.

Bolker, B., H. Skaug, A. Magnusson, and A. Nielsen. 2012. glmmADMB. Version 8.3.3.

Bredt A., and W. Uieda. 1996. Bats from urban and rural environments of Distrito Federal, Mid-western Brazil. Chiroptera Neotropical 2:54-57.

Brigham, R.M. 1991. Flexibility in foraging and roosting behavior by the big brown bat (Eptesicus fuscus). Canadian Journal of Zoology 69:171-121.

Brunsdon, C., and H. Chen. 2014. GIStools: Some further GIS capabilities for R. Written for $\mathrm{R}$ package version 3.4.3. 
Carreiro, M.M., Song, Y.C., and Wu, J. (eds.). 2008. Ecology, planning and management of urban forests. Springer, New York, 456 pp.

City of Toronto. 2009. Forest and Land Cover. https://www.toronto.ca/city-government/ data-research-maps/open-data/open-data catalogue/environment/\#808bc73a-df10284d-9df7-e60dc97b45ae. Accessed Dec 2017.

City of Toronto. 2014a. Ravine Removals. Accessed Dec 2017.

City of Toronto. 2014b. Treeazin Injection Program. Accessed Dec 2017.

City of Toronto. 2014c. Toronto Building Outlines. https://library.carleton.ca/find/gis/ geospatial-data/toronto-geospatial-data. Accessed Dec 2017.

City of Toronto. 2014d. Zoning-by Law. https://www.toronto.ca/city-government/dataresearch-maps/open-data/open-data-catalogue/locations-and-mapping/\#8fef077c9a14-e922-0c57-f390cd68b8a0. Accessed Mar 2018.

Clark, P.J., J.M. Reed, and F.S. Chew. 2007. Effects of urbanization on butterfly species richness, guild structure, and rarity. Urban Ecosystems 10:321-337.

Coleman, J. L., and R.M.R. Barclay. 2012. Urbanization and the abundance and diversity of prairie bats. Urban Ecosystems 15:87-102.

Cornelis, J., and M. Hermy. 2004. Biodiversity relationships in urban and suburban parks in Flanders. Landscape and Urban Planning 69:385-401.

Dixon, M.D. 2012. Relationship between land cover and insectivorous bat activity in an urban landscape. Urban Ecosystems 15:683-695.

Duchamp, J.E., and R.K. Swihart. 2008. Shifts in bat community structure related to evolved traits and features of human-altered landscapes. Landscape Ecology 23:849-860.

Duchamp, J.E., D.W. Sparks, and J.O. Whitaker, Jr. 2004. Foraging-habitat selection by bats at an urban-rural interface: comparison between a successful and a less successful species. Canadian Journal of Zoology 82:1157-1164.

Evelyn, M.J., D.A. Stiles, and R.A. Young. 2004. Conservation of bats in suburban landscapes: roost selection by Myotis yumanensis in a residential area in California. Biological Conservation 115:463-473.

ESRI. 2015. ArcMap 10.3.1. Environmental Systems Research Institute: Redlands, CA. 
Ethier, K., and L. Fahrig. 2011. Positive effects of forest fragmentation, independent of forest amount, on bat abundance in eastern Ontario, Canada. Landscape Ecology 26:865-876.

Fabianek, F., D. Gagnon, and M. Delorme. 2011. Bat distribution and activity in Montréal Island green spaces: responses to multi-scale habitat effects in a densely urbanized area. Écoscience 18:9-17.

Fahrig, L. 2017. Ecological responses to habitat fragmentation per se. Annual Reviews of Ecology, Evolution, and Systematics 48:1-23.

Fenton, M., and G. Bell. 1981. Recognition of species of insectivorous bats by their echolocation calls. Journal of Mammalogy 62:233-243.

Ferenec, M., O. Sedláček, and R. Fuchs. 2014. How to improve urban greenspace for woodland birds: site and local-scale determinants of bird species richness. Urban Ecosystems 17:625-640.

Fernandez-Juricic, E. 2000. Avifaunal use of wooded streets in an urban landscape. Conservation Biology 14:513-521.

Gallo, T., E.W. Lehrer, M. Fidino, R.J. Kilgour., P.J. Wolff, and S.B. Magle. In Press. Need for multiscale planning for conservation of urban bats. Conservation Biology.

Geluso, K., and J.N. Mink. 2009. Use of bridges by bats (Mammalia: Chiroptera) in the Rio Grande Valley, New Mexico. The Southwestern Naturalist 54:421-429.

Griffin, D., F. Webster, and C. Michael. 1960. The echolocation of flying insects by bats. Animal Behaviour 8:141-154.

Grubbs, S.E., and P.R. Krausman. 2009. Use of urban landscape by coyotes. The Southwestern Naturalist 54:1-12.

Jackson, H.B., and L. Fahrig. 2012. What is a biologically relevant landscape? Landscape Ecology 27:929-941.

Janzen, M.K., and M.B. Fenton. 2013. The depth of edge influence among insectivorous bats at forest-field interfaces. Canadian Journal of Zoology 91:287-292.

Kitzes, J., and A. Merenlender. 2014. Large roads reduce bat activity across multiple species. PLoS One 9:e96341.

Law, B.S., and C.R. Dickman. 1998. The use of habitat mosaics by terrestrial vertebrate fauna: implications for conservation and management. Biodiversity and Conservation 7:323-333. 
Lemen, C., P.W. Freeman, J.A. White, and B.R. Andersen. 2015. The problem of low agreement among automated identification programs for acoustical surveys of bats. Western North American Naturalist 75:218-225.

Lerman, S.B., and P.S. Warren. 2011. The conservation value of residential yards: linking birds and people. Ecological Applications 21:1327-1339.

Li, H., and K.T. Wilkins. 2014. Patch or mosaic: bat activity responds to fine-scale urban heterogeneity in a medium-sized city in the United States. Urban Ecosystems 17:1013-1031.

Lintott, P. 2015. The distribution and habitat preferences of bats in a temperate urban landscape. Ph.D. dissertation, University of Sterling, Sterling, Scotland, 265 pp.

McCleery, R.A., R.R. Lopez, N.J. Silvy, and S.H. Kahlick. 2007. Habitat use of fox squirrels in an urban environment. Journal of Wildlife Management 71:11491157.

Melles, S., S. Glenn, and K. Martin. 2003. Urban bird diversity and landscape complexity: species-environment associations along a multiscale habitat gradient. Conservation Ecology 7:5.

Moretto, L., and C.M. Francis. 2017. What factors limit bat abundance and diversity in temperate, North American urban environments? Journal of Urban Ecology 2017:1-9.

Müller, J., M. Mehr, M.B. Fenton, T. Hothorn, H. Pretzsch, H.-J. Klemmt, and R. Brandl. 2012. Aggregative response in bats: prey abundance versus habitat. Oecologia 169:673-684.

Neubaum, D.J., K.R. Wilson, and T.J. O’Shea. 2007. Urban maternity-roost selection by big brown bats in Colorado. Journal of Wildlife Management 71:728-736.

Opera, M., P. Mendes, T.B. Vieira, and A.D. Ditchfield. 2009. Do wooded streets provide connectivity for bats in an urban landscape? Biodiversity and Conservation 18:2361-2173. 
Paradis, E., S. Blomberg, B. Bolker, J. Brown, J. Claude, H.S. Cuong, R. Desper, G. Didier, B. Durand, J. Dutheil, R.J. Ewing, O. Gascuel, C. Heibl, A. Ives, B. Jones, F. Krah, D. Lawson, V. Lefort, P. Legendre, J. Lemon, R. McCloskey, J. Nylander, R. Opgen-Rhein, A-A. Popescu, M. Royer-Carenzi, K. Schliep, K. Strimmer, and D. de Vienne. 2017. ape: Analysis of Phylogenetics and Evolution. Written for $\mathrm{R}$ package version 3.4.3.

Pardee, G.L., and S.M. Philpott. 2014. Native plants are the bee's knees: local and landscape predictors of bee richness and abundance in backyard gardens. Urban Ecosystems 17:641-659

Pardee, G.L., and S.M. Philpott. 2014. Native plants are the bee's knees: local and landscape predictors of bee richness and abundance in backyard gardens. Urban Ecosystems 17:641-659.

R Core Team. 2017. R: A Language and Environment for Statistical Computing. Vienna, Austria.

Revelle, W. 2017. psych: Procedures for Psychological, Psychometric, and Personality Research. Written for R package version 3.4.2.

Russell, A.L., C. Butchkoski, L. Saidak, and G.F. McCracken. 2009. Road-killed bats, highway design, and the community ecology of bats. Endangered Species Research 8:49-60.

Scheffers, B.R., and C.A. Paszkowski. 2013. Amphibian use of urban stormwater wetlands: the role of natural habitat features. Landscape and Urban Planning 113:139-149.

Silva, M.M.S., N.M.S. Harmani, E.B.F. Gonçalves, and W. Uieda. 1996. Bats from the metropolitan region of São Paulo, southeastern Brazil. Chiroptera Neotropical $2: 39-41$.

Smith, A.C., C.M. Francis, and L. Fahrig. 2014. Similar effects of residential and nonresidential vegetation on bird diversity in suburban neighbourhoods. Urban Ecosystems 17:27-44.

Soper, K.D., and M.B. Fenton. 2007. Availability of building roosts for bats in four towns in southwestern Ontario, Canada. Acta Chiropterologica 9:542-546.

Sperling, C.D., and C.J. Lortie. 2010. The importance of urban backgardens on plant and invertebrate recruitment: a field microcosm experiment. Urban Ecosystems $13: 223-235$. 
Threlfall, C.G., B. Law, and P.B. Banks. 2012. Sensitivity on insectivorous bats to urbanization: implications for suburban conservation planning. Biological Conservation 146:41-52.

van Zyll de Jong, C.G. 1985. Handbook of Canadian Mammals II, Bats. National Museums of Canada, Ottawa, Canada, $212 \mathrm{pp}$.

Wei, T., V. Simko, M. Levy, Y. Xie, Y. Jin, and J. Zemla. 2017. corrplot: Visualzation of a Correlation Matrix. Written for R package version 3.4.2.

Whitaker, J.O. Jr., D.W. Sparks, and V. Brack Jr. 2006. Use of artificial roost structures by bats at the Indianapolis International Airport. Environmental Management $38: 28-36$.

Wildlife Acoustics. 2015. Kaleidoscope Pro 3. Maynard, U.S.A.

Wickham, H., and W. Chang. 2016. ggplot2: Create Elegant Data Visualisations Using the Grammar of Graphics. Written for R package version 3.4.2.

Wickham, H., R. Francois, L. Henry, and K. Müller. 2017. dplyr: A Grammar of Data Manipulation. Written for R package version 3.4.2. 